School of Finance

University of St.Gallen

\title{
THE THREAT OF EXCLUSION AND IMPLICIT CONTRACTING
}

MARTIN BROWN

MARTA SERRA-GARCÍA

WORKING PAPERS ON FINANCE No. 2014/07

SWISS INSTITUTE OF BANKING AND FINANCE (S/BF - HSG)

APRIL 2014

THIS VERSION: JUNE 2016 


\title{
The Threat of Exclusion and Implicit Contracting
}

\author{
Martin Brown* and Marta Serra-Garcia**
}

June 2016

\begin{abstract}
Implicit contracts can mitigate moral hazard in labor, credit and product markets. The enforcement mechanism underlying an implicit contract is the threat of exclusion: the agent fears that he will lose future income if the principal breaks off the relationship. This threat may be very weak in environments where an agent can appropriate income-generating resources provided by the principal. For example, in credit markets with weak creditor protection borrowers may be able to appropriate borrowed funds and generate investment income without requiring further loans. We examine implicit contracting in a lending experiment where the threat of exclusion is exogenously varied. We find that weak exclusion undermines implicit contracting: it leads to a more frequent breakdown of credit relationships as well as to smaller loans.
\end{abstract}

Keywords: Economics: Microeconomic Behavior, Economics: Behavior and Behavioral Decision Making, Finance: Corporate finance, Implicit Contracting.

JEL: C73, G21, O16, F21, F34.

\footnotetext{
*University of St.Gallen, e-mail: martin.brown@unisg.ch, address: Swiss Institute of Banking and Finance, Rosenbergstrasse 52, CH-9000 St.Gallen, Switzerland.

**Corresponding author: University of California, San Diego, e-mail: mserragarcia@ucsd.edu, address: Rady School of Management, UCSD, 9500 Gilman Dr., La Jolla, CA 92093 - 0553, USA.

Acknowledgements: We thank Eric van Damme, Hans Degryse, John Duffy, Karolin Kirschenmann, Ola Kvaloy, Sera Linardi, Jan Potters, Joel Sobel and Stefan Trautmann, as well as seminar participants at Maastricht University, Simon Fraser University, Tilburg University, the University of East Anglia, University of Nottingham, University of Osnabrueck, Universitat Autonoma de Barcelona, Universitat Pompeu Fabra, University of Zurich, XIX Finance Forum, CESifo Munich, IMEBE 2011, and $1^{\text {st }}$ LeeX International Conference on Theoretical and Experimental Macroeconomics at Universitat Pompeu Fabra for comments and suggestions.
} 


\section{Introduction}

Economic theory suggests that self-enforcing agreements, i.e. implicit contracts, can mitigate moral hazard in labor, credit and product markets (e.g., Bull, 1987; Boot and Thakor, 1994; Klein and Leffler, 1981). Existing experimental evidence documents that self-enforcing agreements emerge and are efficiency-enhancing in bilateral contracting settings as well as in market contexts with endogenous partner choice (Brown et al., 2004; Fehr et al., 2009). For managers, implicit contracting implies that conflicts of interest with employees, creditors, or suppliers may be resolved through repeated interaction rather than through monitoring, incentive contracts, or a reallocation of ownership.

The enforcement mechanism underlying an implicit contract is the threat of exclusion: the agent fears that he will lose future income if the principal breaks off the relationship. In this paper we emphasize that in some markets and business relations the threat of exclusion is inherently weak. In these environments, implicit contracting may not be an effective instrument to mitigate moral hazard, and managers may therefore need to resort to more formal and costly enforcement mechanisms.

The threat of exclusion is especially weak in environments where the agent can appropriate income-generating resources from the principal, and can independently put these resources to productive use. For example, in credit environments with weak creditor protection borrowers may appropriate and reinvest borrowed funds (Bond and Krishnamurthy, 2004, Bulow and Rogoff, 1989). In the context of foreign direct investment local investment partners (e.g., the host government) may expropriate the physical and financial capital of foreign investors (Thomas and Worrall 1994). In professional services such as consulting, legal advice, or wealth management, advisors may persuade the firm's clients to follow them when they leave the firm or set up their own business. ${ }^{1}$ In such environments, the agent (borrower, investee,

\footnotetext{
${ }^{1}$ It is, e.g., estimated that $60 \%-90 \%$ of wealth management clients follow their advisor when they change firms (http://wealthmanagement.com/viewpoints/will-your-clients-follow-you).
} 
employee) may no longer need to contract with the principal (lender, investor, employer) to maintain income generation.

We implement a laboratory experiment to investigate how implicit contracting is affected when the threat of exclusion is weak. Our main treatments study implicit contracting in the context of repeated, bilateral lending. In each period the lender decides how much to lend to the borrower and what repayment to request. The borrower earns a non-stochastic investment return which depends on the loan size and can decide whether to strategically default or not. In our main treatment, the Weak Exclusion (WE) treatment, a borrower who defaults can continue to use the borrowed funds to invest in future periods. In our control treatment, the Strong Exclusion (SE) treatment, a defaulting borrower must liquidate his investment and consume the proceeds in the same period. If he wants to invest in subsequent periods, the borrower must go back to the lender for a new loan. This treatment closely resembles the design of existing experimental studies which study repeated investment games (for an overview, see Camerer, 2003). By comparing the outcomes of the WE and SE treatments, we examine how the ability of lenders to exclude defaulting borrowers from future income generation affects implicit contracting.

We derive predictions under the assumption that there is a share of non-identifiable social borrowers who repay loans even in a one-shot situation (Kreps et al., 1982). ${ }^{2}$ In the SE treatment an implicit contracting equilibrium with maximum loan sizes and full repayment until the penultimate period is feasible. Borrowers have a strong incentive to repay, since they will otherwise be cut off from future loans and thus investment. By contrast, in the WE treatment the threat of discontinuing a credit relationship is a weaker disciplining device, since, upon default, borrowers can continue to invest the funds already borrowed. Two different types of equilibria can emerge. First, implicit contracting equilibria in which lenders

\footnotetext{
${ }^{2}$ Such an assumption has been shown to hold in a wide range of experiments. Further, evidence of such types has been found in trust games and has been linked to actual repayment decisions in the field (Karlan, 2005).
} 
"start small”: they offer low initial loans and repayment-contingent loan increases in order to establish dynamic incentives for borrowers to repay. Second, screening equilibria in which lenders offer high initial loans to borrowers in order to screen out selfish agents (who will default). Hence, from a theoretical perspective, we show that weak exclusion can lead to either smaller loan sizes or an earlier breakdown of credit relationships.

Our results show both predicted effects of weak exclusion. First, we find that credit relationships are more likely to break down in the WE treatment. By the end of the first period, only $44 \%$ of all relationships are characterized by a loan offered, accepted and repaid in the WE treatment compared to $73 \%$ in the SE treatment. In accordance with screening equilibria, we find that in the initial period of the WE treatment (but not the SE treatment) default is more likely for large loan sizes. Second, we find that credit relationships in the WE treatment feature smaller loans than in the SE treatment. In accordance with the implicit contracting equilibria, a larger fraction of lenders in the WE treatment offer small loan sizes in the initial period.

In robustness tests we document that our main treatment effects are moderated in competitive market conditions. We replicate our experiment with lender competition, i.e. each borrower is matched with two lenders who can make competing loan offers in each period. Under lender competition, we find that self-enforcing credit relationships are also less frequent and loan sizes are smaller in the weak exclusion condition than in the strong exclusion condition. However, lender competition mitigates the negative treatment effect of weak exclusion on the early breakdown of credit relationships. This can be explained by the fact that screening equilibria are no longer feasible under lender competition. Moreover, competition lowers interest rates and thus reduces the incentives of borrowers to default in the weak exclusion condition. 
The main contribution of this paper is to provide evidence that the threat of exclusion is crucial to the efficacy of self-enforcing agreements. The existing experimental literature has explored two conditions under which implicit contracting may not be a perfect substitute for third-party enforcement: lender competition and stochastic investment returns. Competition between lenders could potentially weaken borrowers' incentives to repay a given lender as they may turn to other lenders after default. Similarly, stochastic investment returns may limit the scope for relational contracts as lenders cannot perfectly identify and punish strategic defaults. Brown and Zehnder (2007) show that, even in the presence of competition, relational contracts emerge and lead to large volumes of credit. Fehr and Zehnder (2009) find that even with stochastic investment returns relational contracts emerge and sustain high credit volumes. In contrast to these studies, we document that when agents can appropriate incomegenerating resources from principals implicit contracting may be seriously impaired. ${ }^{3}$

The second contribution of our study is that we examine how the threat of exclusion impacts on the time structure of implicit contracts. Previous theoretical work has examined the time structure of self-enforcing agreements, and suggests that asymmetric information about players' types may explain "starting small” in investment contexts (Ghosh and Ray, 1996 and 2001; Rauch and Watson, 2003; or Sobel, 1985) and in prisoners' dilemmas (see Watson, 1999 and 2002, Andreoni and Samuelson, 2006). Starting small - or "progressive lending” as it is often termed in credit market contexts - is commonly observed in environments with weak creditor protection - e.g., in microfinance (Morduch, 1999; Armendariz and Morduch, 2006). However, there is no evidence to date, documenting that weak creditor protection is a determinant of "progressive lending”. Our results suggest that

\footnotetext{
${ }^{3}$ Falk et al. (2015) show that dismissal barriers can undermine relational contracting in labor markets. Thus similar to our paper they examine how institutions affect the emergence of implicit agreements. In contrast to their paper, we examine institutional features inherent to the credit market (debt enforcement) and not only examine whether these institutions affect the emergence of implicit agreements, but also how these agreements are structured over time.
} 
weak creditor protection can lead to smaller loan offers. However, we find "progressive lending”, i.e. increasing loan sizes over time, independent of the threat of exclusion. ${ }^{4}$

The rest of the paper is organized as follows. Section 2 describes the experimental design. In Section 3, we outline the predictions. We report our experimental results in Section 4 and Section 5. Section 6 concludes.

\section{Experimental design}

We study the consequences of the threat of exclusion for self-enforcing agreements by focusing on repeated, bilateral lending (and use a credit market framing henceforth). We implement two treatments, based on a repeated investment game (Berg et al., 1995). In robustness tests we adapt our main treatments to allow for lender competition. We report on these competition treatments in Section 5.

\subsection{Strong Exclusion treatment}

In the Strong Exclusion (SE) treatment one lender and one borrower are paired for 7 periods. We choose a finite horizon game because it allows us to identify the emergence of self-enforcing implicit agreements. ${ }^{5}$ We choose 7 periods rather than 2 or 3 , to be able to clearly separate 'starting small' in loan sizes from the potential end-game effect, i.e. a reduction of loan sizes in the last periods of the game.

In each period $t=\{1, . ., 7\}$ the borrower has an investment opportunity: he can invest the amount $I_{t} \in\{0,1,2,3, \ldots, 10\}$, which yields a certain gross return of $v I_{t}$, with $v=3$ in our experiment. We restrict the maximum investment size to 10 in each period. The investment

\footnotetext{
${ }^{4}$ Starting small can also be rationalized by profit maximization of the principal who increases the stakes towards the end of the relationship, such that he can extract a greater surplus in the beginning (e.g. Ray, 2002), or by borrowing constraints which are endogenous to the dynamics of debt and thus make increasing loan sizes optimal (Albuquerque and Hopenhayn, 2004).

${ }^{5}$ While reputation concerns are constant in an infinite horizon, they are strong at the beginning and very weak at the end with a finite horizon. As shown, for example, by Brown and Zehnder (2007), self-enforcing credit agreements can be identified as relationships in which the borrower repays in non-final periods and then defaults in the final period.
} 
amount of the borrower in each period $I_{t}=C_{t}+S_{t}$ is equal to his capital $C_{t}$ and the loan size $S_{t}$ he receives from the lender. In all periods of the SE treatment the borrower has zero capital $C_{t}=0$. Thus, in accordance with previous experiments on repeated investment games (e.g., Cochard et al., 2004), borrowers in the SE treatment start from scratch in each period and can only invest if they obtain a loan.

The decision structure in each period is as follows:

- Loan offer: The lender receives an endowment of 10 units at the beginning of each period. The lender can offer a loan size of $S_{t} \in[0,10]$ to the borrower. The lender also chooses her requested repayment $R_{t}$, where $R_{t} \in\left[0, v S_{t}\right]$.

- Loan acceptance: If the lender chooses an offer with a strictly positive loan $S_{t}>0$, the borrower must decide whether to accept $\left(A_{t}=1\right)$ or reject the offer $\left(A_{t}=0\right)$.

- Repayment decision: If the borrower accepts a loan offer $\left(S_{t}, R_{t}\right)$, he decides whether to make the repayment requested by the lender $\left(D_{t}=0\right)$ or default $\left(D_{t}=1\right){ }^{6}$

Both the lender and the borrower receive a symmetric "reservation" income of 10 points per period, if they decide not to trade. This design choice was made so that asymmetric reservation payoffs would not affect the decisions of lenders to offer credit. The income of the lender in each period is equal to her reservation payoff plus her net income from lending as shown below:

$$
\pi_{t}=\left\{\begin{array}{cc}
10 & \text { if no loan }\left(S_{t}=0 \text { or } A_{t}=0\right) \\
10-S_{t}+R_{t} & \text { if loan repaid }\left(S_{t}>0, A_{t}=1, D_{t}=0\right) \\
10-S_{t} & \text { if loan default }\left(S_{t}>0, A_{t}=1, D_{t}=1\right)
\end{array}\right.
$$

The income of the borrower is equal to his reservation payoff plus his investment income $v \cdot I_{t}=v \cdot S_{t}$ minus the repayment he makes to the lender $R_{t}$.

\footnotetext{
${ }^{6}$ Partial repayments are not possible. In reality some borrowers obviously become delinquent without fully defaulting. However, due to the deterministic nature of investment earnings in our design we exclude partial repayments.
} 


$$
u_{t}=\left\{\begin{array}{cc}
10 & \text { if no loan }\left(S_{t}=0 \text { or } A_{t}=0\right) \\
10+v \cdot S_{t}-R_{t} & \text { if loan repaid }\left(S_{t}>0, A_{t}=1, D_{t}=0\right) \\
10+v \cdot S_{t} & \text { if loan default }\left(S_{t}>0, A_{t}=1, D_{t}=1\right)
\end{array}\right.
$$

At the end of each period the lender is informed about the borrower's repayment decision. The lender and the borrower are informed of their own and their partner's payoffs for the period. They also see an overview of the history of their bilateral interaction in previous periods, showing past loan size and requested repayment of the lender, and acceptance and repayment by the borrower.

\subsection{Weak Exclusion treatment}

In the Weak Exclusion (WE) treatment a lender and a borrower are also paired for 7 periods and make the same decisions as in the SE treatment in each period. The WE treatment differs from the SE treatment only with respect to the consequences of a loan default for the borrower's current period payoff and his capital. In the WE treatment the borrower has zero capital in period 1. However, if the borrower receives a loan and does not repay it, he can keep the lender's funds for future investment. We assume that borrowers who default in period $t$ automatically have the loan principal $S_{t}$ added to their capital for all subsequent periods. The borrower liquidates his capital (and consumes the proceeds) in the final period. The capital of a borrower in periods $t=\{2, \ldots, 7\}$ thus equals the sum of the borrowed funds which he did not repay:

$$
C_{t}=\sum_{k=1}^{t-1} D_{k} \cdot S_{k}
$$

The fact that we force borrowers to reinvest funds that they keep after default, rather than allowing them to decide whether to consume or reinvest them, seems restrictive. We chose this design choice for two reasons. First, we wanted to simplify the game as much as possible 
by abstracting from endogenous consumption / saving decisions. ${ }^{7}$ Second, reinvestment of loaned funds is the optimal strategy of a borrower who has defaulted.

The income of the borrower in periods $t=\{1, \ldots, 6\}$ is equal to his reservation payoff plus his investment income $v \cdot I_{t}$, minus the repayment he makes to the lender $\left(R_{t}\right)$ and minus the capital which he keeps for the following period, $C_{t+1}=C_{t}+D_{t} \cdot S_{t}$. In periods $t=\{1, \ldots, 6\}$, the capital is thus deducted from the investment income and transferred to the following period, leading to the following payoffs:

$$
u_{t=1, \ldots, 6}=\left\{\begin{array}{cc}
10+(v-1) \cdot C_{t} & \text { if no loan }\left(S_{t}=0 \text { or } A_{t}=0\right) \\
10+(v-1) \cdot C_{t}+v \cdot S_{t}-R_{t} & \text { if loan repaid }\left(S_{t}>0, A_{t}=1, D_{t}=0\right) \\
10+(v-1) \cdot\left(C_{t}+S_{t}\right) & \text { if loan default }\left(S_{t}>0, A_{t}=1, D_{t}=1\right)
\end{array}\right.
$$

At the end of period 7 the borrower liquidates his capital and consumes it. We make this assumption to ensure that repayment behavior in the final period of the WE treatment has the same payoff implications as in the SE treatment. His payoff in this period is thus:

$$
u_{t=7}=\left\{\begin{array}{cc}
10+v \cdot C_{t} & \text { if no loan }\left(S_{t}=0 \text { or } A_{t}=0\right) \\
10+v \cdot\left(C_{t}+S_{t}\right)-R_{t} & \text { if loan repaid }\left(S_{t}>0, A_{t}=1, D_{t}=0\right) \\
10+v \cdot\left(C_{t}+S_{t}\right) & \text { if loan default }\left(S_{t}>0, A_{t}=1, D_{t}=1\right)
\end{array}\right.
$$

As in the SE treatment, both the lender and the borrower are provided with an overview of the history of the relationship, including any capital accumulated by the borrower.

\subsection{Discussion}

Some features of our experimental design warrant detailed discussion. First, it is important to clarify the underlying assumptions about the debt-enforcement environment in our two treatments. In both the WE and the SE treatment borrowers can strategically default on their loans. If the borrower defaults the lender cannot recover any part of the loaned funds. This design feature is common to previous experimental studies of repeated investment games (e.g.

\footnotetext{
${ }^{7}$ Relative to existing experimental studies we introduce only one change, i.e. that a defaulting borrower can reinvest borrowed funds, and hence there are no endogenous savings/consumption decisions in any of the treatments.
} 
Cochard et al., 2004) and relational contracting in credit markets (e.g. Brown and Zehnder 2007). The assumption of a zero recovery rate implies either a very costly process of enforcing debt or legal impediments to seizing assets of borrowers.

The World Bank "Doing Business" database documents that in many countries the judicial procedures to enforce debt are indeed very costly, even when lenders have secured claims. ${ }^{8}$ In 91 out of 198 countries the estimated recovery rate on a secured loan amounts to less than one-third of the claim. Costly debt enforcement is particularly prevalent in lowincome and emerging economies and negatively impacts on credit market development (Djankov et al., 2008). Recovery rates may be low in high-income countries as well. For example, in many U.S. states a broad range of household assets are exempt from the bankruptcy process (see e.g., White, 1998) ${ }^{9}$ with negative consequences for the supply of consumer credit (Gropp et al., 1997) and small business finance (Cerqueiro and Penas, 2014). Moreover, corporate borrowers may be able to tunnel assets out of their current business (Johnson et al., 2000; Jiang et al. 2010). Thus both in low-income and high-income countries the assumption of a low-recovery rate on defaulted loans seems reasonable for many credit markets.

The difference between the SE and WE treatments lies in what a borrower can do with the funds when he defaults. In the SE treatment, if the borrower defaults, he must liquidate his investment and consume the proceeds within the same period. This treatment inherently implies that, although the recovery rate for lenders is low, the debt enforcement process is very fast. Borrowers cannot hold on to and reinvest appropriated funds. By contrast, in the WE treatment a defaulting borrower can retain borrowed funds and reinvest these in future

\footnotetext{
${ }^{8}$ The Doing Business indicators of „Resolving Insolvency“ compare the costs, time and processes involved in a bank enforcing a secured claim on a non-financial firm which enters bankruptcy procedures. For details of the methodology and data see http://www.doingbusiness.org/data/exploretopics/resolving-insolvency

${ }^{9}$ For example, in the US when individuals file for personal bankruptcy under Chapter 7 or 13, several personal assets can be excluded from seizure during bankruptcy (e.g., owner occupied residences, personal property and retirement accounts). White (1998) argues that "because few debtors have nonexempt assets, more than 90 percent of Chapter 7 cases involve no repayment at all, and the average repayment rate in Chapter 7 cases is less than 3 percent."
} 
periods. This treatment assumes that the debt enforcement process is not only very costly, but also very slow. The "Doing Business" database documents that, especially in low-income countries, the debt enforcement process is very slow. For example, in 109 out of 198 countries the judicial enforcement process for secured claims takes more two years in case of a bankruptcy. And unsurprisingly those countries with low recovery rates on secured debt are typically characterized by lengthy enforcement processes. Our WE treatment captures this environment by allowing a defaulting borrower to continue to use borrowed funds for future investment without having to surrender either his assets or profits to the lender. Anecdotal evidence suggests that in countries with weak creditor protection borrowers do appropriate and continue to use borrowed funds, for example by tunneling them out of existing businesses into new ones. ${ }^{10}$

A further assumption that warrants discussion is the investment limit for borrowers. We hold the investment opportunity of the borrower constant over time in order to examine credit rationing over the course of a relationship. If, for example, we observe that a lender offers a small loan in period 1 and she increases it over time, we know that the borrower was credit constrained in period 1. By contrast, when field studies observe rising loan schedules over time (Ioannidou and Ongena, 2010; Kirschenmann, 2016) they typically cannot distinguish whether this is due to improved investment opportunities of the borrower or a relaxation of credit constraints.

\subsection{Procedures}

\footnotetext{
${ }^{10}$ A recent Economist article on bankruptcy proceedings in India reports that "At the moment, creditors cannot take any legal action against a defaulter until a restructuring plan is in place, which usually takes between three and ten years. In the meantime, the owners of sick firms retain day-to-day management control; and while they drag out court proceedings, creditors see their assets dwindle. In many cases, says a lawyer who works on such cases, the owners start up a fresh company in the name of a relative, and siphon off business from the old one." http://www.economist.com/news/business/21678773-long-awaited-bankruptcy-code-should-help-owners-andlenders-business-going-bust.
} 
We implement our two main treatments in a laboratory experiment. A total 186 students participated in the WE and SE treatments. Our first set of sessions was implemented at Tilburg University (90 participants). Our second set of sessions was implemented at UC San Diego (96). Each subject could only participate in one session and in each session only one of the treatments was implemented. As shown in Online Appendix D, we do not observe a significant difference in behavior in the lending game across locations, except for a small difference in acceptance rates in the SE treatment. We thus pool the observations from Tilburg University and UC San Diego. Additionally, we include a location fixed effect in all regressions.

At the beginning of each session participants are randomly assigned to the role of either a borrower or a lender. These roles are fixed for the whole session. Each player forms part of a matching group, composed of 3 lenders and 3 borrowers. Each player plays three rounds of our lending game: Each lender (borrower) repeats the lending game with the three different borrowers (lenders) in her/his matching group. As a consequence, we observe 9 lenderborrower relationships for each matching group. In the WE treatment there were 15 matching groups, in the SE treatment there were 16 matching groups. This implies that we observe 135 lender-borrower relationships in the WE treatment and 144 relationships in the SE treatment.

The experiment was programmed and conducted with the experimental software z-Tree (Fischbacher, 2007). All sessions lasted approximately 90 minutes. Subjects at Tilburg University received a show-up fee of 5 Euros and 1 additional Euro for every 25 points earned during the experiment. Subjects at UC San Diego received a show-up fee of 10 US Dollars and 1 additional US Dollar for every 20 points earned during the experiment. On average subjects earned 20.9 Euro or 30.0 US Dollars for their participation. ${ }^{11}$

\footnotetext{
${ }^{11}$ We chose to pay a higher show-up fee to subjects and decrease the exchange rate for two reasons. First, due to the Euro to USD exchange rate, which was 0.78 USD/Euro on Oct 29, 2014, shortly before we ran the sessions at UC San Diego. Second, we intended to add sessions with lender competition at UC San Diego (as will be detailed in Section 5), in which participants would make significantly less money for a similar amount of time in
} 
Before starting our lending experiment, each subject read a detailed set of instructions. The instructions can be found in Online Appendix A. The experimental instructions were framed in a credit context. ${ }^{12}$ After reading the instructions participants had to pass a test with control questions. The lending game did not start until all subjects had correctly answered all control questions.

Behavior in our lending game might be affected by individual behavioral traits. First, individual risk preferences affect decisions in investment games (Eckel and Wilson 2004, Schechter 2007, Houser et al. 2010). Second, the level of strategic reasoning, i.e. the anticipation of what other subjects in the matching group might do, can affect behavior significantly (Nagel, 1995). Third, social preferences, i.e. reciprocal motives and fairness preferences of the borrower, as well as the anticipation of these preferences, i.e. trust by the lender, should affect behavior in our experiment (see, e.g., Roe and Wu, 2009).

Participants take part in three "games" aimed at measuring their levels of risk aversion (using a multiple choice list with a fixed lottery and increasing fixed payments), strategic reasoning (using a guessing game), as well as trust and trustworthiness (using a one-shot strategy-method trust game). In our first set of sessions (Tilburg) these games took place before the main experiment (we label them "pre-experiment”). In our second set of sessions (San Diego), the games took place after the main experiment (we label them "postexperiment”). ${ }^{13}$ Online Appendix B describes these pre/post-experiment games and provides

\footnotetext{
the laboratory. To avoid differential selection into sessions, we set the show up fee to $\$ 10$ for all sessions conducted at UC San Diego.

12 The reason why we chose a context-specific and not a neutral framing was that the experiment was relatively complex. In complex experiments a completely neutral language bears the danger that subjects create their own (potentially misleading) interpretation of the decision environment. Thus, the context specific framing gives us control over what our participants have in mind.

${ }^{13}$ Due to logistical constraints the location (Tilburg, San Diego) varied simultaneously with the order of the additional games (pre- vs. post-experiment). We thus acknowledge that we can only measure the joint effect of location and order and cannot rule out that countervailing order and location effects partly offset each other. Our results suggest that location and order do not exert a significant joint effect on behavior in the additional games (as shown in Online Appendix B), and the lending game (as shown in Online Appendix D).
} 
summary statistics for their outcomes in our two treatments. We find no significant differences in behavior in these games across treatments in either location. ${ }^{14}$

\section{Predictions}

Under the assumption of common knowledge of rationality and selfishness of all market participants, the predictions for all three treatments are straightforward. Since repayments are not enforceable, a borrower's best response is to never repay a loan in a one period game. As it is public knowledge that the WE treatment and the SE treatment last for a finite number of periods, a backward induction argument ensures that there is no lending in any period of either treatment.

A broad body of experimental evidence suggests, however, that not all people will maximize monetary payoffs in our experiment. Social preferences based on reciprocity (Dufwenberg and Kirchsteiger, 2004) or distributional concerns (Fehr and Schmidt, 1999) can induce borrowers to repay loans even in one-shot interactions. Evidence from one-period investment games in the lab (Berg et al., 1995) and in the field (Karlan, 2005) suggests that a substantial share of second movers, i.e. borrowers in our context, exhibit such social preferences and repay.

In the following we establish predictions for our treatments under the assumption that some (non-identifiable) borrowers are conditionally reciprocal: they are willing to repay a loan in a one-shot situation, as long as the repayment requested by the lender does not exceed a threshold value. We assume that this threshold $\bar{r}$ can be characterized by the maximum

\footnotetext{
14 Throughout the pre/post-experimental games subjects received no feedback. They were not informed about other subjects' decisions or their own payoffs until the end of the experiment. Subjects also knew that the decisions in each pre/post-experimental game had no effect on the lending game (and vice versa). The instructions for these games are available from the authors upon request. We find that choices in the preexperiment vs. post-experiment games are not significantly different in the risk elicitation task and guessing game. We find differences in the trust game in the SE but not the WE treatment. The higher trust and trustworthiness in the post-experiment games in the SE treatment suggests there was a spillover from successful interaction in the lending game onto the trust game.
} 
(gross) interest rate $i_{t}=\frac{R_{t}}{S_{t}} \leq \bar{r}$ that a social borrower is willing to pay. We assume that the remaining borrowers are selfish in the sense that they never repay loans in a one-shot situation. The share of social borrowers $p$ is assumed to be $\frac{1}{\bar{r}^{T}} \leq p<\frac{1}{\bar{r}}$. The assumption that $p<\frac{1}{\bar{r}}$ implies that it is not profitable for risk-neutral lenders to lend in a one-shot game. The assumption $p \geq \frac{1}{\bar{r}^{T}}$ implies that a repeated game equilibrium in which selfish borrowers repay with positive probability in initial periods exists. ${ }^{15}$

The outcomes of our pre-experimental and post-experimental games, documented in Online Appendix B, suggests that there is a substantial share of social borrowers in both treatments. In particular, behavior in the one-shot, strategy-method trust game suggests that less than $15 \%$ of the subjects in the roles of borrowers can be characterized as pure moneymaximizers, who always default in a 1-shot situation. By comparison, more than $25 \%$ of the subjects behave as social borrowers who are willing to repay a loan as long as the desired repayment implies that they earn at least one-half of surplus. Applied to our experiment this finding would imply that the above conditions on the share of social borrowers is satisfied in our sample. ${ }^{16}$

In the following we outline the main predictions for both treatments. All proofs are presented in Online Appendix C. ${ }^{17}$ Since borrower types are a priori indistinguishable, the WE and SE treatments can be characterized as finitely repeated games of incomplete information. Such games have multiple equilibria (Kreps et al., 1982). We distinguish

\footnotetext{
${ }^{15}$ As we outline in Appendix $\mathrm{C}$, lending relationships with a positive repayment probability for selfish borrowers in non-final periods and certain default by selfish borrowers in the final period are feasible if $T \geq 2$ and $p \geq \frac{1}{\bar{r}^{T}}$. The higher the share of social borrowers $p$ in the population and the larger the number of periods $T$, the more periods with full repayment by all borrowers can be sustained.

${ }^{16}$ In our experiment $i_{t}=2$ is the interest rate that generates the same payoffs for the lender and borrower if the borrower repays a loan. With $v=3, i_{t}=\frac{R_{t}}{S_{t}}=2$ implies that $R_{t}-S_{t}=v \cdot S_{t}-R_{t}$. If we assume that $\bar{r}=2$ and $p=0.25$ then as $T=7$ the condition $\frac{1}{\bar{r}^{T}} \leq p<\frac{1}{\bar{r}}$ is met.

${ }^{17}$ In deriving these predictions, we assume a finite horizon and risk-neutrality of the lenders to simplify the analysis. These assumptions do not change the qualitative effects of weak exclusion, as we discuss in Online Appendix C.
} 
between two types of equilibria and, within each type, concentrate on the profit-maximizing equilibria for the lender (as in Thomas and Worrall, 1994). In implicit contracting equilibria, selfish borrowers imitate the behavior of social borrowers during the first periods but default towards the end of the game. In screening equilibria, selfish borrowers default in the first period, and from period 2 onwards the lender only extends credit to (now identified) social borrowers. It is important to note that in both treatments the one-shot equilibrium of no lending is also feasible.

In the SE treatment the profit-maximizing (and surplus maximizing) implicit contracting equilibrium features loans of maximum size 10 in periods 1 to 6 and a smaller loan of $10 \cdot \frac{\bar{r}}{v}$ in period 7. The interest rate is $i_{t}=\bar{r}$ in each period. Loan offers in periods $t=\{2, \ldots, 7\}$ are contingent on the borrower repaying all past loans. The incentive constraint of a selfish borrower in period $t$ is as follows:

$$
\sum_{k=t}^{T-1}\left(v-i_{k}\right) \cdot S_{k}+v \cdot S_{T} \geq v \cdot S_{t}
$$

Since loans are of size 10 for periods 1 to 6 , IC $\operatorname{SE}$ is satisfied with inequality in these periods. The smaller loan size in period 7 implies that the constraint is satisfied with equality in period 6. Thus, in this period the selfish borrower is indifferent between repaying and defaulting, and defaults with a strictly positive probability. This allows the lender to learn about the borrower's type in period 6 and to break even in period 7.

A screening equilibrium is not feasible in the SE treatment. By definition, in such an equilibrium selfish borrowers would default with certainty in the first period of the game. In the following periods, the lender would offer maximum loans of 10 to the borrowers who did not default, i.e. social borrowers. However, given that the lender offers maximum loans in subsequent periods, a selfish borrower has no incentive to default in the first period. It is impossible for the lender to offer a contract that does not meet IC $\mathrm{CE}_{\mathrm{SE}}$ in the initial period if $i_{1} \leq$ $\bar{r}$. We summarize these results in Proposition 1. 
Proposition 1: In the SE treatment the profit-maximizing implicit contracting equilibrium features the maximum credit volume in periods 1 to 6 and no defaults in periods 1 to 5 . A screening equilibrium is not feasible in this treatment.

In the WE treatment, the potential to reinvest borrowed funds in future periods increases the borrower's incentive to default. This can be seen from the selfish borrower's incentive constraint for this treatment:

$$
\sum_{k=t}^{T-1}\left(v-i_{k}\right) \cdot S_{k}+v \cdot S_{T} \geq v \cdot S_{t}+\sum_{k=t}^{T-1}(v-1) \cdot S_{t}
$$

Implicit contracting equilibria are also feasible in the WE treatment. However, these equilibria must be characterized by "progressive lending": To meet the borrower’s incentive constraint the lender must start with non-maximum loans and increase the loan size offered to the borrower if he repays. The intuition for this result is simple: if the lender offers the maximum loan of 10 in period 1, a selfish borrower could default and reinvest these funds in all future periods without paying interest. The selfish borrower only stands to gain from repaying initial loans if future loans are higher.

In contrast to the SE treatment, a screening equilibrium exists in the WE treatment. If the lender offers a large enough loan in the first period, a selfish borrower prefers to default straight away. For example, from ICwE we see that a selfish borrower will not repay a loan offer with $S_{1}=10$ and $i_{1}=\bar{r}$, while a social borrower will repay such a loan. These results are brought together in Proposition 2.

Proposition 2: In the WE treatment an implicit contracting equilibrium must feature "progressive lending". Loan offers increase gradually over time and there are no defaults in 
periods 1 through 5. In this treatment a screening equilibria is also feasible in which selfish borrowers default with certainty in the first period.

Based on the above predictions we establish the following empirical hypotheses. Our null hypothesis is that there is no difference in observed lending outcomes between the SE and the WE treatment: The share of self-enforcing credit relationships in which loans are offered, accepted and repaid for at least the first five periods is similar. Moreover, the average loan size and interest rate are alike. Our alternative hypothesis is that we will observe a marked difference in lending outcomes between the WE and SE treatments. The nature of this difference will depend on the type of equilibria that dominates empirically in the WE treatment. We outline the expected impact of weak exclusion if mainly implicit contracting equilibria emerge in the WE treatment (H1), and if mainly screening equilibria emerge (H2). Empirically, a combination of these two types of equilibria is likely to occur. ${ }^{18}$

$H 1$ (implicit contracting dominates in the WE treatment): In both treatments there is a similar share of self-enforcing credit relationships. i.e. credit relationships which are characterized by loan offers and loan repayment up to at least period 5 . The average loan size in the SE treatment is higher than in the WE treatment, as the WE treatment is characterized by progressive lending. Loan sizes rise steadily in the WE treatment, while they exhibit a drop in the last period in the SE treatment. Interest rates do not differ between the treatments.

H2 (screening dominates in the WE treatment): In the WE treatments there is a lower share of self-enforcing credit relationships than in the SE treatment Loan sizes and

\footnotetext{
${ }^{18}$ Whether the implicit contracting equilibrium or the screening equilibrium yield higher profits to the lender depends on the gross return from investment $(v)$ and the share of social borrowers. As shown in Appendix C.4., given the choice of $v=3$ in our experiment, and the assumption that the share of social borrowers is $p<\frac{1}{\bar{r}}$, where $\bar{r}=2$, the implicit contracting equilibrium yields higher profits to the lender than the screening equilibrium.
} 
interest rates offered by lenders do not differ between the SE and WE treatments (except for the final period).

\section{Main Results}

\subsection{Credit relationships and credit terms}

In this section we test our main hypotheses by comparing three outcomes of interest across the WE and SE treatments: the share of self-enforcing credit relationships, i.e. relationships in which a loan is offered, accepted and repaid for at least the first 5 periods, ${ }^{19}$ as well as the average Loan size and the average Interest (Requested repayment / Loan size) for accepted loan offers. Our unit of observation are matching-group averages. We hereby compare the outcomes of the 15 matching groups in the WE treatment to the 16 matching groups in the SE treatment using two-sided non-parametric and parametric tests. Since we are comparing three outcomes, we correct for multiple hypothesis testing using Bonferroni adjustments on non-parametric Mann-Whitney (MW) tests, and the adjustment proposed by List et al. (2016) on parametric $t$-tests. ${ }^{20}$

Figure 1 displays the share of credit relationships in which a loan was offered, accepted and repaid in each period. Figure 1 reveals that credit relationships break down much more frequently in the WE treatment compared to the SE treatment. In the first period only $44 \%$ of the 135 relationships in the WE treatment are characterized by a loan being offered, accepted and repaid, compared to $73 \%$ of the 144 relationships in the SE treatment. This difference is driven by a lower number of loans offered (90\% vs. $99 \%$ ), a lower acceptance ratio of offers

\footnotetext{
19 The strength of implicit contracting can also be measured by the average length of relationships in which there offers have been continuously made, accepted and repaid, or more generally, the average number of periods in which a loan has been offered, accepted and repaid. Results remain the same if we use these alternative definitions.

${ }^{20}$ In sections 4.2 and 4.3, where we analyze individual lender and borrower behavior, we do not adjust p-values for multiple hypothesis testing. We follow this approach because the purpose of studying individual behavior is to understand the mechanisms underlying the treatment effects on our main outcome variables, rather than to examine additional hypotheses and outcomes.
} 
made (76\% versus $89 \%)$, and a lower repayment rate for offers that have been accepted (65\% versus $84 \%$ ) in the WE treatment.

The share of relationships featuring a loan offer in period 2 is $78 \%$ in the WE treatment and $92 \%$ in the SE treatment. Thus lenders not only continue those relationships which survived the first period, but also attempt to restart many of the relationships that break down in period 1 (61\% and $72 \%$ of the relationships that break down in period 1 in the WE and SE treatment, respectively, feature a loan offer in period 2). However, the share of relationships in which the period 2 offer is also accepted and repaid again declines to $44 \%$ in the WE treatment and $71 \%$ in the SE treatment. This pattern repeats itself through to period $6 .^{21}$

Figure 1 suggests that the SE treatment is characterized by more self-enforcing credit relationships than the WE treatment. This conclusion is confirmed by the end-game behavior in period 7. In the SE treatment the majority of credit relationships fall subject to the endgame effect: Borrowers default more frequently and more lenders refrain from offering credit in the final period.

In line with Figure 1 we observe a substantial difference in the share of self-enforcing contracting relationships, i.e. relationships in which a loan is offered, accepted and repaid for at least the first 5 periods, between the SE treatment (48\%) and WE treatment (12\%). Table 1 displays the results of non-parametric and parametric tests, which reveal that this treatment difference is statistically significant.

\section{Figure 1 here}

\section{Table 1 here}

\footnotetext{
${ }^{21}$ Out of those relationships that break down in a given period $t, 27 \%$ and $33 \%$ are restarted in the next period $(t+1)$ in the WE and SE treatment, respectively. Most restarts occur after a rejection in the previous period (45\% and $37 \%$ of the restarts observed in the WE and SE treatment, respectively). 35\% and 36\% of the restarts occur after a default, while $20 \%$ and $26 \%$ of the restarts occur after no offer was made in the previous period in the WE and SE treatment, respectively.
} 
Figure 2 presents the credit terms for accepted loan offers, showing the average Loan size (Panel A) and the average Interest (Panel B) by period. The treatment difference between the average loan size increases from period 1 (5.20 vs. 5.97) to period 7 (5.25 vs. 7.89 ). Over all periods the average loan size is significantly smaller in the WE treatment (5.00) than in the SE treatment (6.90). As shown in Table 1, this difference is statistically significant. Panel B of Figure 2 documents that the average interest rate is similar in all periods in both treatments. Average interest rates do not differ significantly between the WE treatment (1.94) and the SE treatment (1.95) as shown in Table 1. The observed interest implies (upon repayment) an equal sharing of surplus between the lender and borrower, in accordance with our behavioral assumptions.

\section{Figure 2 here}

The impact of the WE treatment on credit relationships and credit terms has implications for the distribution of payoffs between the lender and the borrower. Lenders earn less in the WE treatment than in the SE treatment (10.74 vs. 13.04 per period). In contrast, borrowers earn more in the WE treatment than in the SE treatment (20.20 vs. 17.98 per period).

Result 1 (Credit relationships and credit terms): In the WE treatment there is a lower share of self-enforcing credit relationships than in the SE treatment. The average loan size is also smaller in the WE treatment than in the SE treatment. Interest rates do not differ across treatments.

To what extent are the findings presented in Result 1 noteworthy? Maniadis et al. (2014) argue that the judgment of novel empirical findings should not rely solely on an assessment of 
statistical significance. They emphasize that the probability that a significant treatment effect represents a true association depends on the level of significance $(\alpha)$ and power of our empirical test $(1-\beta)$ as well as our prior $(\pi)$ about the probability with which our alternative hypothesis holds. The Post-Study Probability (PSP) informs us about the probability that a treatment difference which we declare as statistically significant is actually a true association.

We illustrate the strength of our main treatment effects by calculating the $P S P=$ $\frac{(1-\beta) \cdot \pi}{(1-\beta) \cdot \pi+\alpha \cdot(1-\pi)}$ for one prominent finding from Table 1: the share of self-enforcing credit relationships in which a loan is offered, accepted, and repaid for at least the first five periods. For this outcome we yield a large and statistically significant difference between the WE (12\%) and the SE (48\%) treatments. Simulations suggest that, given an ex-ante level of significance of $\alpha=0.05$, the power of our experimental design $(1-\beta)$ for this outcome exceeds $0.75 .^{22}$ Table 2 presents the PSP for varying levels of priors $\pi$ and for different levels of power $(1-\beta)$ which are consistent with our simulations. ${ }^{23}$ We conclude from the table that for reasonable levels of ex-ante priors our observed treatment difference shifts priors

\footnotetext{
${ }^{22}$ Our statistical inference is based on comparing the outcomes of 15 matching groups in the WE treatment to 16 matching groups in the SE treatment using two-sided non-parametric (Mann-Whitney) tests. The power $(1-\beta)$ of this test is a function of the level of significance $(\alpha=0.05)$ and the assumed distribution of (matching-grouplevel) outcomes under the null and alternative hypotheses. In each matching group there are 9 relationships. We thus model the outcome of each matching group as drawn from a binomial distribution where $n=9$ is the number of draws and $q$ is the probability that a loan is offered, accepted and repaid in at least five periods. To estimate the power of our test we need to specify $q$ for the null hypotheses (SE=WE) and alternative hypotheses ( $\mathrm{SE} \neq \mathrm{WE}$ ). Based on evidence provided by Brown \& Zehnder (2007) we assume that in the SE treatment 2/3 of the relationships feature implicit contracting so that $q_{\text {null }}=0.66$. The predicted probability for the WE treatment under the alternative hypothesis depends on the share of relationships which feature implicit contracting $\varphi_{1}$, the share which feature screening $\varphi_{2}$, and the share of social types $p$ (as only they repay in a screening equilibrium): $q_{\text {alternative }}=\varphi_{1}+\varphi_{2} \cdot p$. For consistency we assume that there is a similar share of relationships in the SE and WE which feature repeated contracting: $\varphi_{1}+\varphi_{2}=0.66$ and that both implicit contracting and screening are present in the WE: $\varphi_{1}, \varphi_{2} \epsilon[0.22,0.44]$. In line with evidence provided by Brown $\&$ Zehnder (2007) we assume further that the share of social types is $p=0.3$. Together these assumptions imply that $q_{\text {alternative }} \epsilon[0.35,0.5]$. With $q_{\text {null }}=0.66$ and $q_{\text {alternative }} \epsilon[0.35,0.5]$ we yield power estimates of $(1-\beta) \epsilon[0.77,0.99]$ for our Mann-Whitney tests. We simulate the power of our test using the software PASS. When simulating we approximate the binomial distribution for matching group outcomes with a corresponding normal distribution.

${ }^{23}$ Guided by our theoretical predictions, our empirical prior $\pi$ is that weak exclusion should influence credit relationships in our experiment. However, existing experimental studies indicate that implicit contracting can be robust to institutional changes (e.g. competition, stochastic incomes) which appear relevant from a theory perspective (Brown and Zehnder 2007; Fehr and Zehnder 2009). Thus it is feasible that weak exclusion has a negligible impact on credit relationships in our experiment as well.
} 
substantially. For example, if we believed prior to the study that there was a $30 \%$ chance of the WE treatment undermining the emergence of self-enforcing contracts, then our observed treatment effect would move this prior to at least $87 \%$. Likewise, if we believed prior to the study that there was a $50 \%$ chance of the WE treatment undermining the emergence of selfenforcing contracts, then our observed treatment effect would move this prior to at least $94 \%$.

\section{Table 2 here}

\subsection{Lender behavior}

Our above findings show more loan defaults in initial periods in the WE treatment than in the SE treatment suggesting less implicit contracting and more screening in the WE treatment. However, we also find smaller loans in the WE treatment suggesting that self-enforcing agreements were (at least) attempted in this treatment. If lenders attempt to initiate implicit contracts in both treatments we should see lower initial loan sizes offered in the WE treatment than in the SE treatment. Panel A of Figure 3 displays the empirical cumulative distribution function of the Loan size offered by lenders to borrowers in the first period in the WE and SE treatments. The figure reveals that small loans are more frequent in the WE treatment, where close to $70 \%$ of lenders offer a loan smaller than 5. By contrast, in the SE treatment only $49 \%$ of lenders offer a loan smaller than 5. Panel B of Figure 3 shows that the distribution of Interest offered in first-period loan offers is similar in the WE and SE treatments. In both treatments the surplus sharing interest rate of 2 is most common.

Figure 3 here 
Table 3 reports the results of a multivariate analysis relating first-period loan offers to the treatment (WE or SE) and characteristics of the lender. ${ }^{24}$ The estimated coefficient of the dummy variable WE Treatment in column 3 confirms that first-period loans in the WE treatment are on average 1.3 points lower than in the SE treatment. The coefficients of Round 2 and Round 3 in columns (1-2) and that of the interaction terms WE Treatment * Round 2 and WE Treatment * Round 3 in column (4) suggest that the treatment effect is strengthened as subjects become more experienced.

The variation in initial loan offers across lenders is related to individual risk attitudes of lenders as well as the degree to which they trust other participants. In Table 3 we control for three measures of lender characteristics: Risk aversion, Strategic reasoning and Trust, using data from the pre/post-experiment games discussed in Section 2.4. We find that lenders with higher indicators of Risk aversion and lenders who exhibit less Trust in other participants offer smaller period 1 loans in both treatments, but that this is effect is larger and more precisely estimated in the WE treatment. ${ }^{25}$

\section{Table 3 here}

For periods 2-7 we predict that in both treatments the renewal of loan offers by lenders from one period to another should be strongly contingent on the repayment of past loans. Moreover, as implicit contracts must be characterized by progressive lending in the WE

\footnotetext{
${ }^{24}$ Since the correlation between loan sizes and interest is not significantly different from zero, we analyze these two variables separately (Spearman's rho=-0.34, p-value $=0.21$ in WE treatment; Spearman's rho=-0.0721, pvalue $=0.79$ in SE treatment). Results remain qualitatively the same if we estimate both regressions simultaneously instead. Further, results remain qualitatively the same when the decision to make a loan offer is studied separately from the loan size, conditional on making an offer. The results are available from the authors. ${ }^{25}$ Existing studies provide mixed evidence on the relation between risk-aversion, trust and first-mover behavior in investment games. Schechter (2007) for example provides field evidence that first-mover behavior in trustgames is significantly related to individual risk attitudes. By contrast, the evidence provided by Eckel and Wilson (2004) or Houser et al. (2010) suggests that trust in others rather than risk attitudes are associated with first-mover behavior. We find that both factors affect first-mover behavior.
} 
treatment, we expect that - conditional on past loan repayment - the offered loan size increases more strongly over time in the WE treatment than in the SE treatment.

We find that loan offers are strongly contingent on past repayment in both treatments. If the borrower repaid a loan in the previous period, lenders offer a loan in the next period in 98\% of the cases in the WE treatment and $97 \%$ of the cases in the SE treatment. By contrast, if the borrower defaulted, lenders offer a loan in $61 \%$ of the cases in the WE treatment and $62 \%$ of the cases in the SE treatment. ${ }^{26}$

In Table 4 we examine whether - conditional on repayment in all past periods - the Loan size offered by lenders increases over time. ${ }^{27}$ Our explanatory variables are the dummy variables Period 2-3, Period 4-5 and Period 6-7 which indicate if the average loan size offered to borrowers is higher in these periods compared to the baseline period 1 . The results show that offered loan sizes increase over time in both treatments (columns 1-2). In the WE treatment as well as in the SE treatment the offered loan size peaks in periods 4-5, where offered loans are 1.5 - 2 points higher than in period 1. The negative coefficient of WE treatment (column 3) indicates that the loan size offered to borrowers who repaid in the past is significantly lower in the WE than in the SE treatment. The negative (but insignificant) interaction terms of $W E^{*}$ Period 2-3 and $W E^{*}$ Period 4-5 (column 4) suggest that the loan sizes offered to borrowers do not increase faster in the WE treatment than in the SE treatment.

\section{Table 4 here}

Table 5 here

\footnotetext{
${ }^{26}$ There is no significant difference in contract renewal rates across treatments, conditional on past repayment or conditional on past default. Regression results are available from the authors upon request.

27 The regression results reported in Table 4 include individual lender characteristics as well as round fixed effects. Results remain qualitatively the same if we use lender fixed effects.
} 
In Table 5 we compare the resulting time structure of loan sizes within credit relationships across the two treatments. We define the ultimate length of a relationship as the number of periods for which the relationship survives, i.e. loans are offered, accepted and repaid in every previous period. A relationship in which a loan is offered and accepted in period 1, but not repaid is defined as having an ultimate length of 0 periods. By contrast, a relationship which involved positive loan offers in all periods and in which the borrower always accepted and repaid the loan has an ultimate length of 7 periods. We define a long-term relationship as a relationship with an ultimate duration of at least 5 periods. In line with the results presented in Figure 1 only 16 of 135 relationships in the WE treatment (12\%) are long-term compared to 69 of 144 relationships in the SE treatment (48\%).

Long-term relationships in the WE treatment start off with somewhat smaller loan sizes than long-term relationships in the SE treatment. The average first-period loan for these relationships is 5.8 in the WE treatment compared to 6.5 in the SE treatment. This difference is however not statistically significant. ${ }^{28}$ By period five the average loan size in long-term relationships in the WE treatment increases by 1.8 points to 7.6 . This confirms our prediction that long-term relations in the WE treatment should - on average - be characterized by increasing loan sizes. However, we find a similar pattern in the SE treatment. In this treatment the average loan size in period five is 8.6, implying an even stronger increase of 2.3 points from period one.

Result 2 (Lender behavior): Lenders in the WE treatment offer smaller loans in the first period of relationships compared to the SE treatment. Long-term credit relationships in the WE treatment display an increase in loan sizes over time. However, "progressive lending” is observed to a similar degree in the SE treatment.

\footnotetext{
${ }^{28}$ We conduct a Mann -Whitney test at the relationship level. The p-value obtained is 0.776.
} 
Result 2 supports the conjecture that a substantial fraction of lenders attempt to start implicit agreements with small loan sizes in the WE treatment. ${ }^{29}$ However, the long-term relationships that emerge do not exhibit substantially lower initial loan sizes or a stronger time trend in the WE compared to the SE treatment. Two central features in the data seem to explain this behavior. First, as we will see in the next subsection, borrowers in the WE treatment are significantly more likely to reject small loan offers in the initial period of a relationship. Second, loan sizes exhibit an increasing time trend in the SE treatment as well, a finding which has been previously documented in finitely repeated trust games (Anderhub et al., 2002; Cochard et al., 2004; King-Casas et al., 2005; Bornhorst et al., 2010). Our results are in line with these previous findings and suggest that a weak threat of exclusion is not a necessary condition for progressive lending in credit relationships plagued by moral hazard.

\subsection{Borrower behavior}

Figure 4 displays the frequency with which borrowers reject loan offers (Panel A) and default on accepted loans (Panel B) in period 1 by treatment. Table 6 presents results of a corresponding multivariate analysis of borrower behavior in period $1 .^{30}$

\footnotetext{
${ }^{29} \mathrm{~A}$ further piece of evidence that is consistent with this conjecture is lender beliefs. While lenders waited for borrowers' decisions on the acceptance and repayment of loans, we elicited their beliefs about repayment. These were not incentivized to avoid increasing the complexity of the experiment for participants. Lenders simply answered the question 'How probable do you think it is that the borrower will make the desired repayment?' with a scale from 1, 'very unlikely', to 6, 'very likely'. Overall all rounds, in the WE treatment, lenders who offered loans of 1-4 in the first period stated that repayment was likely or very likely in $40 \%$ of the cases, while lenders who offered loans of 5-10 did the same in 38\% of the cases. By contrast in the SE treatment, these percentages are $18 \%$ of the cases for loans of $1-4$, and $42 \%$ for loans of $5-10$. By round 3 , lenders in the WE treatment seem to expect a strategy of "starting small" to be more successful in inducing repayment by borrowers. In $50 \%$ of the cases they believe repayment to be likely or very likely after an offer of size 1-4, compared to $40 \%$ after an offer of size $5-10$. The corresponding percentages are $0 \%$ and $38 \%$ in the SE treatment.

${ }^{30}$ Due to our interest in the interaction effects of treatment dummies and other variables we choose to use linear probability models rather than probit or logit models (see Ai and Norton, 2003 for a discussion of the difficulty of interpreting the marginal effects of interaction terms in non-linear models). An analysis of loan rejection and repayment for periods 2 to 7, as shown in Online Appendix D (Table D.2), reveals that rejection and default are significantly more likely if the interest rate is above 2, while default is more likely for smaller loans in the SE treatment (and not in the WE treatment).
} 


\section{Figure 4 here}

\section{Table 6 here}

In period 1, 25\% of all loan offers are rejected in the WE treatment, while $11 \%$ of the loan offers in the SE treatment are rejected (see Figure 1). For both treatments Figure 4 displays the highest rejection rate among credit offers with Interest above 2 (58\% in the WE treatment, $50 \%$ in the SE treatment). These offers propose an unequal split of surplus to the disadvantage of the borrower. This is in line with our predictions that "social" borrowers will not accept unfair loan offers. The regression results in Table 6 confirm that loan offers which propose Interest $>2$ are significantly more likely to be rejected than loan offers which propose an equal share of surplus to the borrower. There is no difference in the rejection rate of "unfair" offers between the WE and SE treatments, as captured by the insignificant interaction term WE* Interest $>2$ in column (4) of Table 6 . By contrast, loan size is treated differently by borrowers in the WE and SE treatments. The estimate for $W E *$ Loan $<5$ in column (4) reveals that offers with small loan sizes are significantly more likely to be rejected in the WE treatment than in the SE treatment. This finding suggests that some lenders who attempted to start with small loans could not do so due to borrower rejections.

The default rate on first-period loans that are accepted by borrowers is $35 \%$ in the WE treatment compared to $16 \%$ in the SE treatment. Panel B of Figure 3 shows that in the WE treatment the default rate on first-period loans is especially high for larger loans and for loans which propose an 'unfair' split of surplus. This result is confirmed by the column (5) estimates in Table 6. In the WE treatment accepted offers with a loan size of less than 5 (Loan $<5)$ are 19 percentage points less likely to suffer a default, while offers with Interest $>2$ are 25 percentage points more likely to suffer a default. While both of these coefficients are 
imprecisely estimated, they are jointly significant $($ F-test $=0.020)$, suggesting that large loans with high interest rates are 45 percentage points more likely to be defaulted on than small loans with low interest rates in the WE treatment. In the SE treatment, by contrast, we find only a weak impact of the loan size and the interest rate on first-period loan defaults. The estimated coefficients for Loan size $<5$ and Interest $>2$ are jointly insignificant (F-test $=$ 0.764). These results suggest that dynamic incentives to repay are substantially stronger in the initial periods of the SE treatment.

Result 3 (Borrower behavior in period 1): In the initial period, borrowers in both treatments are more likely to reject loan offers which propose an unfair sharing of surplus. In the WE treatment borrowers are also more likely to reject period 1 loan offers with small loan sizes. Borrowers in the WE treatment are much more likely to default on large loans with high interest rates than borrowers in the SE treatment.

The default behavior reported in Result 3 points to screening in the WE treatment. Borrowers that were offered larger loan sizes are more likely to default. At the same time, rejection behavior indicates that implicit contracts are more difficult to establish in the WE treatment. Our findings show that borrowers in the WE treatment often reject the low initial loan offers inherent to progressive lending. One explanation for the prevalence of this behavior is that in the WE treatment social borrowers prefer screening equilibria (in which they receive maximum loan sizes in all periods) to implicit contracting equilibria which feature progressive lending. Thus they may have tried to signal a desire to be tested with larger loans - a test that is only meaningful in this treatment.

\section{Lender Competition}


Weak exclusion has important effects on implicit contracting in bilateral credit relationships, as shown thus far. In this section we examine whether weak exclusion has a similar effect on credit relationships in a competitive environment. Specifically, we examine the effects of weak exclusion when lenders compete for borrowers. We study lender competition (rather than, e.g., borrower competition) as theory suggests that competition between lenders may strongly influence the emergence and time structure of credit relationships. For example, Sharpe (1990) and Petersen \& Rajan (1995) show that competition between banks may undermine the ability of lenders to earn quasi-rents in ongoing lending relationships, and therefore may reduce their incentive to engage in such relationships from the outset.

We implement lender competition by pairing two lenders with one borrower. ${ }^{31}$ The lending game is identical to that without competition, except for the following changes: First, both lenders make a credit offer to the borrower simultaneously at the beginning of each period. Second, the borrower can accept one offer (or none). Third, at the beginning of each period each lender is informed about the past credit volume accepted by the borrower and his repayment behavior, but not the interest rate. ${ }^{32}$ We implement a treatment with lender competition for our weak exclusion condition (WE Competition treatment) and strong exclusion condition (SE Competition treatment).

\subsection{Predictions}

\footnotetext{
${ }^{31}$ We chose this type of design because the presence of two lenders is enough to generate the effects of competition. Our focus is on the effect of weak exclusion on credit offers and repayment behavior, rather than the endogenous formation of credit relationships.

32 This information setting mirrors the functioning of public credit registries and private credit bureaus in many developed and developing countries (Japelli and Pagano, 2002; Miller, 2003), where lenders have access to the volume of credit upon which the borrower defaulted, while not knowing the interest that was required for that loan.
} 
In this section we discuss the main differences in predictions for the WE Competition and SE Competition treatments as compared to our main treatments with bilateral interaction. Detailed predictions are provided in Online Appendix E.

Implicit contracting in the SE Competition treatment exhibit a similar pattern of loan sizes compared to our main SE treatment with bilateral interaction. Implicit contracting equilibria are characterized by maximal loan offers throughout the first six periods and a drop in period 7. However, interest rates are lower with lender competition: they are at the break even rate $\left(i_{t}=1\right)$, rather than the surplus sharing rate $(\bar{r}=2)$, since lenders compete to attract the borrower. Note that since there are two symmetrical lenders with identical information about past repayment, a relationship can emerge with one of the lenders or there can be switching between lenders. We refer to an active credit market as an environment in which at least one offer is made, one offer is accepted and repaid in each period. ${ }^{33}$

The set of equilibria in the WE Competition treatment changes compared to our WE treatment with bilateral trading. In particular, screening equilibria do not exist under weak exclusion with lender competition. The reason is that - as both lenders are equally informed about past repayment behavior - borrowers are not informationally captured by their incumbent lender. ${ }^{34}$ In expectation, therefore, lenders cannot recoup losses from defaulting selfish borrowers in the first period by earning quasi-rents on social borrowers in subsequent periods. In the WE Competition treatment, implicit contracting equilibria exist, but exhibit a different time pattern of loan volumes. Instead of progressively increasing loan volumes, lenders offer a constant loan volume from periods one to six, which is strictly smaller than the maximal loan offer. In the last period, they increase their loan offer, offering the maximal loan size, to induce indifference between repayment and default among borrowers in period

\footnotetext{
${ }^{33}$ We term the two lender and one borrower environment a market, following terminology used by Roth et al. (1991), among others, to describe environments in which multiple buyers (lenders, in our case) make offers to a single seller (borrower, in our case).

${ }^{34}$ See the model by Sharpe (1990) for a game of endogenous asymmetric information between lenders in which borrowers are informationally captured by their incumbent bank.
} 
six. The constant loan size in non-final periods is self-enforcing, as lenders demand the breakeven interest rate $\left(i_{t}=1\right)$.

Our null hypothesis for the comparison of the WE Competition and SE Competition treatments is again that we observe no differences in lending outcomes. Our alternative hypothesis suggests that we observe differences in loan sizes, but not in the frequency of selfenforcing credit relationships:

H3 (lender competition): Self-enforcing credit relationships i.e. credit relationships in which loans are offered, accepted and repaid for at least 5 periods are equally likely in the WE Competition and SE Competition treatments. The average loan size is, however, lower in the WE Competition treatment than in the SE Competition treatment. Interest rates are similar in both treatments.

\subsection{Procedures}

The treatments with lender competition were designed and implemented following the same procedures as our bilateral trading treatments. The only major difference was that two lenders were matched with one borrower in each round. In order to keep the perfect stranger matching used in the main experiment, each matching group consisted of twelve (instead of six) subjects.

We ran 12 sessions with lender competition at UC San Diego with one matching group per session. A total of 144 subjects participated in these sessions, whereby each subject participated in one treatment only. ${ }^{35}$ Six sessions, i.e. matching groups, were run for the WE Competition treatment and six sessions were run for the SE Competition treatment. After the

\footnotetext{
${ }^{35}$ Additionally no subject that participated in the sessions in UC San Diego participated in either of the bilateral contracting treatments.
} 
subjects completed three seven-period rounds of the lending game, they played the postexperiment games as outlined above.

\subsection{Results}

Our aim in this section is to examine whether the main treatment differences documented for our main WE and SE treatments also hold with lender competition. Our discussion of the results for the SE Competition and WE Competition treatments is therefore limited to replicating the analyses presented in section 4.1. As we did there, we compare three outcomes: the share of self-enforcing credit relationships, i.e. relationships in which a loan is offered, accepted and repaid for at least the first 5 periods, as well as the average Loan size and Interest for accepted loan offers. We measure our outcome variables again at the matching group level and thus compare six observations for the WE competition treatment against six observations for the SE competition treatment. Due to the lower number of observations for this robustness test we confine our tests to nonparametric methods (MannWhitney test) and account for multiple hypothesis testing by adjusting p-values using the Bonferroni method.

Figure 5 displays the share of credit markets in which a loan is offered, accepted and repaid by period in the WE Competition and SE Competition treatments. In the WE Competition treatment $72 \%$ of the credit markets survive period 1 , i.e. a loan is offered, accepted and repaid, while this is the case for $82 \%$ of the markets in the SE Competition treatment. By period 3 the gap in credit market performance widens. In the WE Competition treatment $53 \%$ of the markets feature a repaid loan, while $75 \%$ of the markets do so in the SE Competition treatment. This gap remains until the end of period 5. By periods 6 and 7, the gap between the WE and SE Competition treatment closes again due to the end-game effect in the SE Competition treatment. 
Table 7 summarizes our treatment effects under lender competition. In line with Figure 5 we find a smaller share of self-enforcing relationships in the WE treatment (35\%) compared to the SE treatment (50\%). However, the non-parametric tests presented in Table 7 reveal that this treatment difference is not statistically significant after adjusting for multiple hypothesis testing (MW test, adjusted p-value=0.183).

\section{Figure 5 here}

\section{Table 7 here}

Figure 6 displays the credit terms of accepted loan offers in the competition treatments. In line with our predictions accepted loan offers are smaller in all periods in the WE Competition compared to the SE Competition treatment. By contrast, interest rates are similar in both treatments. Table 7 shows that the average Loan size of accepted loan offers over all periods is 7.40 in the WE Competition treatment compared to 8.52 in SE Competition treatment (MW test, adjusted p-value=0.075). Table 7 reveals no difference in average interest rates in the WE Competition treatment (1.27) compared to the SE Competition treatment (1.31, MW test, adjusted p-value=1.00).

\section{Figure 6 here}

Comparing the treatment effect of weak exclusion on lending in competitive credit markets (Table 7) relative to bilateral trading environments (Table 1), we find in both cases a negative effect on the share of self-enforcing credit relationships and on average loan sizes. The magnitude of the effect of weak exclusion on the average loan size is similar in the both trading environments. However, in line with Hypothesis 3, the magnitude of the effect of weak exclusion on the share of self-enforcing contracts is substantially smaller under 
competition (15 percentage points) than under bilateral trading (36 percentage points) and has much weaker statistical significance. ${ }^{36}$

Result 4 (lender competition): Under lender competition weak exclusion is associated with lower loan sizes, and a small, non-significant decrease in the share of self-enforcing relationships. Compared to a bilateral trading environment, the magnitude of the effect of weak exclusion on the share of self-enforcing credit relationships is weaker under lender competition.

\section{Conclusion}

In this paper we examine how the threat of exclusion impacts on self-enforcing agreements in contracting environments plagued by moral hazard. The results of our lending experiment suggest that weak exclusion leads to a more frequent breakdown of lending relationships as well as to smaller loan sizes. These effects are substantial with bilateral trading, and are moderated with lender competition. Our findings provide a new perspective on the conditions under which self-enforcing agreements may - or may not be - a viable instrument for managers to mitigate conflicts of interest with employees, creditors and clients. Implicit contracting is an effective enforcement strategy when agents value the relationship with their current trading partner. This may not be the case when agents can appropriate income-

\footnotetext{
${ }^{36}$ Given the smaller number of observations in the competition treatments (6 matching groups per treatment) compared to our main bilateral trading treatments, one may worry that the lack of significance of an effect of weak exclusion is due to the low number of observations. We perform ex-post power calculations to assess this concern. First, if the magnitude of the treatment effect of weak exclusion were the same as in the main treatments (12 versus 48 percentage points), we would be powered to detect a significant effect (the power would be $93 \%$ with 6 matching groups). Second, given the observed magnitude of the treatment effect in the competition treatments (35 versus 50 percentage points), our power level would be merely $62 \%$ even if we increase the number of observations to 15 per treatment (as in our main treatments). Given the observed magnitude of the treatment effect in the competition treatments 27 matching groups per treatment would be needed in each treatment to obtain a power of $80 \%$ given a significance level of 0.05 .
} 
generating resources provided to them by principals. In this case the threat of exclusion is weak and our experiment suggests that implicit contracting is impaired.

Which markets and business relations are most likely to be subject to a weak threat of exclusion? This threat is particularly weak when (i) agents (employees, debtors, suppliers) use income-generating resources provided to them by the principal, (ii) a weak legal environment enables the agent to appropriate these resources, and (iii) they do not rely on the continued cooperation of the principal to generate future income with these resources. Bank lending in environments with weak creditor protection - the context of interest in our experiment - is a prime example of these conditions. Joint ventures in foreign direct investment is another especially when the foreign partner has the technical know-how to use common assets independently. Likewise, investment relations with upstream firms may be subject to a weak exclusion threat if the supplier can appropriate technology and supply competing firms. Professional services such as wealth management or consulting in which employees may poach clients is another environment where a weak threat of exclusion may undermine incentives. In such markets and business relations, managers may need to resort to formal and costly enforcement mechanisms, e.g. monitoring, incentive contracts, or a reallocation of ownership to mitigate conflicts of interest.

\section{References}

Ai, Chunrong and Edward C. Norton (2003). "Interaction terms in logit and probit models", Economics Letters, 80, 123-129.

Albuquerque, Rui and Hugo A. Hopenhayn (2004). "Optimal Lending Contracts and Firm Dynamics", Review of Economic Studies, 71, 285-315.

Anderhub, Vital, Dirk Engelmann and Werner Güth (2002). "An experimental study of the repeated trust game with incomplete information", Journal of Economic Behavior and Organization, 48, 197-216. 
Andreoni, James and Larry Samuelson (2006). "Building Rational Cooperation", Journal of Economic Theory, 127, 117-154.

Armendariz, Beatriz and Jonathan Morduch (2006). The Economics of Microfinance, MIT Press.

Berg, Joyce, John Dickhaut and Kevin McCabe (1995). "Trust, Reciprocity and Social History", Games and Economic Behavior, 10, 122-142.

Bond, Philip and Arvind Krishnamurthy (2004). "Regulating Exclusion from Financial Markets", Review of Economic Studies, 71, 681-707.

Boot, Arnoud W.A. and Anjan V. Thakor (1994). "Moral Hazard and Secured Lending in an Infinetely Repeated Credit Market Game", International Economic Review, 35, 899-920.

Bornhorst, Fabian, Andrea Ichino, Oliver Kirchkamp, Karl H. Schlag and Eyal Winter (2010). "Similarities and Differences when Building Trust: the Role of Cultures", Experimental Economics, 13, 260-283.

Brown, Martin, Armin Falk and Ernst Fehr (2004). "Relational Contracts and the Nature of Market Interaction", Econometrica, 72, 747-780.

Brown, Martin and Christian Zehnder (2007): "Credit Reporting, Relationship Banking, and Loan Repayment", Journal of Money, Credit, and Banking, 39, 1883-1918.

Bull, Clive (1987). "The Existence of Self-Enforcing Implicit Contracts", Quarterly Journal of Economics, 102, 147-159.

Bulow, Jeremy and Kenneth Rogoff (1989). "Sovereign Debt: Is to Forgive to Forget?", American Economic Review, 79 , 43-50.

Camerer, Colin F. (2003). Behavioral Game Theory: Experiments in Strategic Interaction, Princeton, Princeton University Press.

Cerqueiro, Geraldo and Maria Fabiana Penas (2014). "How does personal bankruptcy law affect start-ups? ", CentER Working Paper No. 2011-106.

Cochard, François, Nguyen, Phu Van and Marc Willinger (2004). "Trusting behavior in a repeated investment game", Journal of Economic Behavior and Organization, 55, 31-44.

Djankov, S., O. Hart, C. McLiesh, and A. Shleifer (2008). "Debt Enforcement around the World", Journal of Political Economy, 116, 1105-1149.

Dufwenberg, Martin and Georg Kirchsteiger (2004). "A Theory of Sequential Reciprocity", Games and Economic Behavior, 47, 268-298.

Eckel, Catherine and Richard K. Wilson (2004). "Is Trust a Risky Decision". Journal of Economic Behavior and Organization", 55, 447-465. 
Falk, Armin, David Huffman and W. Bentley MacLeod (2015). "Institutions and Contract Enforcement", Journal of Labor Economics, 33, 571-590.

Fehr, Ernst, Martin Brown and Christian Zehnder (2009). "On Reputation: A Microfoundation of Contract Enforcement and Price Rigidity", Economic Journal, 119, 333-353.

Fehr, Ernst and Klaus Schmidt (1999). "A Theory of Fairness, Competition and Cooperation", Quarterly Journal of Economics, 114, 817-868.

Fehr, Ernst and Christian Zehnder (2009). "Reputation and Credit Market Formation: How Relational Incentives and Legal Contract Enforcement Interact", IZA Discussion Paper 4351.

Fischbacher, Urs (2007): "z-Tree: Zurich Toolbox for Readymade Economic Experiments", Experimental Economics, 10, 171-178.

Ghosh, Parikshit and Debraj Ray (1996). "Cooperation in Community Interaction without Information Flows", Review of Economic Studies, 63, 491-519.

Ghosh, Parikshit and Debraj Ray (2001). "Information and Enforcement in Informal Credit Markets", working paper.

Gropp, Reint, John Karl Scholz, and Michelle J. White (1997). "Personal bankruptcy and credit supply and demand", Quarterly Journal of Economics, 112, 217-251.

Houser, Dan, Daniel Schunk, and Joachim Winter (2010). "Distinguishing Trust from Risk: An Anatomy of the Investment Game", Journal of Economic Behavior and Organization, 74, 72-81.

Ioannidou, Vasso P., and Steven Ongena (2010). "Time for a Change: Loan Conditions and Bank Behavior When Firms Switch", Journal of Finance, 65, 1847-1878.

Jappelli, Tullio and Marco Pagano (2002). "Information sharing, lending and defaults: Crosscountry evidence” Journal of Banking and Finance, 26, 2017-2045.

Jiang, Guohua, Charles Lee, and Heng Yue (2010). "Tunneling through intercorporate loans: The China experience", Journal of Financial Economics, 98, 1-20.

Johnson, Simon, Rafael LaPorta, Florencio Lopez-de-Silanes and Andrei Shleifer (2000). "Tunneling", American Economic Review (Papers and Proceedings), 90, 22-27.

Karlan, Dean (2005). "Using Experimental Economics to Measure Social Capital and Predict Financial Decisions", American Economic Review, 95, 1688-1699.

King-Casas, Brooks, Damon Tomlin, Cedric Anen, Colin F. Camerer, Steven R. Quartz and P. Read Montague (2005). "Getting to Know You: Reputation and Trust in a Two-Person Economic Exchange", Science, 308, 78-83. 
Kirschenmann, Karolin (2016). "Credit Rationing in Small Firm-Bank Relationships", Journal of Financial Intermediation, 26, 68-99.

Klein, Benjamin and Keith B. Leffler (1981). "The Role of Market Forces in Assuring Contractual Performance", Journal of Political Economy, 89, 615-641.

Kreps, David, Paul Milgrom, John Roberts and Robert Wilson (1982). "Rational Cooperation in the Finitely Repeated Prisoners’ Dilemma", Journal of Economic Theory, 27, 245-252.

List, John A., Azeem L. Shaikh and Yang Xu (2016). "Multiple Hypothesis Testing in Experimental Economics”, NBER Working Paper 21875.

Maniadis, Zacharias, Fabio Tufano and John A. List (2014). "One Swallow Doesn’t Make a Summer: New Evidence on Anchoring Effects", American Economic Review, 104, 277290.

Miller, M. J. (2003). Credit Reporting Systems and The International Economy. MIT Press, Cambridge.

Morduch, Jonathan (1999). “The Microfinance Promise”, Journal of Economic Literature, 37, 1569-1614.

Nagel, Rosemarie (1995). "Unraveling in Guessing Games: An Experimental Study", American Economic Review, 85, 1313-1326.

Petersen, Mitchell A. and Raghuram G. Rajan (1995). "The Effect of Credit Market Competition on Lending Relationships", Quarterly Journal of Economics, 110, 406 - 443.

Rauch, James and Joel Watson (2003). "Starting small in an unfamiliar environment", International Journal of Industrial Organization, 21, 1021-1042.

Ray, Debraj (2002). "The Time Structure of Self-Enforcing Agreements", Econometrica, 70, 574-582.

Roe, Brian E. and Steven Y. Wu (2009). "Do the Selfish Mimic Cooperators? Experimental Evidence from Finitely-Repeated Labor Markets", IZA Discussion Papers 4084.

Roth, Alvin E., Vesna Prasnikar, Masahiro Okuno-Fujiwara and Shmuel Zamir (1991). "Bargaining and Market Behavior in Jerusalem, Ljubljana, Pittsburgh, and Tokyo: An Experimental Study", American Economic Review 81, 1068-1095.

Schechter, Laura (2007). "Traditional Trust Measurement and the Risk Confound: An Experiment in Rural Paraguay", Journal of Economic Behavior and Organization, 62, 6776.

Sharpe, Steven A. (1990). "Asymmetric information, bank lending and implicit contracts: A stylized model of customer relationships", Journal of Finance, 45, 1069-1087.

Sobel, Joel (1985). "A Theory of Credibility", Review of Economic Studies, 52, 557-573. 
Thomas, Jonathan, and Tim Worrall (1994). "Foreign Direct Investment and the Risk of Expropriation", Review of Economic Studies, 61, 81-108.

Watson, Joel (1999). "Starting Small and Renegotiation", Journal of Economic Theory, 85, $52-90$.

Watson, Joel (2002). "Starting Small and Commitment", Games and Economic Behavior, 38, 176-199.

White, Michelle J. (1998). "Why It Pays to File for Bankruptcy: A Critical Look at the Incentives under U.S. Personal Bankruptcy Law and a Proposal for Change", The University of Chicago Law Review, 65, 685-732. 
Figure 1. Loans offered, accepted and repaid

This figure displays the share of credit relationships which are characterized by a loan offer, a loan acceptance and a loan repayment in each period by treatment. The means and standard errors are calculated considering each matching group average as one independent observation. The total number of credit relationships (matching groups) is 135 (15) in the WE treatment and 144 (16) in the SE treatment.

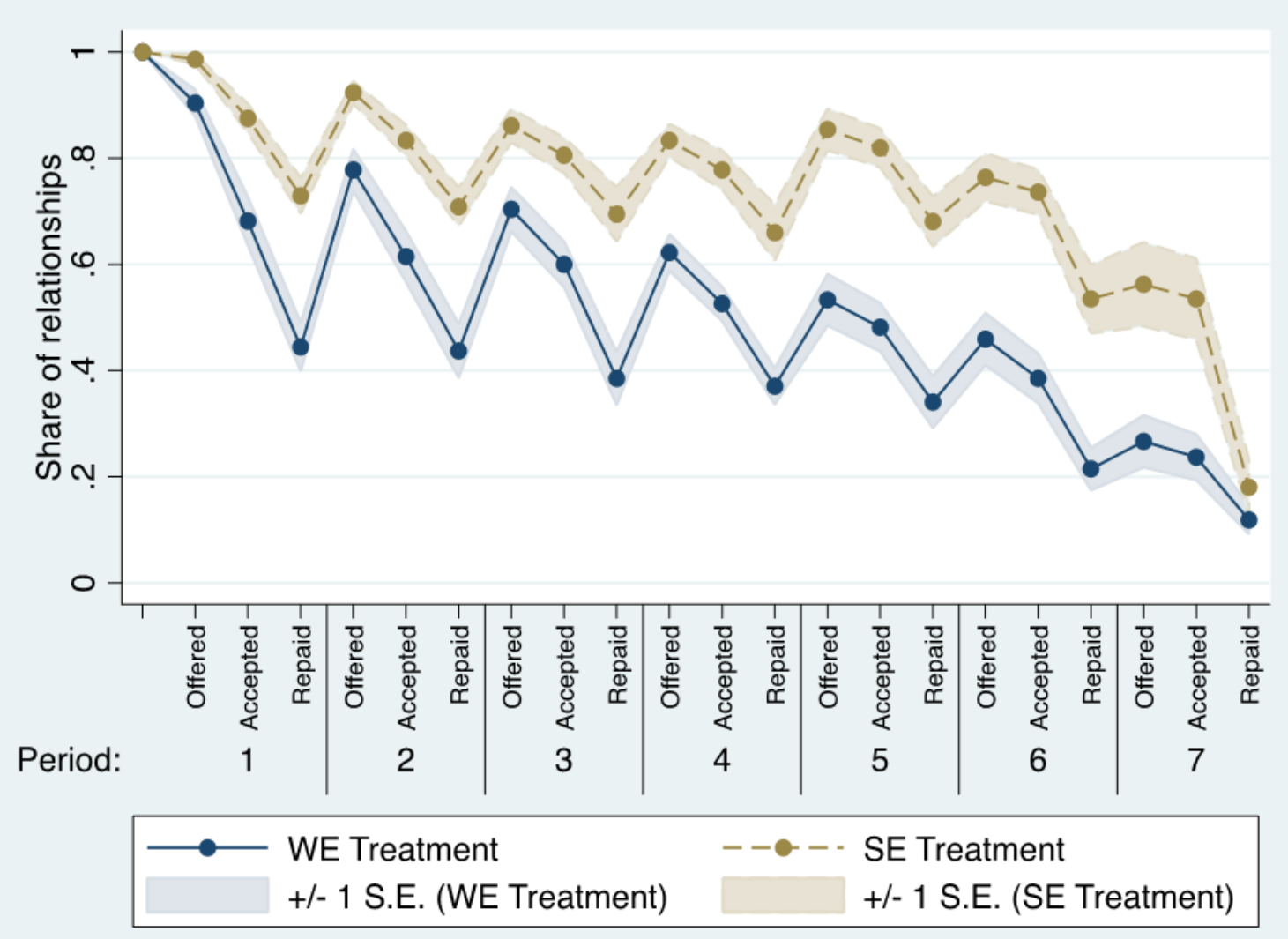




\section{Figure 2. Contract terms of accepted loan offers}

This figure displays the contract terms of accepted loan offers by period and treatment. Panel A shows the Loan size. Panel B shows the Interest (Requested repayment / Loan size). The means and standard errors are calculated considering each matching group average as one independent observation.

Panel A. Average loan size by period

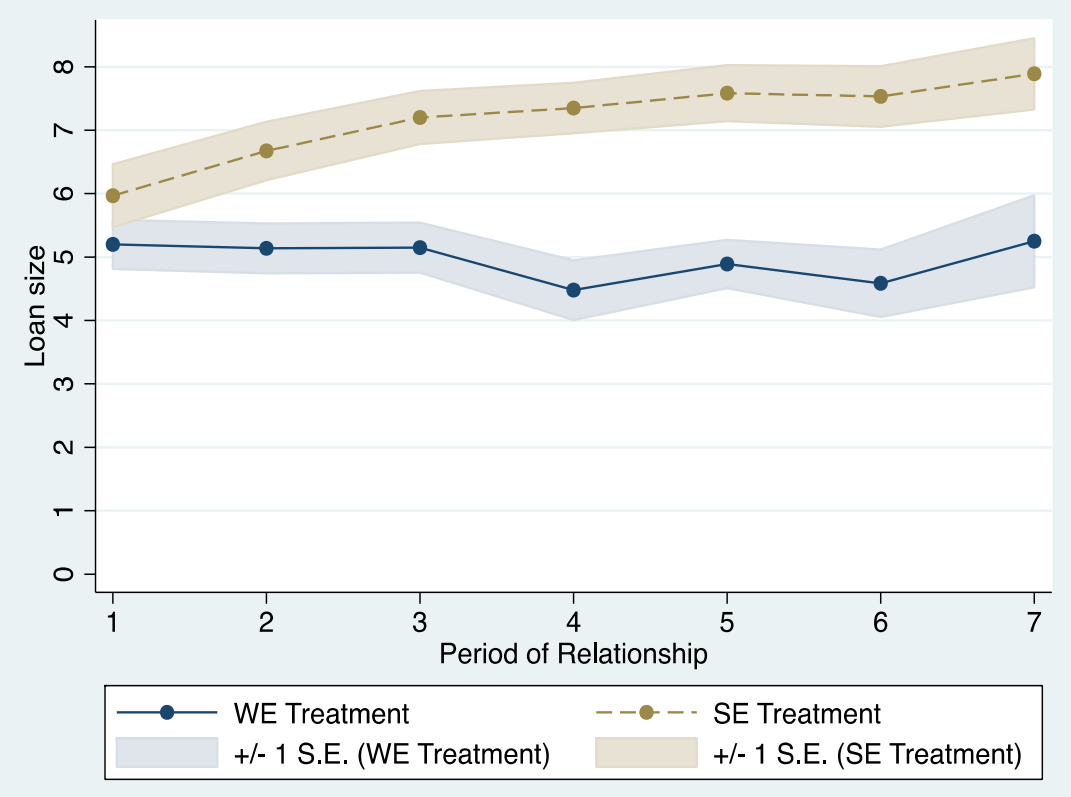

Panel B. Average interest by period

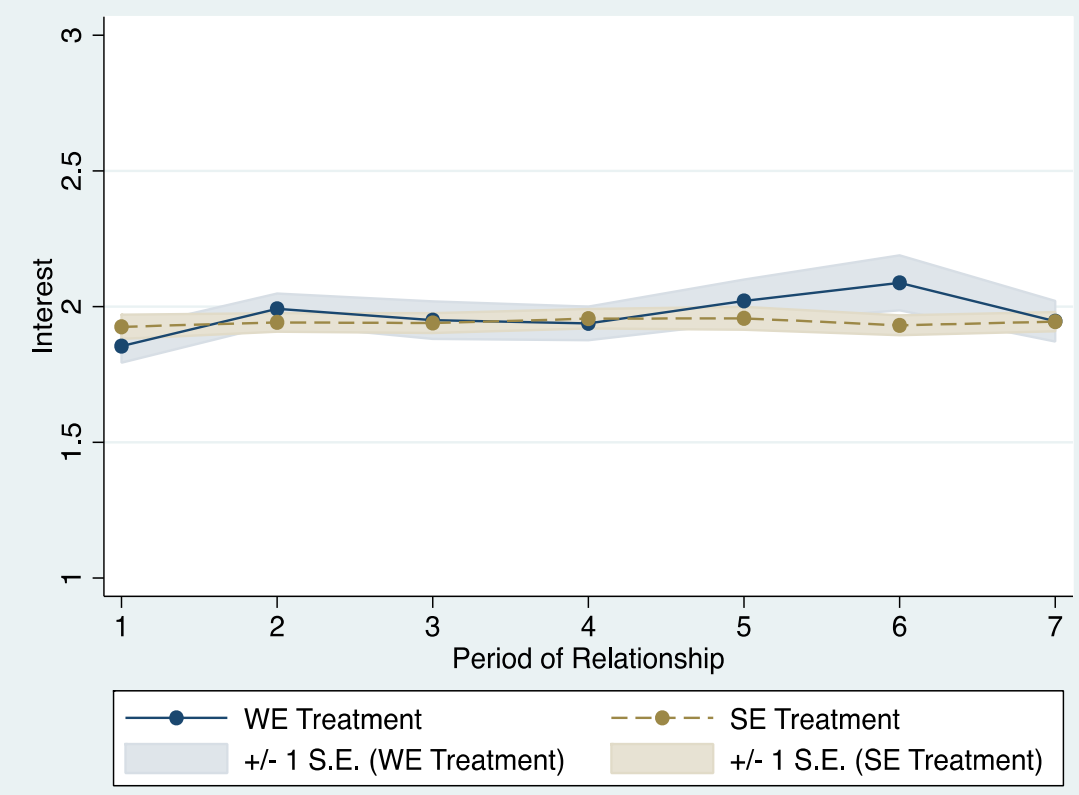




\section{Figure 3. First period loan offers}

This figure displays the period 1 loan offers by treatment. Panel A displays the cumulative frequency of offers by Loan size. Panel B displays the cumulative frequency of offers by Interest (Requested repayment / Loan size).

Panel A. Loan size

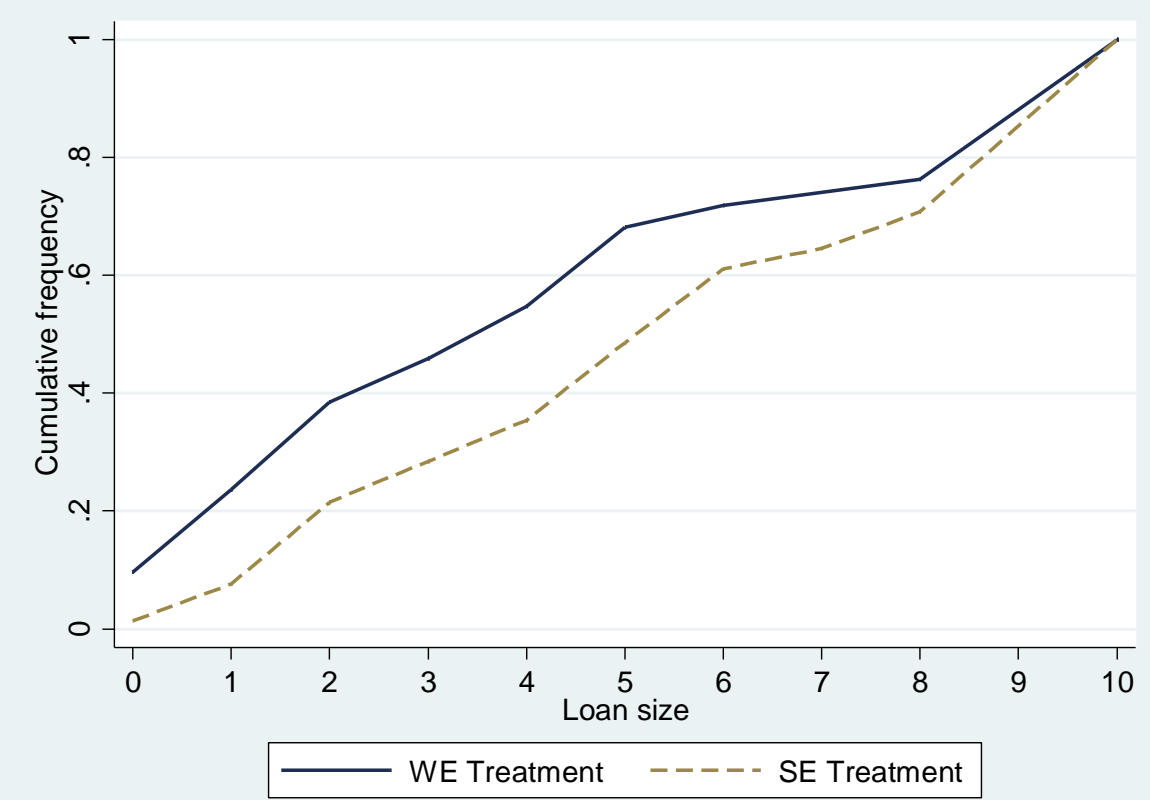

Panel B. Interest

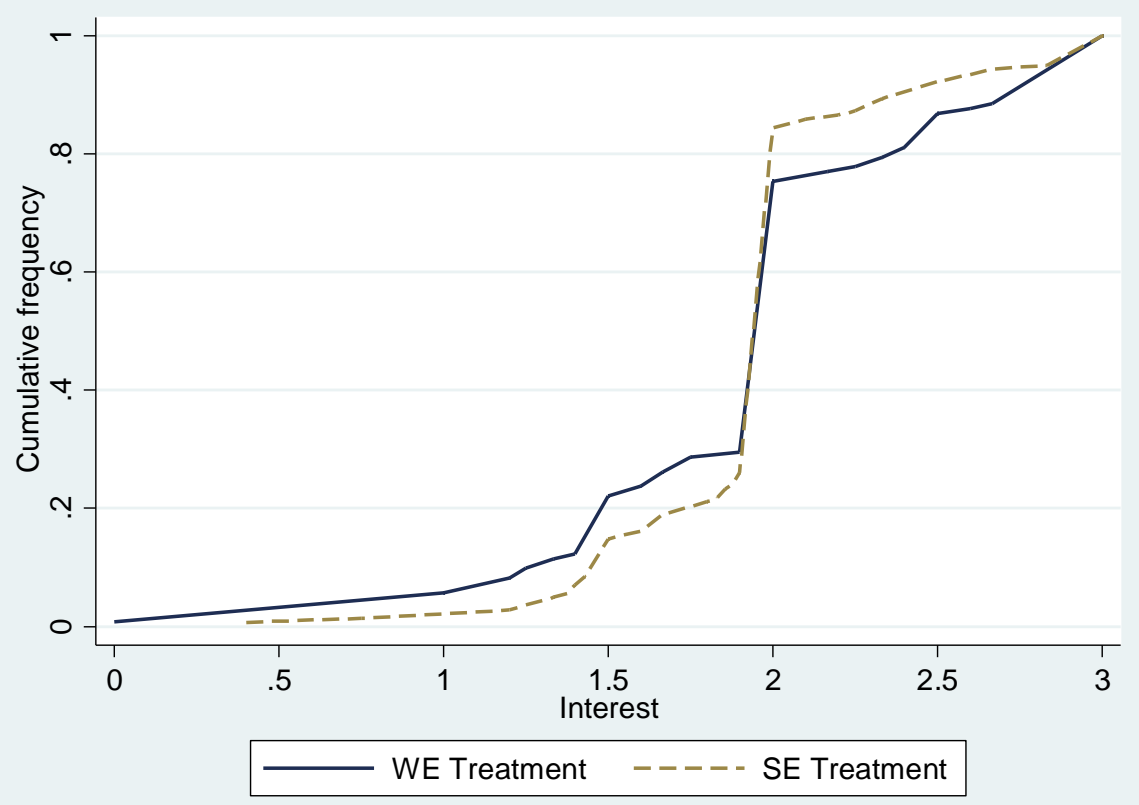


Figure 4. Borrower behavior in period 1

Panel A displays the average Rejection rate in period 1 over Loan size (left) and over Interest (right), by treatment. Panel B displays the average Default rate over Loan size (left) and over Interest (right), by treatment. The average rejection and default rate are calculated considering each matching group average as one independent observation.

\section{Panel A. Rejection}
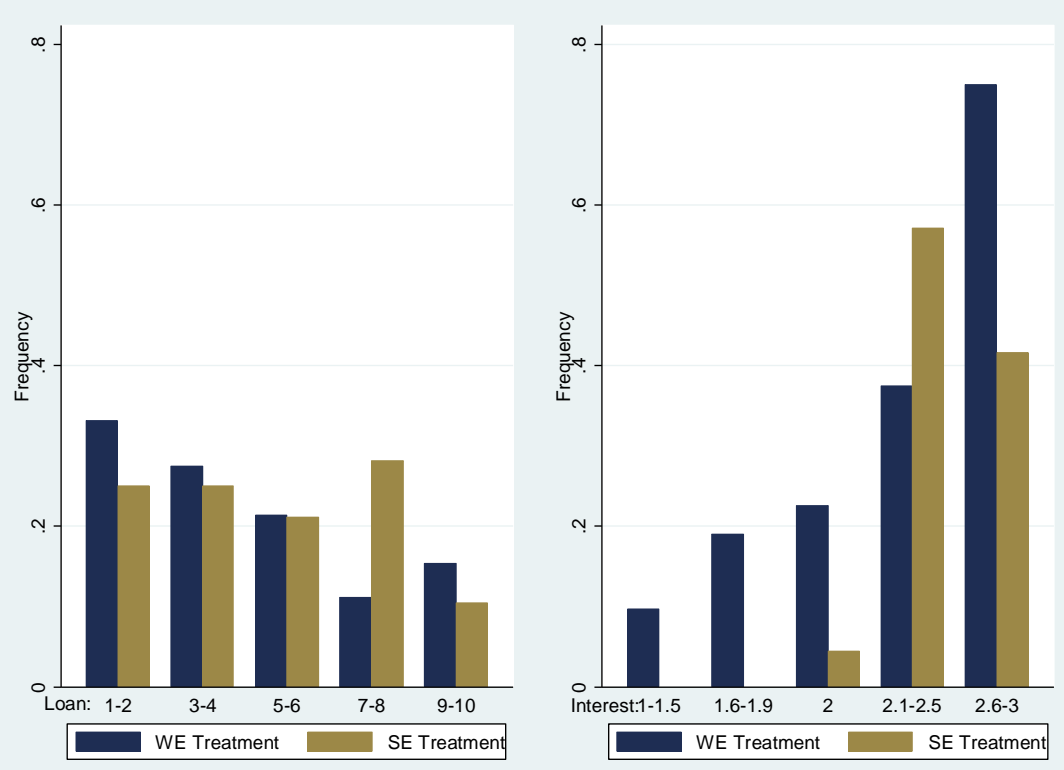

Panel B. Default
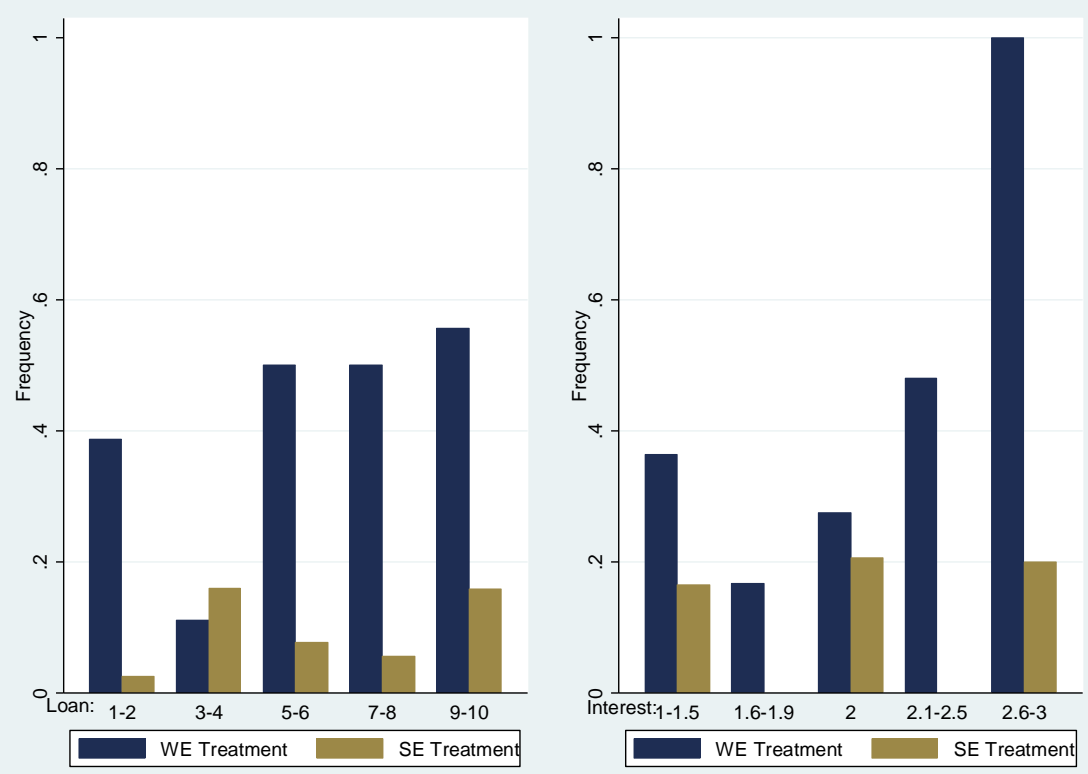
Figure 5. Loans offered, accepted and repaid - Competition treatments

Figure 5 displays the share of credit markets which are characterized by a loan offer, a loan acceptance and a loan repayment in each period for both competition treatments. The means and standard errors are calculated considering each matching group average as one independent observation. The total number of credit markets (matching groups) is 54 (6) in the WE competition treatment and 54 (6) in the SE competition treatment.

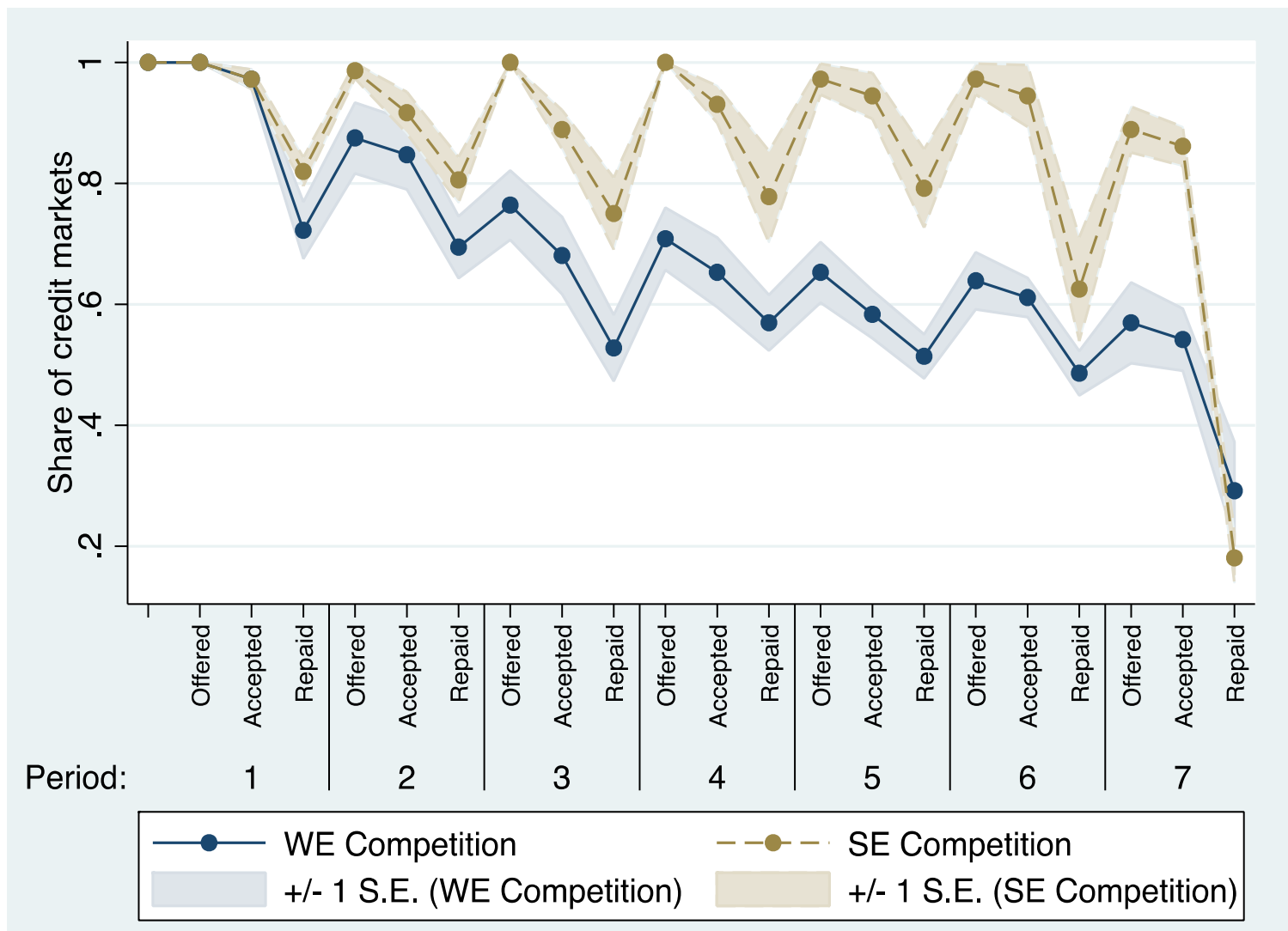


Figure 6. Credit terms of accepted loan offers in the Competition treatments

This figure displays the average contract terms of accepted loan offers in the competition treatments by period and treatment. Panel A shows the Loan size. Panel B shows the Interest (Requested repayment / Loan size). The means and standard errors are calculated considering each matching group average as one independent observation.

Panel A. Average loan size by period

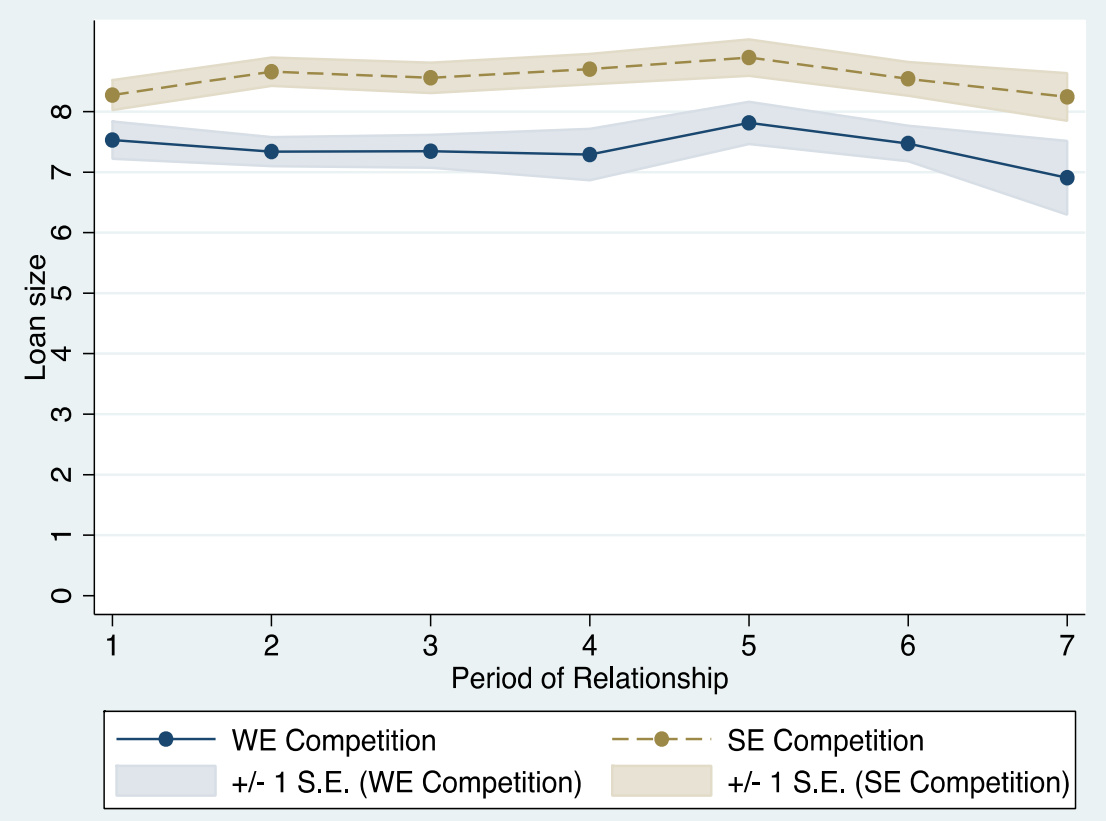

Panel B. Average interest by period

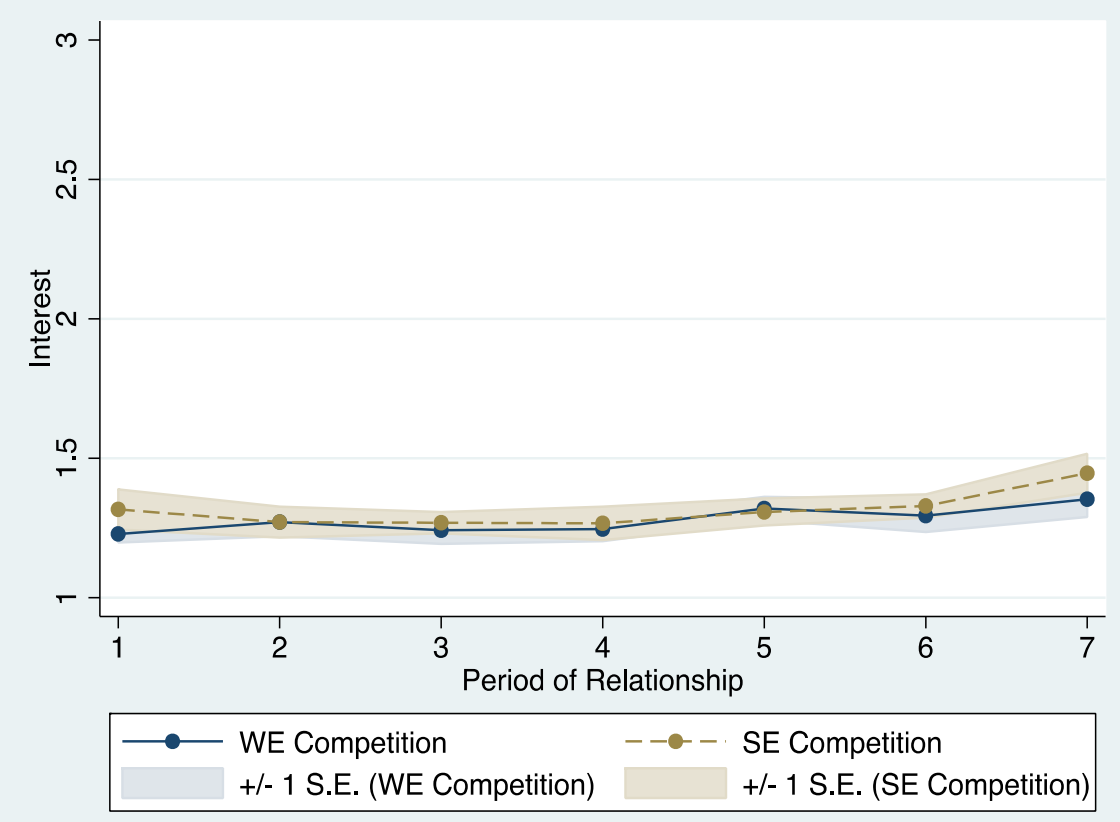




\section{Table 1. Main Treatment Effects}

This table presents the means of our three main outcome variables for each treatment. We also present the results of the Mann-Whitney test on the treatment differences, including the naïve $p$-values and the Bonferroni adjusted p-values for multiple-hypotheses-testing. We also present the results of t-tests for the treatment differences, including the naive $p$-values and the $p$-values using the adjustment for multiple-hypotheses-testing proposed by List et al. (2016).

\begin{tabular}{lcccccc}
\hline \hline & \multicolumn{2}{c}{ Mean } & \multicolumn{2}{c}{ Mann-Whitney test } & t-test \\
Outcome variable & WE & SE & naïve & $\begin{array}{c}\text { Bonferroni } \\
\text { adjusted p-value }\end{array}$ & $\begin{array}{c}\text { naïve } p \text { - } \\
\text { value }\end{array}$ & $\begin{array}{c}\text { List et al. (2016) } \\
\text { adjusted p-value }\end{array}$ \\
\hline Share of self-enforcing relationships & 0.12 & 0.48 & 0.0000 & 0.0000 & 0.0003 & 0.0003 \\
Loan size & 5.00 & 6.90 & 0.0044 & 0.0132 & 0.0043 & 0.0083 \\
Interest rate & 1.95 & 1.94 & 0.9842 & 1.0000 & 0.9290 & 0.9290 \\
\hline \hline
\end{tabular}




\section{Table 2. Post-Study Probability calculations}

This table illustrates the significance of the treatment differences between the WE and SE treatments by calculating the Post-Study Probability (PSP) for one of our outcome variables: the share of relationships in which a loan is offered, accepted, and repaid in period 1. The PSP is calculated in line with Maniadis et al. (2014) as $(1-\beta)^{*} \pi /\left((1-\beta)^{*} \pi+\alpha^{*}(1-\pi)\right)$. Hereby $\alpha$ is the level of significance $(0.05), 1-\beta$ is the ex-ante power of our empirical test and $\pi$ is our prior about the probability of the alternative hypothesis occurring.

\begin{tabular}{|c|c|c|c|c|c|}
\hline \multirow{2}{*}{$\begin{array}{c}\text { Prior } \\
(\pi)\end{array}$} & \multicolumn{5}{|c|}{ Power (1- $\beta)$} \\
\hline & 0.75 & 0.8 & 0.9 & 0.95 & 0.99 \\
\hline 0.1 & 0.63 & 0.64 & 0.67 & 0.68 & 0.69 \\
\hline 0.2 & 0.79 & 0.80 & 0.82 & 0.83 & 0.83 \\
\hline 0.3 & 0.87 & 0.87 & 0.89 & 0.89 & 0.89 \\
\hline 0.4 & 0.91 & 0.91 & 0.92 & 0.93 & 0.93 \\
\hline 0.5 & 0.94 & 0.94 & 0.95 & 0.95 & 0.95 \\
\hline
\end{tabular}


Table 3. First-period loan offers

The table reports OLS estimates for the dependent variables Loan size (columns 1-4) and Interest (columns 5-8), using observations from first period loan offers only. Loan size is the loan offered by lenders, taking values from 0 to 10. Interest is the Repayment requested divided by Loan Size and takes values 0 to 3 . WE Treatment is a dummy variable which is 1 for all observations from the WE treatment and zero for those from the SE treatment. All regressions include round fixed effects, whereby Round 1 is the omitted category, and location fixed effects, where Tilburg University is the omitted category. The variables Risk aversion, Strategic reasoning and Trust are lender-specific measures elicited from pre/post-experiment games. Standard errors are reported in brackets and are corrected for clustering at the matching group level. $*, * *, * * *$ indicate significance at the $10 \%, 5 \%$, and $1 \%$ level respectively.

\begin{tabular}{|c|c|c|c|c|c|c|c|c|}
\hline \multirow{3}{*}{ Dependent variable } & (1) & (2) & (3) & (4) & (5) & (6) & (7) & (8) \\
\hline & \multicolumn{4}{|c|}{ Loan size } & \multicolumn{4}{|c|}{ Interest } \\
\hline & & & & & & & WE and & WE and \\
\hline Treatment & WE & SE & WE and SE & WE and SE & WE & SE & SE & SE \\
\hline \multirow[t]{2}{*}{ WE Treatment } & & & $-1.333^{* *}$ & 0.218 & & & 0.024 & -0.022 \\
\hline & & & [0.553] & {$[0.547]$} & & & {$[0.083]$} & [0.132] \\
\hline \multirow[t]{2}{*}{ WE Treatment * Round 2} & & & & $-1.829 * * *$ & & & & 0.132 \\
\hline & & & & [0.483] & & & & [0.126] \\
\hline \multirow[t]{2}{*}{ WE Treatment * Round 3} & & & & $-2.824 * * *$ & & & & 0.006 \\
\hline & & & & [0.591] & & & & [0.135] \\
\hline \multirow[t]{2}{*}{ Round 2} & $-0.933^{*}$ & $0.896 * * *$ & 0.011 & $0.896 * * *$ & $0.231^{* *}$ & 0.096 & $0.158^{* *}$ & 0.095 \\
\hline & [0.437] & [0.232] & [0.291] & [0.227] & [0.098] & [0.084] & [0.064] & [0.082] \\
\hline \multirow[t]{2}{*}{ Round 3} & $-1.844 * * *$ & $0.979 * *$ & -0.387 & $0.979 * *$ & 0.124 & 0.116 & $0.119 *$ & 0.115 \\
\hline & [0.429] & [0.427] & [0.394] & [0.418] & [0.115] & {$[0.073]$} & {$[0.065]$} & [0.073] \\
\hline \multirow[t]{2}{*}{ Risk aversion } & $-0.420 * * *$ & -0.300 & $-0.383 * * *$ & $-0.383^{* * *}$ & 0.014 & -0.015 & 0.004 & 0.004 \\
\hline & [0.111] & [0.257] & [0.114] & [0.114] & [0.029] & [0.033] & {$[0.022]$} & [0.022] \\
\hline \multirow[t]{2}{*}{ Strategic Reasoning } & 0.000 & 0.031 & 0.014 & 0.014 & -0.003 & -0.003 & -0.004 & -0.004 \\
\hline & [0.029] & [0.039] & {$[0.023]$} & [0.023] & [0.003] & [0.004] & {$[0.002]$} & [0.002] \\
\hline \multirow[t]{2}{*}{ Trust } & $0.336^{* *}$ & 0.166 & $0.242^{* *}$ & $0.242^{* *}$ & 0.006 & 0.005 & 0.008 & 0.008 \\
\hline & [0.118] & [0.149] & [0.098] & [0.098] & [0.029] & {$[0.013]$} & {$[0.015]$} & [0.015] \\
\hline \multirow[t]{2}{*}{ Constant } & $5.927^{* *}$ & 4.483 & $6.235^{* * *}$ & $5.484^{* *}$ & $2.133^{* * *}$ & $2.185^{* * *}$ & $2.132 * * *$ & $2.154 * * *$ \\
\hline & [2.655] & [2.964] & [2.100] & {$[2.103]$} & {$[0.354]$} & {$[0.388]$} & {$[0.279]$} & [0.284] \\
\hline Method & OLS & OLS & OLS & OLS & OLS & OLS & OLS & OLS \\
\hline Observations & 135 & 144 & 279 & 279 & 122 & 142 & 264 & 264 \\
\hline Number of Lenders & 45 & 48 & 93 & 93 & 45 & 48 & 93 & 93 \\
\hline $\mathrm{R}^{2}$ & 0.228 & 0.096 & 0.143 & 0.172 & 0.110 & 0.032 & 0.058 & 0.062 \\
\hline
\end{tabular}


Table 4. Dynamics of loan offers

The table reports panel estimates for Loan size for periods 1 to 7 in relationships without past default. The dependent variable is Loan size and ranges from 0 to 10. Period 2-3, Period 4-5 and Period 6-7 are dummy variables denoting the corresponding period of the relationship (Period 1 is the omitted category). WE is a dummy variable which is 1 for all observations from the WE treatment and zero for those from the SE treatment. All regressions include lender characteristics (risk aversion, strategic reasoning and trust), round fixed effects, the interaction of round fixed effects with the treatment dummy (columns 3-4 only) and location fixed effects, where Tilburg University is the omitted category. Standard errors are clustered at the matching group level and reported in brackets. ${ }^{*}, * * * *$ indicate significance at the $10 \%, 5 \%$, and $1 \%$ level respectively.

\begin{tabular}{|c|c|c|c|c|}
\hline \multirow{3}{*}{$\begin{array}{r}\text { Dependent variable: } \\
\text { Treatment }\end{array}$} & (1) & (2) & (3) & (4) \\
\hline & \multicolumn{4}{|c|}{ Loan size } \\
\hline & WE & SE & WE and SE & WE and SE \\
\hline \multirow[t]{2}{*}{ Period 2-3 } & $0.998 * * *$ & $1.274 * * *$ & $1.179 * * *$ & $1.273 * * *$ \\
\hline & [0.112] & [0.219] & [0.141] & [0.217] \\
\hline \multirow[t]{2}{*}{ Period 4-5 } & $1.553 * * *$ & $2.032 * * *$ & $1.912^{* * *}$ & $2.027^{* * *}$ \\
\hline & [0.239] & [0.335] & [0.234] & [0.332] \\
\hline \multirow[t]{2}{*}{ Period 6-7 } & $1.248^{* * *}$ & $1.047^{*}$ & $1.058^{* *}$ & $1.040 *$ \\
\hline & [0.328] & {$[0.565]$} & [0.427] & [0.557] \\
\hline \multirow[t]{2}{*}{ WE Treatment } & & & $-1.472 * * *$ & -0.805 \\
\hline & & & [0.476] & [0.517] \\
\hline \multirow[t]{2}{*}{ WE * Period 2-3 } & & & & -0.248 \\
\hline & & & & [0.246] \\
\hline \multirow[t]{2}{*}{ WE * Period 4-5 } & & & & -0.432 \\
\hline & & & & [0.402] \\
\hline \multirow[t]{2}{*}{ WE * Period 6-7 } & & & & 0.255 \\
\hline & & & & [0.639] \\
\hline \multirow[t]{2}{*}{ Constant } & $5.092^{* *}$ & $4.941 * * *$ & $5.950 * * *$ & $5.727^{* * *}$ \\
\hline & [2.205] & [1.902] & [1.524] & [1.544] \\
\hline Method & OLS & OLS & OLS & OLS \\
\hline Lender characteristics & Yes & Yes & Yes & Yes \\
\hline Round fixed effects & Yes & Yes & Yes & Yes \\
\hline Observations & 307 & 604 & 911 & 911 \\
\hline Number of Lenders & 45 & 48 & 93 & 93 \\
\hline$R^{2}$ - overall & 0.338 & 0.178 & 0.250 & 0.257 \\
\hline
\end{tabular}


Table 5. Time structure of relationships

This table displays the average Loan size offered by lenders by period conditional on the relationship length. Relationship length is determined by the number of periods in which a loan is offered, accepted and repaid. If no loan is offered, accepted or repaid in period 1 , the relationship length is 0 . If a loan is offered, accepted and repaid in period 1 , but not in period 2, the relationship length is 1 . If a loan is offered, accepted and repaid all periods, the relationship length is 7 . Panel A displays results for the WE treatment, Panel B for the SE treatment. N reports the number of relations by relationship length per treatment

\begin{tabular}{ccccccccr}
\hline \hline & \multicolumn{8}{c}{ Loan size offered in period: } \\
\cline { 2 - 8 } $\begin{array}{c}\text { Relationship length } \\
\text { in periods }\end{array}$ & $\mathrm{N}$ & 1 & 2 & 3 & 4 & 5 & 6 & 7 \\
\hline \multicolumn{7}{c}{ Panel A. WE Treatment } \\
\hline 0 & 75 & 4.2 & & & & & & \\
$1-2$ & 34 & 4.7 & 5.5 & & & & & \\
$3-4$ & 10 & 5.5 & 6.5 & 7.2 & 7.0 & & & \\
$5-7$ & 16 & 5.8 & 6.5 & 6.9 & 7.4 & 7.6 & 7.8 & 6.8 \\
\hline 0 & 39 & 5.9 & & & & & & \\
$1-2$ & 24 & 4.4 & 5.2 & 8.2 & & & & \\
$3-4$ & 12 & 5.5 & 6.3 & 7.2 & 8.2 & & & \\
$5-7$ & 69 & 6.5 & 7.7 & 8.2 & 8.5 & 8.8 & 9.0 & 9.5 \\
\hline \hline
\end{tabular}


Table 6. Borrower behavior in period 1

This table reports panel estimates for Reject (columns 1 to 4 ) and Default (columns 5 to 8 ) in surviving relationships in Period 1 . Reject is a dummy variable that takes value 1 if the borrower rejects the lender's offer, 0 otherwise. Default is a dummy variable that takes value 1 if the borrower does not repay an accepted loan offer. Loan size $<5$ is a dummy variable that takes value 1 if the loan size is $1-4,0$ otherwise. Interest $>2$ is a dummy variable that takes value 1 if Interest (Requested repayment / Loan size) exceeds the surplus sharing rate of 2, 0 otherwise. WE is a dummy variable which is 1 for all observations from the WE treatment and zero for those from the SE treatment. All regressions include round fixed effects and the interaction of round fixed effects with the treatment dummy (columns 3-4 and 7-8). Standard errors are clustered at the matching group level and reported in brackets. *,**,*** indicate significance at the $10 \%, 5 \%$, and $1 \%$ level respectively.

\begin{tabular}{|c|c|c|c|c|c|c|c|c|}
\hline \multirow{3}{*}{$\begin{array}{r}\text { Dependent variable } \\
\text { Treatment }\end{array}$} & (1) & (2) & (3) & (4) & (5) & (6) & (7) & (8) \\
\hline & \multicolumn{4}{|c|}{ Reject } & \multicolumn{4}{|c|}{ Default } \\
\hline & WE & SE & WE and SE & WE and SE & WE & SE & WE and SE & WE and SE \\
\hline \multirow[t]{2}{*}{ Loan size $<5$} & 0.127 & -0.050 & 0.033 & -0.050 & $-0.192 *$ & -0.034 & $-0.121^{*}$ & -0.034 \\
\hline & [0.086] & [0.052] & [0.052] & [0.052] & [0.102] & [0.087] & {$[0.068]$} & [0.086] \\
\hline \multirow[t]{2}{*}{ Interest >2 } & $0.376^{* *}$ & $0.471 * * *$ & $0.413 * * *$ & $0.471 * * *$ & 0.256 & -0.074 & 0.116 & -0.074 \\
\hline & [0.144] & [0.092] & [0.090] & [0.091] & [0.166] & {$[0.110]$} & [0.108] & [0.108] \\
\hline \multirow[t]{2}{*}{ WE Treatment } & & & $0.087^{*}$ & 0.114 & & & $0.188 * * *$ & $0.270 * *$ \\
\hline & & & {$[0.046]$} & {$[0.075]$} & & & [0.066] & [0.124] \\
\hline \multirow[t]{2}{*}{ WE $*$ Loan $<5$} & & & & $0.178^{*}$ & & & & -0.158 \\
\hline & & & & [0.099] & & & & [0.132] \\
\hline \multirow[t]{2}{*}{ WE $*$ Interest $>2$} & & & & -0.095 & & & & 0.330 \\
\hline & & & & {$[0.168]$} & & & & [0.196] \\
\hline \multirow[t]{2}{*}{ Constant } & $0.189 * * *$ & 0.076 & $0.092 * *$ & $0.076 *$ & $0.436 * * *$ & $0.166 * *$ & $0.205^{* * *}$ & $0.166 * *$ \\
\hline & [0.062] & {$[0.044]$} & [0.040] & {$[0.044]$} & [0.103] & [0.072] & [0.063] & [0.072] \\
\hline Method & OLS & OLS & OLS & OLS & OLS & OLS & OLS & OLS \\
\hline Round fixed effects & Yes & Yes & Yes & Yes & Yes & Yes & Yes & Yes \\
\hline Observations & 122 & 142 & 264 & 264 & 92 & 126 & 218 & 218 \\
\hline Number of Lenders & 45 & 48 & 93 & 93 & 43 & 48 & 91 & 91 \\
\hline Overall $R^{2}$ & 0.197 & 0.282 & 0.231 & 0.254 & 0.088 & 0.013 & 0.072 & 0.095 \\
\hline
\end{tabular}


Table 7. Treatment Effects with Lender Competition

This table presents the means of our three main outcome variables for each lender competition treatment. We also present the results of the Mann-Whitney test on the treatment differences, including the naïve $p$-values and the Bonferroni adjusted p-values for multiple-hypotheses-testing.

\begin{tabular}{lcccc}
\hline \hline & \multicolumn{2}{c}{ Mean } & \multicolumn{2}{c}{ Mann-Whitney test } \\
Cutcome variable & $\begin{array}{c}\text { Competition } \\
\text { Treatment }\end{array}$ & $\begin{array}{c}\text { Sempetition } \\
\text { Treatment }\end{array}$ & naïve p-value & $\begin{array}{c}\text { Bonferroni } \\
\text { adjusted p-value }\end{array}$ \\
\hline $\begin{array}{l}\text { Share of self-enforcing } \\
\text { relationships }\end{array}$ & 0.35 & 0.50 & 0.0609 & 0.1827 \\
Loan size & 7.40 & 8.52 & 0.0250 & 0.0750 \\
Interest rate & 1.27 & 1.31 & 0.7488 & 1.0000 \\
\hline \hline
\end{tabular}




\section{Online Appendix A}

\section{Instructions}

The instructions displayed below are for the Weak Exclusion (WE) and Strong Exclusion (SE) treatments. Parts of the text which are specific to a treatment are presented in brackets and the corresponding treatment (WE or SE) is mentioned.

\section{Instructions for Lenders}

For simplicity, throughout these instructions we refer to the lender in the masculine form, i.e "he", and the borrower in the feminine form, i.e. "she".

\section{Overview of the experiment}

a) For this experiment you have been grouped together with 5 other participants. In this group there are 3 lenders and 3 borrowers. You will be a lender for the entire duration of the experiment.

b) The experiment consists of 3 rounds: in each round you will be matched with a different borrower. You will not be matched with the same borrower twice. You will not be informed about the identity of the other participants at any point.

c) Each round consists of 7 periods. You will interact with the same borrower for 7 periods only.

d) In each period you have an endowment which you can use to offer credit to the borrower. If you offer credit you can ask for a repayment from the borrower. If you make a credit offer, the borrower decides whether to accept this offer. If the borrower accepts your credit offer, she decides whether to make the repayment desired by you.

e) The points you earn in each period depend on the amount of credit you offer in each period, your desired repayment, whether the borrower accepts the offer, and whether the borrower makes your desired repayment.

f) All points that you earn during the course of the experiment will be exchanged into euro at the end of the experiment. The exchange rate will be:

\section{5 points $=1$ euro}

g) This is the final experiment. Your earnings from this experiment will be paid out together with your earnings from the previous 3 experiments after this experiment is completed. 


\section{Experimental Procedures}

There are 3 lenders and 3 borrowers in this experiment. You are a lender for the entire duration of the experiment. The experiment lasts for 3 rounds, and in each round you will be matched with a different borrower. Each round consists of 7 periods, so that you interact with the same borrower for 7 periods. In the following we describe in detail how you and the borrower make decisions in each period. Attached to these instructions are screen shots of each screen on which either you or the borrower will be required to enter a decision.

\section{Investment}

In each period of this experiment the borrower has an investment opportunity. The amount the borrower invests is determined [WE: by her capital and] by the credit amount the borrower receives from you. The borrower's investment amount cannot exceed 10 points in any period.

\section{[WE:}

In period 1 the borrower's capital is 0 . Her capital in periods 2-7 depends on her and your decisions in periods 1-6. How the borrower's capital in period 2-7 is determined is explained in detail in section 4 .

]

Section 2 describes in detail how the borrower's credit amount in each period is determined.

In each period the investment income of the borrower is three times her investment amount.

Investment amount $=[\mathrm{WE}$ : Capital +$]$ Credit amount $\leq \mathbf{1 0}$

\section{Investment income $=3 \mathrm{x}$ Investment amount}

\section{$\underline{\text { 2. Credit offers }}$}


In each period you have an endowment of $\mathbf{1 0}$ points. With this endowment you can make a credit offer to the borrower. For this purpose, the "credit offer" screen (screen shot attached to these instructions) will be shown to you at beginning of each period.

At the top of the screen you can see which round of the experiment you are in, what your identification number is, and the identification number of the borrower you are matched with for this round. All lenders and borrowers keep their identification number for the whole duration of the experiment. This allows you to check that within each round of 7 periods you are always matched with the same borrower, and that in each new round you are matched with a new borrower. At the top of the screen you also see which period you are in, and the remaining time left to make your credit offer (in seconds). In each period you have 30 seconds to make your credit offer.

To make a credit offer you first choose the credit amount. As the borrower has a maximum investment amount of 10 [WE: which also includes her capital], the maximum credit amount you can offer in any period is 10 [WE: - the borrower's capital].

You then choose your desired repayment. The desired repayment may not exceed three times the credit amount.

\section{$0 \leq$ Credit amount $\leq 10$ [WE: - Capital ]}

\section{$0 \leq$ Desired repayment $\leq 3 \times$ Credit amount}

You do not have to make a credit offer to the borrower in any period. If you do not want to make a credit offer you can enter a credit amount of 0 and a desired repayment of 0 .

\section{[WE:}

If the borrower's capital equals the maximum investment amount of 10 , then you cannot make a credit offer in this period. In this case the credit offer screen will inform you that no credit offer can be made.] 
After you have determined your credit offer by entering a credit amount and desired repayment you must click on the "enter" button to finalize this offer. As long as you have not clicked on "enter" you may revise your offer.

On the left hand side of the "Credit offer" screen you can see the history of your interaction for all completed periods in this round. The history displays the following items for each period: [WE: the borrower's capital,] your credit amount offered, your desired repayment and whether the desired repayment was made (yes/no).

\section{Accepting the credit offer and making the desired repayment.}

If you make a credit offer, the borrower will see the details of this offer on the "Credit acceptance" screen (screen shot attached). The borrower can then decide whether to accept the credit offer or not.

If the borrower accepts a credit offer she then chooses her Actual repayment. The borrower's actual repayment can either be your desired repayment or 0 . The borrower decides whether to make the desired repayment by choosing "yes" or "no" on the "Repayment decision" screen (screen shot attached).

\section{Actual repayment $=$} Desired repayment or 0

[WE:

\section{The borrower's capital}

In period 1 the borrower's capital is 0 .

The borrower's capital for periods 2, 3, 4, 5 ,6 , or 7 depends on her credit amount and her actual repayment in the previous periods.

- If the borrower did not accept a credit offer in the previous period, her capital is equal to that in the previous period. 
- If the borrower accepted a credit in the previous period and made the desired repayment to the lender, her capital is equal to that in the previous period.

- If the borrower accepted a credit in the previous period and did not make the desired repayment to the lender, her capital is equal to that in the previous period plus the credit amount in the previous period.

\begin{tabular}{|c|c|c|}
\hline \multirow{3}{*}{$\begin{array}{l}\text { Capital for periods } \\
2,3,4,5,6 \text { or } 7\end{array}$} & = Capital in previous period & $\begin{array}{l}\text { if no credit offer is accepted in the } \\
\text { previous period. }\end{array}$ \\
\hline & = Capital in previous period & $\begin{array}{l}\text { if a credit offer is accepted and the } \\
\text { desired repayment is made in the } \\
\text { previous period }\end{array}$ \\
\hline & $\begin{array}{c}=\text { Capital in previous period } \\
+ \text { Credit Amount in previous } \\
\text { period }\end{array}$ & $\begin{array}{l}\text { if a credit offer is accepted and the } \\
\text { desired repayment is not made in the } \\
\text { previous period }\end{array}$ \\
\hline
\end{tabular}

1

\section{$\underline{\text { 5. Income calculation }}$}

If you did not make a credit offer or your offer was not accepted by the borrower your income equals your endowment of 10 points in this period. If you did make a credit offer and it was accepted by the borrower your income depends on the amount of credit you offered and the actual repayment of your borrower.

\section{Your Income $=10-$ Credit amount + Actual repayment}

In each period the borrower has a certain income of 10 points. As mentioned in section 1 the borrower earns an additional investment income which is three-times the size of her investment amount. The borrower's income in each period equals her 10 points plus her investment income minus her actual repayment [WE: and minus the borrower's capital for the next period. As period 7 is the final period the borrower's income in this period equals her 10 points plus her investment income minus her actual repayment.] 


\section{Income of the Borrower $=$ 10 + Investment income - Actual repayment [WE: - capital for next period ]}

You will be informed about your income [WE:,][SE: and] the income of the borrower [WE: and the borrower's capital] on the "Income" screen (screen shot attached).

After you have studied the income screen, you can record this information on your documentation sheet. You can then proceed to the next period or next round.

\section{Exercises}

The experiment will not commence, until all participants are completely familiar with all procedures. In order to secure that this is the case, we kindly ask you to solve the exercises that will be displayed on your computer screen. Wrong answers have no consequences for you. If you have any questions, please contact us.

\section{Exercise 1:}

[WE: In period 1,] what is the maximum credit amount you can offer?

$$
\text { Maximum credit amount [WE: in period } 1 \text { = ] }
$$

\section{Exercise 2:}

In period 1 you do not make a credit offer. How high is your income and that of the borrower in period 1 [WE: and the borrower's capital for period 2]?

Your income in period $1=$

[WE: Borrower's capital for period 2=]

Income of the borrower in period $1=$

\section{Exercise 3:}

In period 1 you make a credit offer with a credit amount of 8 and a desired repayment of 10 . The borrower does not accept the offer. How high is your income and that of the borrower in period 1 [WE: and the borrower's capital for period 2]?

Your income in period $1=$ 
[WE: Borrower's capital for period 2=]

Income of the borrower in period $1=$

\section{Exercise 4:}

In period 1 you make a credit offer with a credit amount of 8 and a desired repayment of 10 . The borrower accepts the offer and makes the desired repayment of 10. How high is your income and that of the borrower in period 1 [WE: and the borrower's capital for period 2]?

Your income in period $1=$

[WE: Borrower's capital for period 2=]

Income of the borrower in period $1=$

\section{Exercise 5:}

In period 1 you make a credit offer with a credit amount of 8 and a desired repayment of 10 . The borrower accepts the offer and does not make the desired repayment of 10. How high is your income and that of the borrower in period 1 [WE: and the borrower's capital for period 2? ]

Your income in period $1=$

[WE: Borrower's capital for period 2=]

Income of the borrower in period $1=$

\section{[WE: Exercise 6:}

In period 2 the borrower has a capital of 0 . What is the maximum credit amount you can offer to the borrower?

Maximum credit amount period 2= ]

\section{[WE: Exercise 7:}

In period 2 the borrower has a capital of 8 . What is the maximum credit amount you can offer to the borrower?

Maximum credit amount period 2= ] 


\section{Documentation Sheet - Lenders}

\begin{tabular}{|c|c|c|c|c|c|}
\hline \multicolumn{6}{|c|}{ Round 1: you are matched with Borrower Nr. : } \\
\hline Period & $\begin{array}{c}\text { [WE: } \\
\text { Borrower's } \\
\text { capital] }\end{array}$ & Credit Amount & Desired Repayment & Actual Repayment & Your Income \\
\hline 1 & 0 & & & & \\
\hline 2 & & & & & \\
\hline 3 & & & & & \\
\hline 4 & & & & & \\
\hline 5 & & & & & \\
\hline 6 & & & & & \\
\hline 7 & & & & & \\
\hline
\end{tabular}

\begin{tabular}{|c|c|c|c|c|c|}
\hline \multicolumn{6}{|c|}{ Round 2: you are matched with Borrower Nr. : } \\
\hline Period & $\begin{array}{c}\text { [WE: } \\
\text { Borrower's } \\
\text { capital] }\end{array}$ & Credit Amount & Desired Repayment & Actual Repayment & Your Income \\
\hline 1 & 0 & & & & \\
\hline 2 & & & & & \\
\hline 3 & & & & & \\
\hline 4 & & & & & \\
\hline 5 & & & & & \\
\hline 6 & & & & & \\
\hline 7 & & & & & \\
\hline
\end{tabular}

\begin{tabular}{|c|c|c|c|c|c|}
\hline \multicolumn{6}{|c|}{ Round 3: you are matched with Borrower Nr. : } \\
\hline Period & $\begin{array}{c}\text { [WE: } \\
\text { Borrower' } \\
\text { s capital] }\end{array}$ & Credit Amount & Desired Repayment & Actual Repayment & Your Income \\
\hline 1 & 0 & & & & \\
\hline 2 & & & & & \\
\hline 3 & & & & & \\
\hline 4 & & & & & \\
\hline 5 & & & & & \\
\hline 6 & & & & & \\
\hline 7 & & & & & \\
\hline
\end{tabular}




\section{Instructions for Borrowers}

For simplicity, throughout these instructions we refer to the lender in the masculine form, i.e

"he", and the borrower in the feminine form, i.e. "she".

\section{Overview of the experiment}

h) For this experiment you have been grouped together with 5 other participants. In this group there are 3 lenders and 3 borrowers. You will be a borrower for the entire duration of the experiment.

i) The experiment consists of 3 rounds: in each round you will be matched with a different lender. You will not be matched with the same lender twice. You will not be informed about the identity of the other participants at any point.

j) Each round consists of 7 periods. You will interact with the same lender for 7 periods only.

k) In each period the lender has an endowment which he can use to offer credit to you. If the lender offers credit he can ask for a repayment from you. If the lender offers credit, you decide whether to accept this credit offer. If you accept the credit offer, you decide whether to make the repayment desired by the lender.

l) The points you earn in each period depend the amount of credit offered by the lender, his desired repayment, whether you accept the lender's credit offer, and whether you make the desired repayment to him.

m) All points that you earn during the course of the experiment will be exchanged into euro at the end of the experiment. The exchange rate will be:

\section{5 points $=1$ euro}

n) This is the final experiment. Your earnings from this experiment will be paid out together with your earnings from the previous 3 experiments after this experiment is completed. 


\section{Experimental Procedures}

There are 3 lenders and 3 borrowers in this experiment. You are a borrower for the entire duration of the experiment. The experiment lasts for 3 rounds, and in each round you will be matched with a different lender. Each round consists of 7 periods, so that you interact with the same lender for 7 periods. In the following we describe in detail how you and the lender make decisions in each period. Attached to these instructions are screen shots of each screen on which either you or the lender will be required to enter a decision.

\section{Investment}

In each period of this experiment you have an investment opportunity. The amount you invest is determined [WE: by your capital and] by the credit amount you receive from the lender. Your investment amount cannot exceed 10 points in any period.

\section{[WE:}

In period 1 your capital is 0 . Your capital in periods 2-7 depends on your and the lender's decisions in periods 1-6. How your capital in period 2-7 is determined is explained below in section 4. ]

Section 2 describes in detail how your credit amount in each period is determined.

In each period your investment income is three times your investment amount.

$$
\text { Investment amount }=[\mathrm{WE}: \text { Capital }+] \text { Credit amount } \leq 10
$$

\section{Investment income $=3 \mathrm{x}$ Investment amount}

\section{$\underline{\text { 2. Credit offers }}$}


In each period the lender has an endowment of $\mathbf{1 0}$ points. With this endowment the lender can make a credit offer to you. For this purpose, the "credit offer" screen (screen shot attached to these instructions) will be shown to the lender at beginning of each period.

To make a credit offer the lender first chooses the credit amount. As you have a maximum investment amount of 10 [WE: which also includes your capital], the maximum credit amount the lender can offer in any period is 10 [WE: - capital].

The lender then chooses his desired repayment. The desired repayment may not exceed three times the credit amount.

\section{$0 \leq$ Credit amount $\leq 10[$ WE: - Capital $]$}

\section{$0 \leq$ Desired repayment $\leq 3 \times$ Credit amount}

The lender does not have to make a credit offer to you in any period. If the lender does not want to make a credit offer he can enter a credit amount of 0 and a desired repayment of 0 .

[WE:

If your capital equals your maximum investment amount of 10 , then the lender cannot make a credit offer to you.]

\section{Accepting credit offers and choosing the actual repayment}

If the lender makes a credit offer to you, you will see the details of this offer on the "Credit acceptance” screen (screen shot attached).

At the top of the screen you can see which round of the experiment you are in, what your identification number is, and the identification number of the lender you are matched with for this round. All lenders and borrowers keep their identification number for the whole duration of the 
experiment. This allows you to check that within each round of 7 periods you are always matched with the same lender, and that in each new round you are matched with a new lender. At the top of the screen you also see which period you are in, and the remaining time left to make your decision (in seconds). In each period you have 30 seconds to accept a credit offer.

On the right hand side of the screen you see the credit offer made by the lender. You can decide to accept a credit offer or not by clicking on the yes or no button on the right hand side of this screen. After you have made your decision you must click on the "enter" button to finalize this decision. As long as you have not clicked on "enter" you may revise your decision.

If you decide to accept the credit offer you then choose your Actual repayment. Your Actual repayment is either equal to the desired repayment of the lender or 0 . You decide whether to make the desired repayment by choosing "yes" or "no" on the "Repayment decision" screen (screen shot attached).

\section{Actual repayment $=$} Desired repayment or 0

On the left hand side of the "Credit acceptance" screen and "Repayment decision" screen you can see the history of your interaction for all completed periods in this round. The history displays the following items for each period: [WE: your capital,] the credit amount offered, the desired repayment and whether the desired repayment was made (yes/no).

[WE:

\section{Your capital}

In period 1 your capital is 0 .

Your capital for periods 2, 3 , 4, 5, 6 or 7 depends on your credit amount and your actual repayment in the previous periods.

- If you did not accept a credit offer in the previous period, your capital is equal to that in the previous period. 
- If you accepted a credit in the previous period and made the desired repayment to the lender, your capital is equal to that in the previous period.

- If you accepted a credit in the previous period and did not make the desired repayment to the lender, your capital is equal to that in the previous period plus the credit amount in the previous period.

\begin{tabular}{|c|c|c|}
\hline \multirow{3}{*}{$\begin{array}{l}\text { Capital for periods } \\
2,3,4,5,6 \text { or } 7\end{array}$} & = Capital in previous period & $\begin{array}{l}\text { if you did not accepted a credit offer in } \\
\text { the previous period. }\end{array}$ \\
\hline & = Capital in previous period & $\begin{array}{l}\text { if you accepted a credit offer and made } \\
\text { the desired repayment in the previous } \\
\text { period }\end{array}$ \\
\hline & $\begin{array}{c}=\text { Capital in previous period } \\
+ \text { Credit Amount in previous } \\
\text { period }\end{array}$ & $\begin{array}{c}\text { if you accepted a credit offer and did } \\
\text { not make the desired repayment in the } \\
\text { previous period }\end{array}$ \\
\hline
\end{tabular}

l

\section{Income calculation}

If the lender did not make a credit offer or you did not accept the lender's offer, the lender's income equals his endowment of 10. If the lender did make a credit offer and it was accepted by you, the lender's income depends on the amount of credit offered and your actual repayment.

\section{Income of Lender $=\mathbf{1 0}-$ Credit amount + Actual repayment}

In each period you earn a certain income of 10 points. As mentioned in section 1 you earn an additional investment income which is three-times the size of your investment amount. Your income in each period equals your 10 points plus your investment income minus your actual repayment [WE: and minus your capital for the next period. As period 7 is the final period your income in this period equals your 10 points plus your investment income minus your actual repayment.] 


\section{Your Income =}

\section{0 + Investment income - Actual repayment [WE: -Capital for next period ]}

You will be informed about your income [WE:, your capital] and the income of the lender on the "Income" screen (screen shot attached).

After you have studied the income screen, you can record this information on your documentation sheet. You can then proceed to the next period or next round.

\section{Exercises}

The experiment will not commence, until all participants are completely familiar with all procedures. In order to secure that this is the case, we kindly ask you to solve the exercises that will be displayed on your computer screen. Wrong answers have no consequences for you. If you have any questions, please contact us.

\section{Exercise 1:}

[WE: In period 1, ] what is the maximum credit amount the lender can offer to you?

$$
\text { Maximum credit amount [WE: in period } 1=\text { ] }
$$

\section{Exercise 2:}

In period 1 the lender does not make a credit offer. How high is your income and that of the lender in period 1[WE: and your capital for period 2]?

[WE: Your capital for period 2=]

Your income in period $1=$ Income of the lender in period $1=$

\section{Exercise 3:}

In period 1 the lender makes a credit offer with a credit amount of 8 and a desired repayment of 10. You do not accept the offer. How high is your income and that of the lender in period 1 [WE: and your capital for period 2]?

[WE: Your capital for period 2=] 
Your income in period $1=$

Income of the lender in period $1=$

\section{Exercise 4:}

In period 1 the lender makes a credit offer with a credit amount of 8 and a desired repayment of 10. You accept the offer and make the desired repayment of 10 . How high is your income and that of the lender in period 1 [WE: and your capital for period 2]?

[WE: Your capital for period 2=]

Your income in period $1=$ Income of the lender in period $1=$

\section{Exercise 5:}

In period 1 the lender makes a credit offer with a credit amount of 8 and a desired repayment of 10. You accept the offer and do not make the desired repayment of 10. How high is your income and that of the lender in period 1 [WE: and your capital for period 2]?

[WE: Your capital for period 2=]

Your income in period $1=$

Income of the lender in period $1=$

\section{[WE: Exercise 6:}

In period 2 you have a capital of 0 . What is the maximum credit amount the lender can offer to you?

Maximum credit amount period 2= ]

\section{[WE: Exercise 7:}

In period 2 you have a capital of 8 . What is the maximum credit amount the lender can offer to you?

Maximum credit amount period 2=] 
Documentation Sheet - Borrowers

\begin{tabular}{|c|c|c|l|l|l|}
\hline \multicolumn{7}{|c|}{ Round 1: you are matched with Lender Nr.: } \\
\hline Period & $\begin{array}{c}\text { [WE: } \\
\text { Capital] }\end{array}$ & Credit Amount & Desired Repayment & Actual Repayment & Your Income \\
\hline 1 & 0 & & & & \\
\hline 2 & & & & & \\
\hline 3 & & & & & \\
\hline 4 & & & & & \\
\hline 5 & & & & & \\
\hline 6 & & & & & \\
\hline 7 & & & & & \\
\hline
\end{tabular}

\begin{tabular}{|c|c|c|c|c|c|}
\hline \multicolumn{7}{|c|}{ Round 2: you are matched with Lender Nr.: } \\
\hline Period & $\begin{array}{c}\text { [WE: } \\
\text { Capital }\end{array}$ & Credit Amount & Desired Repayment & Actual Repayment & Your Income \\
\hline 1 & 0 & & & & \\
\hline 2 & & & & & \\
\hline 3 & & & & & \\
\hline 4 & & & & & \\
\hline 5 & & & & & \\
\hline 6 & & & & & \\
\hline 7 & & & & & \\
\hline
\end{tabular}

\begin{tabular}{|c|c|c|l|l|l|}
\hline \multicolumn{7}{|c|}{ Round 3: you are matched with Lender Nr.: } \\
\hline Period & $\begin{array}{c}\text { [WE: } \\
\text { Capital }]\end{array}$ & Credit Amount & Desired Repayment & Actual Repayment & Your Income \\
\hline 1 & 0 & & & & \\
\hline 2 & & & & & \\
\hline 3 & & & & & \\
\hline 4 & & & & & \\
\hline 5 & & & & & \\
\hline 6 & & & & & \\
\hline 7 & & & & & \\
\hline
\end{tabular}




\section{Online Appendix B}

\section{Behavior in Pre/Post-experiment Games}

Table B.1 summarizes the behavior of our subjects in the three pre/post-experiment games.

Table B.1. Behavior in pre/post-experiment games in each treatment

\begin{tabular}{|c|c|c|c|c|c|c|c|c|c|c|}
\hline & WE $(\mathrm{r}$ & $=7)$ & SE $(n$ & & \multirow[t]{2}{*}{$\begin{array}{c}\text { MW- } \\
\text { test }\end{array}$} & WE (1 & & \multicolumn{2}{|c|}{$\mathrm{SE}(\mathrm{n}=8)$} & $\begin{array}{l}\text { MW- } \\
\text { test }\end{array}$ \\
\hline & \multicolumn{4}{|c|}{ Pre-experiment games } & & \multicolumn{5}{|c|}{ Post-experiment games } \\
\hline & Mean & SD & Mean & SD & $\mathrm{p}$-val & Mean & SD & Mean & SD & p-val \\
\hline Risk aversion & 5.9 & 0.4 & 6.1 & 0.6 & 0.45 & 5.1 & 0.9 & 5.4 & 0.7 & 0.60 \\
\hline Strategic reasoning & 71.7 & 4.7 & 71.8 & 2.8 & 0.91 & 69.5 & 5.8 & 68.1 & 7.1 & 0.60 \\
\hline Trust & 5.8 & 1.3 & 5.1 & 1.4 & 0.18 & 5.8 & 2.0 & 7.2 & 1.7 & 0.25 \\
\hline Trustworthiness & 19.5 & 7.7 & 18.6 & 5.6 & 0.56 & 22.3 & 8.1 & 27.3 & 6.1 & 0.25 \\
\hline
\end{tabular}

Note: WE: Weak Exclusion treatment, SE: Strong Exlcusion treatment, n: number of matching groups. MW-test: nonparametric tests of WE vs. SE using matching group averages as observations.

The first game was a risk preference elicitation task (following Dohmen et al. 2010). In this task, each player made eleven decisions, each of which had two options, A and B. Option A was a lottery with two outcomes, 0 and 100 points. The probability that the second outcome would be drawn was one half in each decision. Option B was a certain amount, which ranged from 0 points (in decision number 1) to 100 points (in decision number 11) and incremented by 10 points as the decision number increased. The indicator Risk aversion in Table B.1 reports the number of times a subject chose option B in this game. Table B.1 shows that there is no significant difference in risk aversion across treatments, both when this task was completed before and after the main experiment.

The second game was a one-shot guessing game (Nagel 1995). Each participant was randomly matched with 5 other participants. Each participant had to choose a number between 0 and 100 . The participant whose choice was closest to 2/3 of the average choice would be the winner of a prize of 150 points. The indicator Strategic Reasoning in Table B.1 is the choice made by subjects in this guessing game. Table B.1 shows there is no significant difference in strategic reasoning between the WE and SE treatments. This result is observed both when the guessing game was completed before and after the main experiment.

The third game was a one-shot lending game, played using the strategy method. First, subjects were asked to make decisions in the role of borrower. They were shown a table in which each column displayed a loan size in steps of 2 (2, 4, 6, 8 and 10), while each row displayed a requested repayment in steps of $2(2,4, \ldots, 30)$. They were asked whether they would make the desired repayment, in each cell of the table for which the desired repayment was smaller or equal 
to three times the loan size. The subject then moved onto a different screen in which he was asked to make his decisions as a lender, i.e. to make a loan offer and request a repayment, both in steps of 2. The indicator Trust in Table B.1 is the loan offer a subject chose to make as a lender in this game. The indicator Trustworthiness in Table B.1 is the number of times a subject chose to repay as a borrower in this game. Table B.1 shows there is no significant difference in average trust and trustworthiness across treatments, both when the game was played before and after the main experiment.

We note that, methodologically, we do not generally find a difference in the choices made in pre-experimental vs. post-experimental games. For the risk preference elicitation task and the guessing game, there is no significant difference between sessions with pre-experimental vs. post-experimental games in the WE and the SE treatments (p-val>0.1 in all cases, except for risk in the SE treatment, p-val=0.07). For the trust game, we find no difference between pre- and postexperimental games in the WE treatment ( $\mathrm{p}-\mathrm{val}=0.95$ and 0.64 for trust and trustworthiness, respectively). In the SE treatment, however, we find increased trust and trustworthiness in the sessions in which it was played after the main experiment (p-val=0.02 for trust and trustworthiness). We conjecture that this may be a spillover from successful trade in the main experiment.

Table B.2 examines the heterogeneity among individuals in terms of their trustworthiness, across treatments. This table speaks to our assumption of the presence of social borrowers. A money-maximizing borrower would not repay any loan in the strategy-method trust game. We find that between $9 \%$ and $14 \%$ of borrowers do not repay any loan. An additional 1\% to 2\% repay less than the loan size. In contrast, more than a quarter, $27 \%$ and $39 \%$, of the borrowers choose to always repay, when requested to repay at least the equal split or more. Hence, at least one out of four borrowers is a social borrower. The shares of the different types of borrowers do not vary significantly across treatments (Chi-square test, p-value=0.249).

Table B.2. Repayments in the strategy-method trust game

\begin{tabular}{lrr}
\hline \hline & \multicolumn{2}{c}{ Share of borrowers } \\
& WE & SE \\
Types & $(\mathrm{n}=90)$ & $(\mathrm{n}=96)$ \\
\hline Never repay & $9 \%$ & $14 \%$ \\
Repay less than the loan size & $2 \%$ & $1 \%$ \\
Repay at least loan size, but less than "fair" split & $21 \%$ & $15 \%$ \\
Repay at least "fair" split & $27 \%$ & $39 \%$ \\
Other & $41 \%$ & $32 \%$ \\
\hline \hline
\end{tabular}




\section{Online Appendix C \\ Predictions for the WE and SE treatments}

\section{C.1. The Repeated Lending Game}

A lender and a borrower interact for $T=7$ periods. In every period, the schedule of events is the following:

1. The lender has an endowment of 10 in every period $t$. The borrower has a capital of $C_{t}$, where $C_{1}=0$.

2. The lender makes an offer $\left(S_{t}, R_{t}\right)$ to the borrower. Whereby $S_{t} \in\left[0,10-C_{t}\right]$ and $R_{t} \in[1, v] S_{t}$, where $v>1$.

3. The borrower chooses to accept $\left(A_{t}=1\right)$ or reject $\left(A_{t}=0\right)$ the offer.

4. If the offer is accepted, the borrower earns an investment income of $I_{1}=v \cdot\left(S_{t}+C_{t}\right)$ and chooses whether to repay $\left(D_{t}=0\right)$ or default $\left(D_{t}=1\right)$

We examine behavior in this game under two different conditions. First, in what we call the lending game with strong exclusion, the capital of the borrower is $C_{t}=0$ in all periods. Second, in the lending game with weak exclusion, where we have that the borrower's capital for $t>1$ is:

$$
C_{t}=\sum_{k=1}^{t-1} S_{k} D_{k}
$$

The monetary payoff for the lender $\Pi_{t}$ is 10 if he decides not to give a loan or if his loan offer is not accepted. If he gives out a loan, his offer specifies a loan size $S_{t}$ and a repayment of $R_{t}=i_{t} S_{t}$, where $i_{t} \in[1, v]$. If the borrower accepts the offer $\left(A_{t}=1\right)$, he receives $S_{t}$ and chooses whether to repay or not. Thus the lender's payoff $\Pi_{t}$ in period $t$ is:

$$
\Pi_{t}=10-A_{t} S_{t}\left(1-i_{t}\left(1-D_{t}\right)\right)
$$

In turn, the borrower's income stems from two sources. He has a fixed income from other self-financed projects or income from other activities of 10. Additionally, he earns an investment income, which depends on whether he accepts a loan offer and the loan size offered $S_{t}$, as well as his own capital. If the borrower decides to repay, $R_{t}=i_{t} S_{t}$ is transferred to the lender. If he defaults, he accumulates capital for the next period, $C_{t+1}$, if in the lending game with weak exclusion. The borrower's payoff $U_{t}$ in period $t$ is:

$$
U_{t}=10+v \cdot\left(A_{t} S_{t}+C_{t}\right)-A_{t} R_{t}\left(1-D_{t}\right)-C_{t+1}
$$

There are two borrower types, conditionally reciprocal ( $H$ for 'high') and selfish ( $L$ for 'low'), not observable to the lender. An $L$ type repays a loan if it maximizes his monetary payoffs. An $L$ type borrower will thus never repay a loan in period $T$. Assuming that lenders offer contracts $\left(S_{t}, i_{t}\right)$ only to a borrower who repays in all prior periods, the incentive constraint of an $L$ type borrower in the game with strong exclusion for periods $t=\{1, \ldots, T-$ 1\} is: 
$\left[\mathbf{I C}_{L, S E}\right] \sum_{k=t}^{T-1}\left(v-i_{k}\right) S_{k}+v S_{T} \geq v S_{t}$

In the game with weak exclusion the incentive constraint for the $L$ type borrower is

$\left[\mathbf{I C}_{L, W E}\right] \sum_{k=t}^{T-1}\left(v-i_{k}\right) S_{k}+v S_{T} \geq \sum_{k=t}^{T-1}(v-1) S_{t}+v S_{t}$

Note that in both incentive constraints, the monetary payoff of the borrower is positive. His participation constraint is therefore satisfied and has an incentive to accept any loan offer.

The $H$ type borrower repays any loan he has accepted. However, the $H$ type also cares about relative payoffs, which makes him yield negative utility if the gross interest rate is above a threshold $\bar{r} \in(1, v)$. The participation constraint of the $H$ type can thus be written as

$\left[\mathbf{P C}_{H}\right] i_{t} \leq \bar{r}$

The lender's prior about the borrower being of type $H$ is $\bar{p} \in(0,1)$, i.e. $\bar{p}$ is the ex-ante probability that the borrower is of type $H$. For any period $t>1$ the lender updates his belief $p_{t}$ on the borrower's type using Bayes' Rule. If selfish borrowers repay in period $t-1$ with a probability $\gamma_{t-1} \in[0,1]$, then the lender's updated belief is given by $p_{t}=\frac{p_{t-1}}{p_{t-1}+\gamma_{t-1}\left(1-p_{t-1}\right)}$.

Assuming that the participation constraint of $H$ borrowers is met in all periods $\left(i_{t} \leq \bar{r}\right)$ and that $L$ type borrowers repay with a repayment probability $\gamma_{1}, \ldots \gamma_{7}$, whereby $\gamma_{7}=0$, the participation constraint of the lender can be defined as

$[$ PC Lender $t] \sum_{k=t}^{T} S_{k}\left(\left(p_{k}+\gamma_{k}\left(1-p_{k}\right)\right) i_{k}-1\right) \geq 0$, whereby $i_{k} \leq \bar{r}$

Since $\gamma_{7}=0$, for lenders to lend in the final period we must have $p_{T} \bar{r}-1 \geq 0$.

In what follows we will describe the equilibria of the repeated lending game, both with weak and strong exclusion. The equilibrium concept used throughout is that of Perfect Bayesian Equilibrium (PBE). We will consider two types of equilibria: implicit contracting and screening equilibria. Implicit contracting equilibria are defined as those equilibria in which the $L$ borrower repays loans at least in period 1. Screening equilibria are defined as those in which the $L$ type borrower defaults with certainty in period 1 . Therefore, for the rest of the game $L$ borrowers have been screened out and $H$ types are identified. Whenever these equilibria exist, there exist a plethora of them. As is conventional in the literature (e.g. Thomas and Worral, 1994), we concentrate on the equilibrium which is profit-maximizing for the lender, as he is the player making offers and the borrower only has the option of accepting them or not.

We make the following assumptions regarding the ex-ante probability $\bar{p}$ that the borrower is of type $H$. Assumption 1 implies that the proportion of $H$ type borrowers does not make it profitable to extend a loan in a one-shot situation:

Assumption 1: $\bar{p}<\frac{1}{\bar{r}}$

Assumption 2 implies that the proportion of $H$ type borrowers is high enough to make an implicit contracting equilibrium feasible in the repeated game with $T$ periods feasible:

Assumption 2: $\bar{p} \geq \frac{1}{\bar{r}^{T}}$ 


\section{C.2. Lending under strong exclusion}

Given our assumptions about $\bar{p}$, the profit-maximizing implicit contracting equilibrium for the lender has maximum loan sizes in all non-final periods, and a smaller loan in the final period. Borrowers pool in periods 1 through 5, during which $L$ borrowers always repay. In period $6 L$ borrowers default with positive probability and in period 7 they default always.

Proposition 1: In the lending game with strong exclusion the profit-maximizing implicit contracting equilibrium for the lender is characterized by offers $\left(S_{t}, i_{t}\right)=(10, \bar{r})$ if $t \leq 6$ and $\left(S_{7}, i_{7}\right)=\left(10 \frac{\bar{r}}{v}, \bar{r}\right)$. The $H$ type borrower accepts and repays in all periods. The $L$ type borrower accepts in all periods, repays with $\gamma_{t}=1$ in periods $t \leq 5$, with $\gamma_{6}=\frac{\bar{p}}{(1-\bar{p})}(\bar{r}-1)$ and $\gamma_{7}=0$.

Proof: We first consider whether the IC of the $L$ type borrower is satisfied in periods 1 to 6 . Then, we check whether the $\mathrm{PC}$ of the $\mathrm{H}$ type borrower is satisfied. Finally, whether the lender's PC is satisfied and whether the equilibrium is profit-maximizing.

- $L$ type borrower repayment: Condition $\left[\mathrm{IC}_{L, S E}\right]$ holds with inequality in all periods $t<6$. In period 6 it holds with equality, so we know that the $L$ type borrower is indifferent between repaying and not. Thus, $\gamma_{1}=\ldots=\gamma_{5}=1$ and $\gamma_{6}=\frac{\bar{p}}{(1-\bar{p})}(\bar{r}-1)$ is a best response behavior.

- $H$ type borrower accepts and repays as $i_{t}=\bar{r}$ for all $t$.

- Lender contracts: Condition $\left[\mathrm{PC}\right.$ Lender $\left._{T}\right]$ is met with equality if he offers $\left(S_{7}, i_{7}\right)=$ $\left(10 \frac{\bar{r}}{v}, \bar{r}\right)$, as $p_{T}=\frac{\bar{p}}{\bar{p}+\gamma_{6}(1-\bar{p})}=\frac{1}{\bar{r}}$. The lender's profits from lending in period 6 are $S_{T-1}\left(\left(\bar{p}+\gamma_{6}(1-\bar{p})\right) i_{T-1}-1\right)$ which are positive for $\left(S_{6}, i_{6}\right)=(10, \bar{r})$, as $\bar{p}>\frac{1}{\bar{r}^{2}}$ (Assumption 2). Since $\gamma_{t}=1$ in all periods $t \leq 5$ the lender's participation constraint is met.

- This equilibrium is profit-maximizing for the lender for three reasons: (i) $i_{t}=\bar{r}$, therefore the $H$ type borrower repays, and the lender extracts the maximum surplus; (ii) since $\frac{\partial \pi_{t}}{\partial S_{t}}>0$, conditional on repayment, offering maximum loan sizes (of 10) until period 6 is profit-maximizing; (iii) Since $\gamma_{t}=1$ until period 5 , he obtains maximum profits until this period and screening starts in the last period possible, 6 .

In the game with strong exclusion, a separating equilibrium, in which $L$ borrowers default with certainty in period 1 , does not exist. In such an equilibrium the lender will offer maximum credit at the interest rate $\bar{r}$ for all periods 2 through 7 to borrowers who repay in period 1. Given this prospective loan schedule $L$ borrowers would not default in period 1.

Proposition 2: In the lending game with strong exclusion no fully separating equilibrium $\left(\gamma_{1}=0\right)$ exists.

Proof: In a fully separating equilibrium the lender will set the maximum possible interest rate and loan size $\left(S_{t}, i_{t}\right)=(10, \bar{r})$ in all periods $t>1$. The incentive constraint of $L$ borrowers is then $\sum_{t=2}^{6}(v-\bar{r}) 10+v 10 \geq i_{1} S_{1}$. Given that the interest rate in period 
1 cannot exceed $\bar{r}$ it is impossible for the lender to offer a contract which does not meet $\left[\mathrm{IC}_{L, S E}\right]$.

Finally, note that the equilibrium described in Proposition A1 is 'second-best', as the loan sizes are maximal until period 6 , but must fall in period 7 to meet the $L$ borrower's IC.

\section{C.3. Lending under weak exclusion}

Given the above parameters a implicit contracting equilibrium exists in the lending game with weak exclusion. In contrast to the strong exclusion treatment, loans are of a smaller size in period 1 and increase over time, with maximum credit only in the final period. Repayment behavior is identical to the implicit contracting equilibrium under strong exclusion: borrowers pool in periods 1 through 5 , with $L$ borrowers repaying always. In period $6 L$ borrowers default partly and in period 7 they default always.

Proposition 3: In the game with weak exclusion the profit-maximizing implicit contracting equilibrium for the lender is characterized by offers $\left(S_{7}, i_{7}\right)=(10, \bar{r})$ and for all periods $t<7: i_{t}=\bar{r}, S_{t}=\frac{(v-I)}{((7-t)(v-1)+\bar{r})} \sum_{k=t+1}^{6} S_{k}+\frac{v}{((7-t)(v-1)+\bar{r})} 10$. The $H$ type borrower accepts and repays in all periods. The $L$ type borrower accepts in all periods, repays with certainty in periods 1-5, with probability $\gamma_{6}=\frac{\bar{p}}{(1-\bar{p})}(v-1)$ and $\gamma_{7}=0$.

\section{Proof:}

- $L$ type borrower repayment: The incentive constraint $\left[\mathrm{IC}_{L, W E}\right]$ holds with equality in all periods $t \leq 6$. As a result $\gamma_{6}=\frac{\bar{p}}{(1-\bar{p})}(\bar{r}-1)$ and $\gamma_{t}=1$ if $t<6$ is a best response behavior.

- $H$ type borrower accepts and repays as $i_{t}=\bar{r}$ for all $t$.

- Lender contracts: Proposition A1 shows that the participation constraint of the lender is met in all periods. The same holds under weak exclusion, as the repayment behavior of the $L$ type borrowers is identical.

- By the same reasons as in Proposition A1, the interest rate and the repayment behavior are profit-maximizing for the lender. To incetivize the $L$ type borrower to repay until period 6 loan sizes have to be increasing, as follows from $\left[\mathrm{IC}_{L, W E}\right]$. Therefore, to reach maximum profits the lender starts by choosing the maximum loan size of 10 in the last period, 7. In the previous periods, the loan size is chosen such that the borrower's $\mathrm{IC}$ is satisfied with equality.

Under weak exclusion a separating equilibrium exists in which $L$ borrowers default with certainty in period 1 .

Proposition 4: In the lending game with weak exclusion a fully separating equilibrium $\left(\gamma_{1}=0\right)$ exists. The profit-maximizing screening equilibrium for the lender has offers $\left(S_{1}, i_{1}\right)=\left(10 \frac{6 v-5}{6(v-1)+I}, \bar{r}\right) ;\left(S_{2}, i_{2}\right) \ldots\left(S_{7}, i_{7}\right)=(10, \bar{r})$.

Proof: In a screening equilibrium, which maximizes the lender's profits, the lender will set the maximum interest rate $\left(i_{t}=\bar{r}\right)$ and loan size $\left(S_{t}=10\right)$ in each period $t>1$. In 
period 1 the lender offers the maximum interest rate and lowest loan size such that the borrower does not prefer to default in period 2. This implies that $6(v-1) S_{1}+v S_{1}>$ $\left(v-i_{1}\right) S_{1}+5(v-1) 10+v 10$. This implies that $i_{1}=\bar{r}$ and $S_{1}=10 \frac{6 v-5}{6(v-1)+\bar{r}}$.

Note that the screening equilibrium is more efficient than the implicit contracting equilibrium. This is due to the fact that loan sizes are larger in period 1 under the screening equilibrium and L type borrowers default and reinvest these large loans until period 7 . Therefore, investment levels are higher than under the implicit contracting equilibrium. However, full efficiency is not reached, because this would require an initial loan size of 10 , which is not profit-maximizing for the lender, who can screen by giving out a loan of $S_{1}=10 \frac{6 v-5}{6(v-1)+\bar{r}}<10$.

Whether the lender earns a higher profit under the implicit contracting equilibrium or the separating equilibrium depends on the schedule of loan sizes in the implicit contracting equilibrium, as well as the share of $\mathrm{H}$ type borrowers. In the next subsection, we use the parameters in place in our experiment, to generate the predicted loan sizes and compare profits.

\section{C.4. Application to the experiment}

In our experiment we have that $v=3$. We assume that $H$ type borrowers are conditionally reciprocal and will repay only if the receive at least half of the gains from trade in any period, i.e. $\bar{r}=2$. This gross interest rate also coincides with that observed in the experiment. Assuming $\bar{r}=2$, our Assumptions 1 and 2 on the share of $H$ borrowers hold if $\frac{1}{2}>\bar{p}>\left(\frac{1}{2}\right)^{7}$.

This implies from Assumption 2 that a implicit contracting equilibrium would be possible even in a 2 period repeated game. These parameters also imply the following schedule of loan sizes.

\begin{tabular}{ccc}
\hline Period & Strong Exclusion & Weak Exclusion \\
\hline 1 & 10 & 4.19 \\
2 & 10 & 4.51 \\
3 & 10 & 4.92 \\
4 & 10 & 5.47 \\
5 & 10 & 6.25 \\
6 & 10 & 7.5 \\
7 & 6.67 & 10 \\
\hline
\end{tabular}

Table C.1: Predicted loan sizes over time

The profits from the implicit contracting equilibrium are $(4.19+4.51+4.92+5.47+$ $6.25)(\bar{r}-1)+7.5\left(\bar{p}+(1-\bar{p}) \gamma_{6}\right) \bar{r}-7.5=25.34+7.5\left(\bar{p} \bar{r}^{2}-1\right)=25.34+7.5 * 4 \bar{p}-7.5=$ $17.84+30 \bar{p}$. In contrast, the profits from the screening equilibrium are $9.29(\bar{r} \bar{p}-1)+60 \bar{p}(\bar{r}-$ $1)=9.29(2 \bar{p}-1)+60 \bar{p}=78.58 \bar{p}-9.29$. The lender earns higher profits in the screening equilibrium if $78.58 \bar{p}-9.29>17.84+30 \bar{p}$. This is not the case for any $\bar{p}<27.13 / 48.58=0.56$. If $\bar{p}<1 / \bar{r}=1 / 2$, as in Assumption 1, the lender is better off under the implicit contracting equilibrium. 


\section{C.5. Discussion}

How sensitive are our predictions to the assumption of a finite horizon? In an infinite horizon weak exclusion would have the same qualitative effects on credit volume and repayment: it would lead to a lower credit volume and higher defaults. Under strong exclusion the implicit contracting equilibrium with maximum loan sizes is still profit-maximizing while screening is not feasible, as in the finite horizon case. Additionally, "starting small" equilibria may also be profit-maximizing (as in Ray, 2002), if the share of social borrowers is relatively small. Under weak exclusion a implicit contracting equilibrium featuring "starting small" is still profit-maximizing, and screening is feasible as well. Note that, if exclusion is strong and there are no social borrowers, implicit contracting equilibria are feasible in the infinite horizon case, while they are not in the finite horizon case. At the same time, if exclusion is weak and there are no social borrowers, lending cannot occur in equilibrium, as in Bulow and Rogoff (1989), or as in the finite horizon case.

Our predictions above also assume that lenders are risk neutral. Allowing for moderate risk aversion does not affect the comparison between WE and SE treatments qualitatively. Under risk-aversion the implicit contracting equilibrium in the WE treatment will still feature lower initial loan sizes than in the SE treatment, as this is the only way the incentive constraint of borrowers can be met. Furthermore, the screening equilibrium in the WE treatment is still feasible with risk-averse lenders, but would feature lower first-period loan offers 


\section{Online Appendix D}

Table D1. Summary statistics by location of experiments (Tilburg University and UC San Diego)

This table shows the share of self-enforcing relationships, i.e. relationships in which a loan is offered, accepted and repaid for at least 5 periods, the average Loan size and Interest (Requested repayment / Loan Size) in accepted offers. Panel A shows results by round and location for the WE Treatment, and Panel B shows these results for the SE Treatment. The adjusted (Bonferroni) p-value for a MannWhitney test comparing all rounds at Tilburg University and at UC San Diego is shown in the last column.

\begin{tabular}{|c|c|c|c|c|c|c|c|c|c|}
\hline & \multicolumn{8}{|c|}{ Panel A. WE Treatment } & \multirow{3}{*}{$\begin{array}{l}\text { MW-test } \\
\text { All rounds }\end{array}$} \\
\hline & \multicolumn{4}{|c|}{ Tilburg University } & \multicolumn{4}{|c|}{ UC San Diego } & \\
\hline & Round 1 & Round 2 & Round 3 & All rounds & Round 1 & Round 2 & Round 3 & All rounds & \\
\hline Share of self-enforcing relationships & 0.10 & 0.00 & 0.14 & 0.08 & 0.13 & 0.21 & 0.13 & 0.15 & 0.66 \\
\hline Loan size & 5.60 & 4.60 & 4.50 & 4.92 & 5.81 & 4.63 & 4.65 & 5.08 & 1.00 \\
\hline Interest rate & 2.08 & 2.05 & 2.03 & 2.06 & 1.78 & 1.96 & 1.78 & 1.85 & 0.25 \\
\hline
\end{tabular}

Panel B. SE Treatment

\begin{tabular}{lcccc|cccc|c} 
& \multicolumn{4}{c}{ Tilburg University } & \multicolumn{4}{c|}{ UC San Diego } \\
& Round 1 & Round 2 & Round 3 & All rounds & Round 1 & Round 2 & Round 3 & All rounds & All rounds \\
\hline Share of self-enforcing relationships & 0.42 & 0.50 & 0.67 & 0.53 & 0.46 & 0.38 & 0.46 & 0.43 & 0.94 \\
Loan size & 7.14 & 7.40 & 7.47 & 7.34 & 6.40 & 6.27 & 6.65 & 6.46 & 0.74 \\
Interest rate & 1.99 & 1.96 & 1.99 & 1.98 & 1.80 & 2.00 & 1.92 & 1.91 & 1.00 \\
\hline
\end{tabular}


Figure D1. Loans offered, accepted and repaid - by round

Figure D1a. Round 1

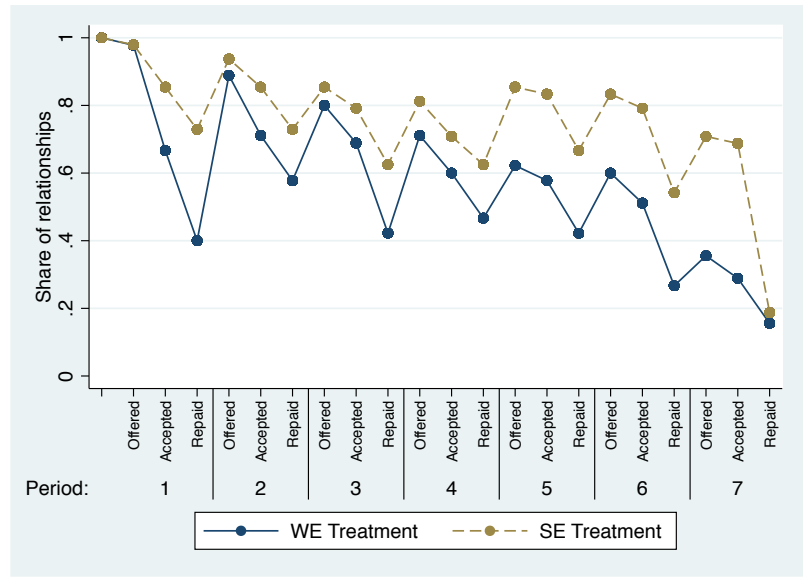

Figure D1b. Round 2

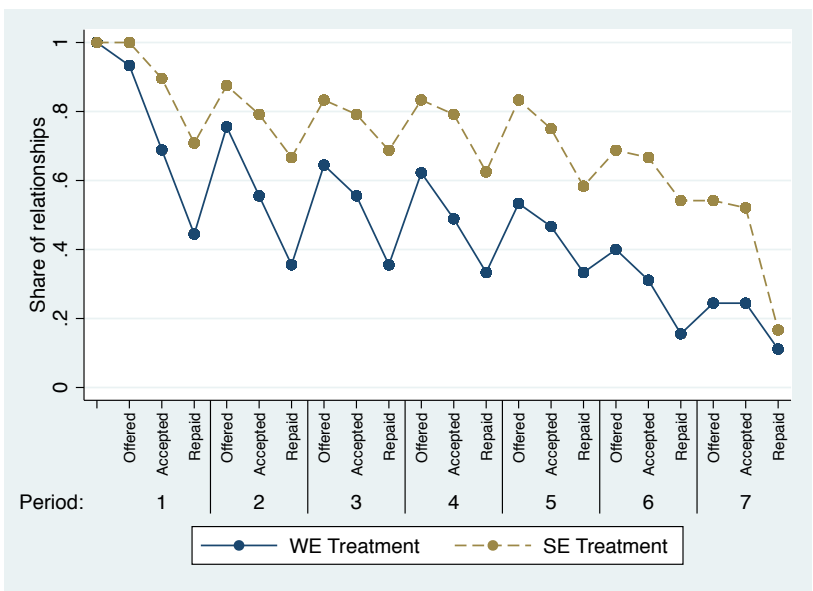

Figure D1c. Round 3

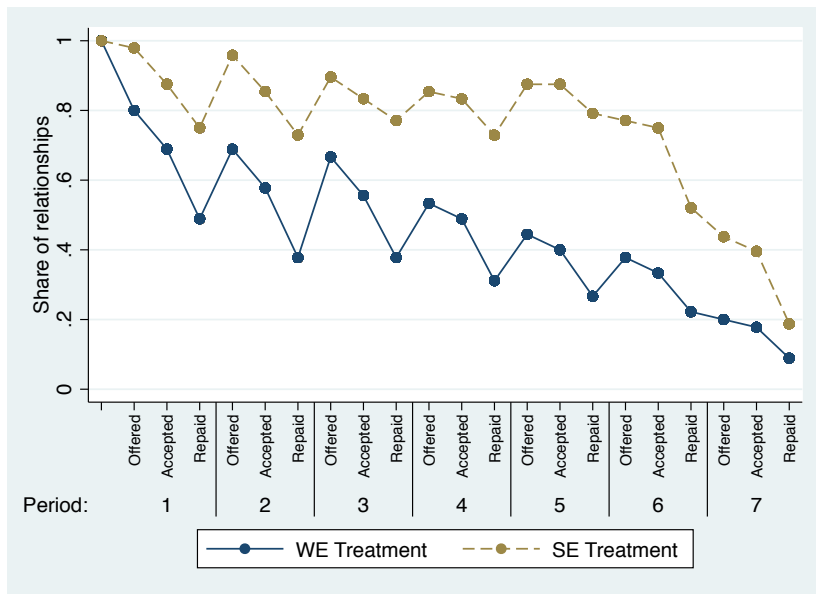


Figure D2. First period loan offers, by round

Figure D2a. Loan size
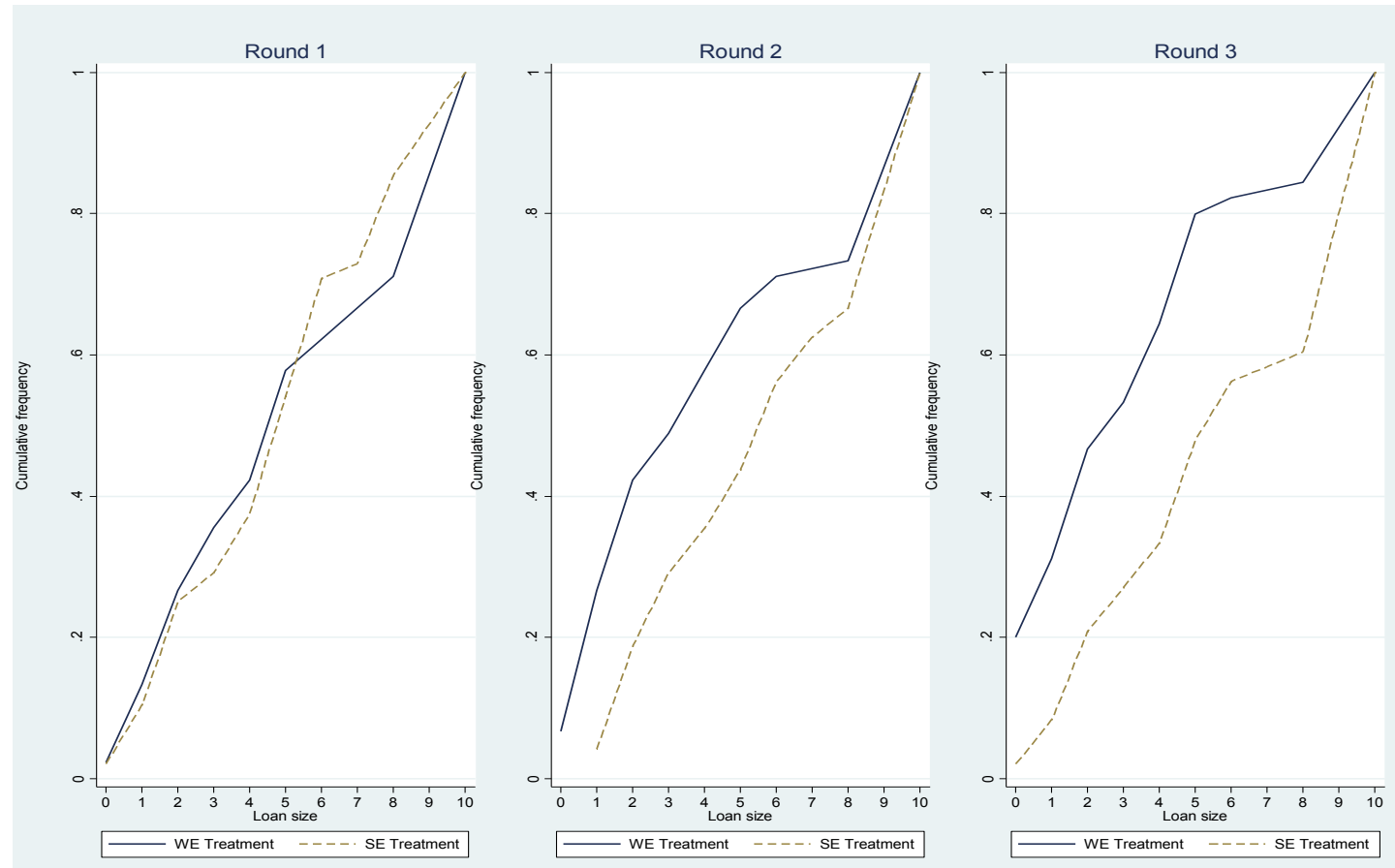

Figure D2b. Interest
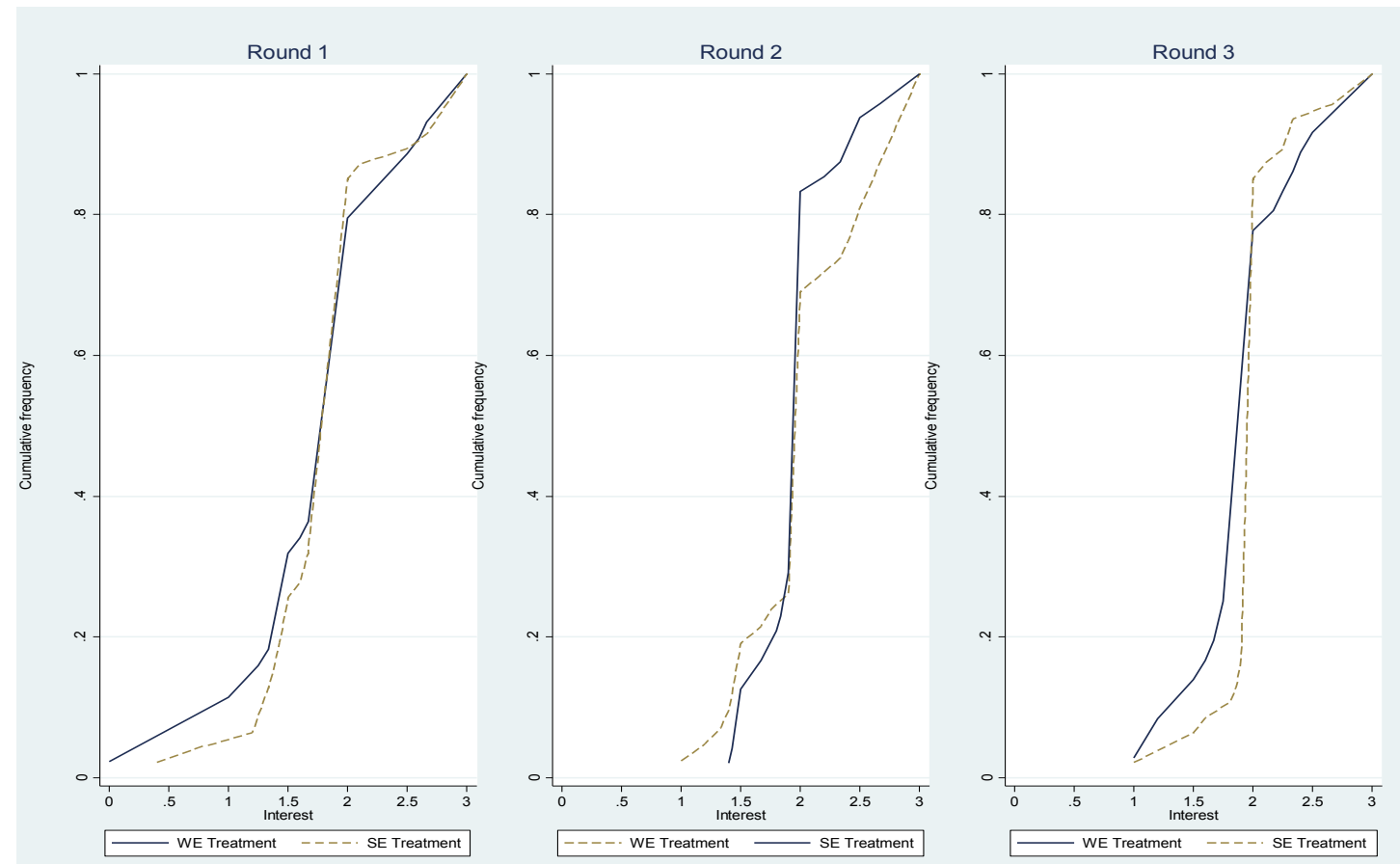
Table D2: Rejection and Default in Periods 2-7

This table reports panel estimates for Reject (columns 1 to 4 ) and Default (columns 5 to 8 ) in surviving relationships in Periods 2 to 7. Reject is a dummy variable that takes value 1 if the borrower rejects the lender's offer, 0 otherwise. Default is a dummy variable that takes value 1 if the borrower does not repay an accepted loan offer. Loan $<5$ is a dummy variable that takes value 1 if the loan size is $1-4,0$ otherwise. Interest $>2$ is a dummy variable that takes value 1 if the gross interest rate is above the "fair" interest rate of 2, 0 otherwise. Period 4-5 and 6-7 are dummy variables denoting the corresponding period of the relationship (Period 2-3 is the ommitted category). WE is a dummy variable which is 1 for all observations from the WE treatment and zero for those from the SE treatment. All regressions include round fixed effects and the interaction of round fixed effects with the treatment dummy (coumns 3-4 and 7-8). All regressions also include borrower characteristics (risk aversion, strategic reasoning and trustworthiness) and location fixed effects, where Tilburg University is the ommitted category. Standard errors are clustered at the matching group level and reported in brackets. ${ }^{*}, * * * *$ indicate significance at the $10 \%, 5 \%$, and $1 \%$ level respectively.

\begin{tabular}{|c|c|c|c|c|c|c|c|c|}
\hline & (1) & $(2)$ & (3) & (4) & (5) & (6) & (7) & (8) \\
\hline Dependent variable & \multicolumn{4}{|c|}{ Reject } & \multicolumn{4}{|c|}{ Default } \\
\hline Treatment & WE & SE V & WE and SE & WE and $\mathrm{SE}$ & \multicolumn{4}{|c|}{$\begin{array}{l}\text { Default } \\
\text { SE WE and SE WE and SE }\end{array}$} \\
\hline \multirow[t]{2}{*}{ Loan $<5$} & 0.055 & -0.000 & 0.016 & -0.016 & 0.007 & $0.080^{* *}$ & 0.030 & $0.066^{* *}$ \\
\hline & [0.058] & {$[0.021]$} & {$[0.024]$} & {$[0.023]$} & {$[0.052]$} & {$[0.032]$} & {$[0.031]$} & {$[0.029]$} \\
\hline \multirow[t]{2}{*}{ Interest >2 } & $0.175^{* *}$ & $0.223 * * *$ & $0.209 * * *$ & $0.234 * * *$ & $0.355^{* * *}$ & $0.325^{* * *}$ & $0.342 * * *$ & $0.328 * * *$ \\
\hline & {$[0.085]$} & [0.060] & [0.047] & [0.059] & [0.079] & [0.100] & [0.070] & [0.100] \\
\hline \multirow[t]{2}{*}{ Periods 4-5 } & -0.018 & -0.017 & -0.014 & -0.013 & 0.021 & -0.012 & -0.008 & -0.009 \\
\hline & {$[0.038]$} & {$[0.018]$} & {$[0.015]$} & {$[0.017]$} & [0.059] & [0.022] & [0.020] & [0.022] \\
\hline \multirow[t]{2}{*}{ Periods 6-7 } & -0.026 & -0.015 & -0.012 & -0.012 & 0.180 & $0.333 * * *$ & $0.304 * * *$ & $0.344 * * *$ \\
\hline & {$[0.053]$} & {$[0.022]$} & {$[0.020]$} & {$[0.020]$} & [0.127] & [0.066] & [0.057] & [0.066] \\
\hline \multirow[t]{2}{*}{ WE Treatment } & & & 0.056 & 0.091 & & & $0.108^{* *}$ & 0.065 \\
\hline & & & {$[0.042]$} & {$[0.059]$} & & & {$[0.045]$} & [0.064] \\
\hline \multirow[t]{2}{*}{$W E *$ Loan $<5$} & & & & 0.063 & & & & -0.076 \\
\hline & & & & {$[0.058]$} & & & & [0.055] \\
\hline \multirow[t]{2}{*}{$W E *$ Interest $>2$} & & & & -0.074 & & & & 0.012 \\
\hline & & & & {$[0.100]$} & & & & [0.127] \\
\hline \multirow[t]{2}{*}{ WE * Periods 4-5 } & & & & -0.011 & & & & 0.017 \\
\hline & & & & {$[0.041]$} & & & & {$[0.061]$} \\
\hline \multirow[t]{2}{*}{ WE * Periods 6-7 } & & & & -0.017 & & & & -0.189 \\
\hline & & & & {$[0.056]$} & & & & [0.140] \\
\hline \multirow[t]{2}{*}{ Constant } & 0.292 & 0.029 & 0.095 & 0.100 & 0.162 & $0.215^{*}$ & $0.249 * *$ & $0.245^{* *}$ \\
\hline & {$[0.308]$} & {$[0.066]$} & {$[0.152]$} & {$[0.148]$} & {$[0.250]$} & {$[0.112]$} & {$[0.113]$} & {$[0.108]$} \\
\hline Method & OLS & OLS & OLS & OLS & OLS & OLS & OLS & OLS \\
\hline Borrower characteristics & Yes & Yes & Yes & Yes & Yes & Yes & Yes & Yes \\
\hline Round fixed effects & Yes & Yes & Yes & Yes & Yes & Yes & Yes & Yes \\
\hline Observations & 168 & 445 & 613 & 613 & 156 & 430 & 586 & 586 \\
\hline Number of Lenders & 35 & 46 & 81 & 81 & 31 & 46 & 77 & 77 \\
\hline Overall $R^{2}$ & 0.0582 & 0.175 & 0.109 & 0.114 & 0.127 & 0.246 & 0.196 & 0.211 \\
\hline
\end{tabular}




\section{Online Appendix E WE Competition and SE Competition Treatments: Predictions}

\section{E.1. Lending Game with Lender Competition}

Two lenders and a borrower interact for $T=7$ periods. Every period the schedule of events is the following:

1. Each lender has an endowment of 10 in every period $t$. The borrower has a capital of $C_{t}$, where $C_{1}=0$.

2. Both lenders make an offer $\left(S_{t}, R_{t}\right)$ simultaneously to the borrower, whereby $S_{t} \in$ $\left[0,10-C_{t-1}\right]$ and $R_{t} \in[1, v] S_{t}$, where $v>1$.

3. The borrower chooses which offer to accept $\left(A_{t}=1\right)$, or rejects both offers $\left(A_{t}=0\right)$. He can accept at most one offer.

4. If the offer is accepted, the borrower earns an investment income of $I_{1}=v \cdot\left(S_{t}+C_{t}\right)$ and chooses whether to repay $\left(D_{t}=0\right)$ or default $\left(D_{t}=1\right)$

At the beginning of each period both lenders observe the previous offer that the borrower accepted and her repayment choice, as well as her capital $C_{t}$. This is equivalent to having a credit registry. We examine behavior in this game under two conditions: with strong exclusion, where the capital of the borrower is $C_{t}=0$ in all periods; with weak exclusion, where we have that the borrower's capital for $t>1$ is $C_{t}=\sum_{k=1}^{t-1} S_{k} D_{k}$.

The monetary payoff of the lender and the borrower is as defined in Appendix B. Further, we make the same assumptions regarding the existence of two types of borrowers, a social ( $H$ type) borrower and a selfish ( $L$ type) borrower. Note that the lender has information about the borrower's past repayment behavior (at the beginning of each period), and hence can form a prior about the type of the borrower as in the case where competition between lenders is absent.

As in Online Appendix $\mathrm{C}$, we make the following assumptions regarding the ex-ante probability $\bar{p}$ that the borrower is of type $H$. Assumption 1 implies that the proportion of $H$ type borrowers does not make it profitable to extend a loan in a one-shot situation.

Assumption 1: $\bar{p}<\frac{1}{\bar{r}}$

Assumption 2 implies that the proportion of $H$ type borrowers is high enough to make a implicit contracting equilibrium feasible in the repeated game with $T$ periods feasible:

Assumption 2: $\bar{p} \geq \frac{1}{\bar{r}^{T}}$

For ease of exposition, we assume that the share of $H$ type borrowers is high enough to make a implicit contracting equilibrium feasible in the repeated game with two periods. This allows unravelling to occur only in the last two periods of the game. The same approach with more complex notation would lead to implicit contracting equilibria with earlier unravelling. 
In what follows we will describe the equilibria of the repeated lending game, both with weak and strong exclusion. The equilibrium concept used throughout is that of Perfect Bayesian Equilibrium (PBE). We restrict attention to pure strategy symmetric equilibria. ${ }^{1}$

\section{E.2 Lending under Strong Exclusion}

Competition between lenders means they must make zero profits in equilibrium. We begin by solving the problem by backwards induction, focusing on the lender's profits in periods 6 and 7 , as well as the borrower's IC in period 6 . If the lender's offer is accepted, her expected profits in period 7 are:

$$
\Pi_{L, 7}=S_{7}\left(p_{7} i_{7}-1\right) .
$$

Several facts are important to note in period 7 :

- The lender's profits must be zero, i.e. $\Pi_{L, 7}=0$

- $i_{7}$ must be between $(1, \bar{r}] .^{2}$

Using Bayes' rule, this implies that:

$$
\frac{\bar{p}}{\bar{p}+\gamma_{6}(1-\bar{p})}=\frac{1}{i_{7}} \text {. }
$$

We can now turn to period 6. Consider expected profits if the offer is accepted:

$$
\Pi_{L, 6}=S_{6}\left(p_{6} i_{6}-1\right)=S_{6}\left(\left[\bar{p}+\gamma_{6}(1-\bar{p})\right] i_{6}-1\right) .
$$

Several facts are important to note in period 6 :

- Again, the lender's profits must be zero, i.e. $\Pi_{L, 6}=0$

- Second, we can use equation (2), which must be fulfilled in equilibrium, i.e. $\bar{p}+\gamma_{6}(1-$ $\bar{p})=\bar{p} i_{7}$.

This leads to the main constraint that must be satisfied by lender offers:

$$
i_{6}=\frac{1}{i_{7}} \cdot \frac{1}{\bar{p}}
$$

Turn to the $L$ type borrower's IC in period 6 :

- Repayment yields: $S_{6}\left(v-i_{6}\right)+v S_{7}$

- Default yields: $S_{6} v$

\footnotetext{
${ }^{1}$ In the presence of two lenders asymmetric equilibria in mixed strategies are possible. If these emerge under strong exclusion, endogenous asymmetric information in the last period of the lending game is possible, due to the fact that lenders observe borrower repayment and past loan sizes, but not interest rates. This leads to a setting that is analogous to that in von Thadden (2004).

${ }^{2}$ Note that $i_{7}=1$ would require $p_{7}=1$, hence it would require $\gamma_{6}=0$ which would make lending in period 6 unprofitable.
} 
This implies,

$$
S_{7}=\frac{i_{6}}{v} S_{6}
$$

Proposition 1: In the game with strong exclusion and lender competition, a unique symmetric implicit contracting equilibrium exists. For $t<6$, each lender $j$ offers $\left(S_{t}^{j}, i_{t}^{j}\right)=$ $(10,1)$, where $j \in\{1,2\}$, to borrowers who have repaid all previous loans, and $L$ borrowers choose $\gamma_{1}=\ldots=\gamma_{5}=1$. In period 6 , each lender $j$ offers $\left(S_{6}^{j}, i_{6}^{j}\right)=\left(10, \frac{1}{\bar{p} \bar{r}}\right)$, and in period 7 each lender offers $\left(S_{7}^{j}, i_{7}^{j}\right)=\left(\frac{\bar{r}}{v} 10, \bar{r}\right)$. Further, $\gamma_{6}=\frac{\bar{p}}{(1-\bar{p})}(\bar{r}-1)$ and $\gamma_{7}=0$.

\section{Proof:}

- $L$ type borrower repayment: The $L$ type borrower has a strict incentive to repay for periods 1 to 5 . Given $S_{6}, S_{7}$ and $i_{6}$ he is indifferent between repaying and defaulting in period 6. Thus, $\gamma_{1}=\ldots=\gamma_{5}=1$ and $\gamma_{6}=\frac{\bar{p}}{(1-\bar{p})}(\bar{r}-1)$ is a best response behavior.

- $H$ type borrower accepts and repays as $i_{t} \leq \bar{r}$ for all $t$.

- Lender contracts: Throughout the lender makes zero profits. The lender's participation constraint is met with equality in periods 1 to 5 , as $i_{t}=1$ and $\gamma_{t}=1$ for $t<6$. The lender's profits from lending in period 6 are $S_{6}\left(\left(\bar{p}+\gamma_{6}(1-\bar{p})\right) i_{6}-1\right)$ which are zero for $\left(S_{6}, i_{6}\right)=\left(10, \frac{1}{\bar{p} \bar{r}}\right)$ and since $\gamma_{6}=\frac{\bar{p}}{(1-\bar{p})}(\bar{r}-1)$ and $i_{7}^{j}=\bar{r}$. In period 7 , he offers $\left(S_{7}, i_{7}\right)=\left(\frac{\bar{r}}{v} 10, \bar{r}\right)$ as $p_{T}=\frac{\bar{p}}{\bar{p}+\gamma_{6}(1-\bar{p})}=\frac{1}{i_{7}}$.

- This equilibrium is the most profitable for the $H$ and $L$ borrower. Any contract that fulfills (2), (4) and (5), yields profits in period 6 and 7 to the $L$ and $H$ type respectively of:

$$
\begin{aligned}
& -U_{L}=S_{6}\left(v-i_{6}\right)+S_{7} v=S_{6} v \\
& -U_{H}=S_{6}\left(v-i_{6}\right)+S_{7}\left(v-i_{7}\right)=S_{6} v-S_{6} \frac{1}{v \bar{p}}
\end{aligned}
$$

Since $\frac{\partial U_{H}}{\partial i_{6}}>0, S_{6}=10$ is profit maximizing.

- Since $i_{t}=1$ for $t<6$, no lender can deviate from $(10,1)$ profitably. The lowest interest rate that the lender can offer in period 6 is determined by his expected profits for that period, which are $S_{6}\left(i_{7} \bar{p} i_{6}-1\right)$. Hence, the lowest $i_{6}$ is limited by the maximal $i_{7}$, which is $\bar{r}$. Each lender makes zero expected profits by offering $\left(\frac{\bar{r}}{v} 10, \bar{r}\right)$ in period 7. No lender can credibly increase $i_{6}$ and promise $i_{7}<\bar{r}$ in $t=7$. Conditional on repayment, if one lender offers $S_{7}=\frac{i_{6}}{v} 10$ and $i_{7}<\bar{r}$, the competing lender will have an incentive to deviate, offering $S_{7}+\epsilon$ and requesting $i_{7}=\bar{r}$, thereby attracting all borrowers.

With lender competition and common knowledge there is no screening equilibrium.

Proposition 2: In the lending game with strong exclusion and lender competition, no fully separating equilibrium $\left(\gamma_{1}=0\right)$ exists. 
Proof: In a fully separating equilibrium, the $H$ borrower repays in the first period, while the $\mathrm{L}$ borrower defaults. Due to common knowledge, after $t=1$, no rents can be extracted from screening in the first period. Hence, no lender has an incentive to make an offer in the first period that will lead to separation between the $H$ and $L$ type borrowers, since by Assumption 1, $\bar{p}<\frac{1}{\bar{r}}$ and hence losses will be incurred in the first period. Further, as in the monopoly case, no offer can be generated that violates incentive compatibility constraint of the selfish borrower in $t=1$.

\section{E.3. Lending under Weak Exclusion}

Under weak exclusion, lender profits remain the same. Hence, equations (2) and (4) must continue to hold. However, condition (5) now changes, since the borrower's incentives to repay in period 6 are determined by the following:

- Repayment yields: $S_{6}\left(v-i_{6}\right)+v S_{7}$

- Default yields: $S_{6}(v-1)+v S_{6}$

This implies,

$$
S_{6}=\frac{v}{v-1+i_{6}} S_{7}
$$

It follows that lender offers in period 6 and 7 must satisfy (6). Further, due to lender competition, lender should also induce the maximum profits for the borrower. Lender competition induces $i_{1}=\ldots=i_{5}=1$, and hence leads to $S_{1}=\ldots=S_{6}$. The total profits for the $L$ type borrower are:

$$
\sum_{i=1}^{6} U_{i}=6 S_{6}(v-1)+v S_{6}=(7 v-6) \frac{v}{v-1+i_{6}} S_{7}
$$

The total profits for the $H$ type borrower are:

$$
\begin{aligned}
\sum_{i=1}^{7} U_{i} & =5(v-1) S_{6}+\left(v-i_{6}\right) S_{6}+\left(v-i_{7}\right) S_{7} \\
& =5(v-1) S_{6}+(2 v-1) S_{6}-i_{7} S_{7} \\
& =\left[7 v-6-\frac{1}{v \bar{p}}-\frac{\bar{r}(v-1)}{v}\right] S_{6}
\end{aligned}
$$

where the first step, from (8) to (9), follows from (6), and the second step follows from (4).

From (6) and (10), it follows that the profit maximizing offers for the borrower must have $S_{7}=10$ and $S_{6}=\frac{v}{v-1+i_{6}} 10$. Further, it can be shown that $i_{6}$ must be the minimum interest rate possible (see proof below). This implies that $i_{7}$ be the maximal interest rate, i.e. $i_{7}=\bar{r}$.

Proposition 3: In the game with weak exclusion and lender competition, there are two possible symmetric implicit contracting equilibria for the $H$ borrower. In both, for $t<6$, each lender $j$ offers $\left(S_{t}^{j}, i_{t}^{j}\right)=\left(\frac{v}{v-1+i_{6}} 10,1\right)$. Further,

$$
\begin{cases}\left(S_{6}^{j}, i_{6}^{j}\right)=\left(\frac{v}{v-1+\frac{1}{\bar{p} \bar{r}}} 10, \frac{1}{\bar{p} \bar{r}}\right) \text { and }\left(S_{7}, i_{7}\right)=(10, \bar{r}) & \text { if } \bar{p} \geq \frac{1}{(6 v-\bar{r})(v-1)+v^{2}} \\ \left(S_{6}^{j}, i_{6}^{j}\right)=\left(\frac{v}{v-1+\bar{r}} 10, \bar{r}\right) \text { and }\left(S_{7}, i_{7}\right)=\left(10, \frac{1}{\bar{r} \bar{p}}\right) & \text { if } \bar{p}<\frac{1}{(6 v-\bar{r})(v-1)+v^{2}} .\end{cases}
$$


$L$ borrowers choose $\gamma_{1}=\ldots=\gamma_{5}=1, \gamma_{6}=\frac{\bar{p}}{(1-\bar{p})}\left(i_{7}-1\right)$ and $\gamma_{7}=0$.

\section{Proof:}

- $L$ type borrower repayment: Condition $\left[\mathrm{IC}_{L, W E}\right]$ holds with equality for periods 1 to 6. Hence, $\gamma_{1}=\ldots=\gamma_{5}=1$ and $\gamma_{6}=\frac{\bar{p}}{(1-\bar{p})}(\bar{r}-1)$ is a best response behavior.

- $H$ type borrower accepts and repays as $i_{t} \leq \bar{r}$ for all $t$.

- Lender contracts: Throughout the lender makes zero profits. The lender's participation constraint is met with equality in periods 1 to 5 , as $i_{t}=1$ and $\gamma_{t}=1$ for $t<6$. The lender's profits from lending in period 6 are $S_{6}\left(\left(\bar{p}+\gamma_{6}(1-\bar{p})\right) i_{6}-1\right)$ which are zero if the lender offers either, $\left(S_{6}, i_{6}\right)=\left(\frac{v}{v-1+i_{6}} 10, \frac{1}{\bar{p} \bar{r}}\right)$, where $\gamma_{6}=\frac{\bar{p}}{(1-\bar{p})}(\bar{r}-1)$. and in period $7\left(S_{7}, i_{7}\right)=(10, \bar{r})$, or if he offers $\left(\frac{v}{v-1+\bar{r}} 10, \bar{r}\right)$, where $\gamma_{6}=\frac{\bar{p}}{(1-\bar{p})}(\bar{p} \bar{r}-1)$, and in period $7\left(S_{7}, i_{7}\right)=\left(10, \frac{1}{\bar{r} \bar{p}}\right)$

- Competition leads each lender to make zero expected profits and to offer the best possible loan schedule and interest rate to the $H$ borrower. We have that $\frac{\partial \sum_{i=1}^{6} U_{i}}{\partial i_{6}}<0$ if and only if

$$
7 v-6-\frac{1}{v \bar{p}}-\frac{\bar{r}(v-1)}{v}>0
$$

We can rewrite (11) to,

$$
\bar{p} \geq \frac{1}{(6 v-\bar{r})(v-1)+v^{2}}
$$

If (11) holds, $\frac{\partial \sum_{i=1}^{6} U_{i}}{\partial i_{6}}<0$ and hence $i_{6}$ must be minimal. From [PC Lender 6 it follows that $i_{7}=\frac{1}{i_{6}} \cdot \frac{1}{\bar{p}}$. Hence, $i_{7}=\bar{r}$ in the borrower's profit maximizing equilibrium, and in turn $i_{6}=\frac{1}{\bar{r} \bar{p}}$. Instead, if (11) does not hold, and thus $\frac{\partial \sum_{i=1}^{6} U_{i}}{\partial i_{6}}>0, i_{6}$ must be maximal. Since by Assumption $1 \bar{p}<\frac{1}{\bar{r}}, i_{6}=\bar{r}$. This, in turn implies that $i_{7}=\frac{1}{\bar{p}}$.

Proposition 4: In the lending game with weak exclusion no fully separating equilibrium $\left(\gamma_{1}=0\right)$ exists.

Proof: In a fully separating equilibrium, the $H$ borrower repays in the first period, while the $L$ borrower defaults. Due to common knowledge, after $t=1$, no rents can be extracted from screening in the first period. Hence, no lender has an incentive to make an offer in the first period that will lead to separation between the $H$ and $L$ type borrowers, since by Assumption $1, \bar{p}<\frac{1}{\bar{r}}$ and hence losses will be incurred in the first period. 